\title{
Cardiac and vascular riskfactors in stroke : the role of cardiac valve calcification and silent brain infarcts
}

Citation for published version (APA):

Boon, A. E. (1996). Cardiac and vascular riskfactors in stroke: the role of cardiac valve calcification and silent brain infarcts. [Doctoral Thesis, Maastricht University]. Datawyse / Universitaire Pers Maastricht. https://doi.org/10.26481/dis.19960628ab

Document status and date:

Published: 01/01/1996

DOI:

10.26481/dis.19960628ab

Document Version:

Publisher's PDF, also known as Version of record

\section{Please check the document version of this publication:}

- A submitted manuscript is the version of the article upon submission and before peer-review. There can be important differences between the submitted version and the official published version of record.

People interested in the research are advised to contact the author for the final version of the publication, or visit the DOI to the publisher's website.

- The final author version and the galley proof are versions of the publication after peer review.

- The final published version features the final layout of the paper including the volume, issue and page numbers.

Link to publication

\footnotetext{
General rights rights.

- You may freely distribute the URL identifying the publication in the public portal. please follow below link for the End User Agreement:

www.umlib.nl/taverne-license

Take down policy

If you believe that this document breaches copyright please contact us at:

repository@maastrichtuniversity.nl

providing details and we will investigate your claim.
}

Copyright and moral rights for the publications made accessible in the public portal are retained by the authors and/or other copyright owners and it is a condition of accessing publications that users recognise and abide by the legal requirements associated with these

- Users may download and print one copy of any publication from the public portal for the purpose of private study or research.

- You may not further distribute the material or use it for any profit-making activity or commercial gain

If the publication is distributed under the terms of Article $25 \mathrm{fa}$ of the Dutch Copyright Act, indicated by the "Taverne" license above, 
Cardiac and Vascular Riskfactors in Stroke:

The Role of Cardiac Valve Calcification and Sulent BRAIN INFARCTS 
C Boon, Arthur Edwin

Cardiac and vascular riskfactors in stroke: the role of cardiac valve calcification and silent brain infarcts.

Thesis University of Limburg Maastricht

ISBN ni: 90-5278-218-0

Cover and layout: A. Boon

Production: University Press Maastricht - Datawyse

Printing was sponsored by:

Glaxo BV (main sponsor), Eily Lilly, Janssen-Cilag, Katwijk, Boehringer, Ciba-Geigy, Schering, Sanofi, Yamanouchi, Nourypharma, and Asta Medica. 


\section{CARDIAC AND VASCULAR RISKFACTORS IN STROKE}

\section{The Role of Cardiac Valve Calcification and Silent}

BRAIN INFARCTS

\section{PROEFSCHRIFT}

TER VERKRIJGING VAN DE GRAAD VAN DOCTOR AAN DE RIJKSUNIVERSITEIT LIMBURG TE MAASTRICHT, OP GEZAG VAN DE RECTOR MAGNIFICUS,

Prof. Mr. M.J. Cohen, volgens het besluit Van het College VAN DEKANEN, IN HET OPENBAAR TE VERDEDIGEN OP VRIJDAG 28 JUNI

1996 OM 14.00 UUR

DOOR

Arthur Edwin Boon

GEBOREN OP 28 AUGUSTUS 1957 TE 'S-GRAVENHAGE 


\section{Promotor:}

Prof. Dr. J. Troost

Co-promotor:

Dr. J. Lodder

Beoordelingscommissie:

Prof. Dr. H.J. Wellens (voorzitter)

Prof. Dr. ir. A.P.G. Hoeks

Prof. Dr. P.G. Knipschild

Prof. Dr. P.W. de Leeuw

Prof. Dr. J. Stam (Academisch Medisch Centrum Amsterdam) 
If your experiments need statistics, you ought to have done a better experiment

Lord Rwherford

to birike 
. 


\section{Contents}

GENERAL INTRODUCTION

Chapter I

Introduction

Chapter II

Silent brain infarcts in 755 consecutive patients with a first-ever supratentorial ischemic stroke; the relationship with index stroke subtype, vascular risk factors, and mortality.

\section{Chapter III}

Characteristics of Patients with Calcification of the Mitral Annulus or Aortic Valve.

\section{Chapter IV}

The Risk of Stroke in a Cohort of 815 Patients With Calcification of the Aortic Valve with or without Stenosis.

\section{Chapter V}

The Risk of Stroke in a Cohort of 657 Patients With Mitral Annulus Calcification.

Chapter VI

General Discussion

Chapter VII

Summary

\section{Chapter VIII}

Samenvatting....

PAPERS 



\section{General Introduction}

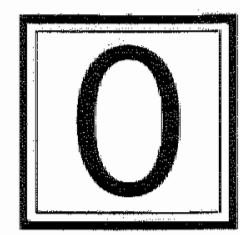



This thesis questions some presumed cardioembolic stroke 1 mechanisms and discusses related subjects. About one quarter of all strokes is attributed to a cardiac source of embolism. " Established major sources of cardioembolic stroke are atrial fibrillation, (rheumatic) mitral stenosis, intracardiac thrombi, prosthetic heart valves, recent (less than six weeks) myocardial infarction, endocarditis, dilated cardiomyopathy, and intracardiac tumor like atrial myxoma. Less certain potential cardioembolic stroke causes are patent foramen ovale, mitral valve prolapse, mitral annular and aortic valve calcification, ${ }^{2,3}$ and atrial septum aneurysm. ${ }^{4}$ Cardioembolic strokes demonstrated by autopsy are rare, and therefore the assumption of a cardioembolic stroke mechanism is often speculative. Whereas anticoagulant therapy is now the therapy of choice in high risk patients, it remains unclear whether and how patients with questionable potential sources of cardiac emboli should be treated.

Other cardiac and vascular risk factors for stroke often accompany a potential cardioembolic stroke source, a fact which complicates the identification of the real stroke cause, and the consequent choice of adequate therapies. To determine the contribution to stroke risk of questionable cardioembolic risk factors in patients with concomitant vascular risk factors, is difficult. Therefore, many reports focuss on efforts to identify specific clinical and CT scan features of strokes in patients in whom a potential cardioembolic stroke source has been identified (Table 1). ${ }^{15-8}$ Because multiple brain infarcts may increase the risk of cognitive decline as a result of accumulating cerebrall damage, a cardioembolic stroke source may signify an increased risk of vascular dementia. ${ }^{910}$ Some patients presenting with a stroke but without a previous history of stroke, may coincidentally show signs of previous brain infarcts on CT scan. Although this possibly tells more about the attention of the patient and the doctor than about the nature of those infarcts, the concept of these so called "silent" or "asymptomatic" brain infarcts is widely established. Several authors consider silent brain infarcts, specially when multiple, as possible indicators of a cardioembolic stroke source. 126-8.11-17 However, these conclusions are based on studies with selected subgroups of patients such as those with atrial fibrillation, or with carotid stenosis, increasing the apriori risk of both silent as well as symptomatic brain infarcts. It might be interesting to infer causes of silent infarcts and their subtypes from a possible association with subtypes of clinically manifest strokes. The reason of the study on silent infarcts presented 
Table1. Characteristics of Cardioembolic Stroke

Large contical brain infarcts

Sever hondicep

High mortality

Non-progressine onset

Hamianopia without long tract signs

Wornickes aphasia

Idsomotor aparaxia

Pasterior division of the middle cerebral artery

Anterior carebral antery

Cerabellar anteries

Multiple ternitories

Hemorrhagic intarction

Silent (asymptomatic) burain infarction

Progressilve cognitive decline (dementia) 
in this thesis was the suspicion that silent and symptomatic infarcts may reflect a common underlying type of vasculopathy, and that silent brain infarcts are no specific indicators of the presence of a cardioembolic stroke cause.

Silent brain infarcts and related subjects are discussed in Chapter 2. In a prospective investigation of 755 consecutive patients presenting with a first supratentorial brain infarct, silent brain infarcts and their clinical and CT scan correlates were studied, in order to determine clinical risk factors independently associated with their presence, especially potential cardiac sources of emboli. Further, it was investigated whether the types of symptomatic and silent infarcts in the same patient are similar, suggesting a common underlying cause.

Among the less certain potential cardioembolic stroke sources are three cardiac valve disorders that have been repeatedly associated with brain infarcts: aortic valve calcification with or without stenosis, ${ }^{18-22}$ and calcification of the mitral annulus ${ }^{23-30}$ Cardiac calcification is due to deposition of calcified material in the cardiovascular skeleton. Severe calcification in cardiac valve tissue may lead to damage of the intracardiac conductive tissue with consequent heart block, to stenosis by reducing the valvular orifice, or to cerebral and systemic embollic events by release of fragments from calcified material or secondary thrombus protruding in the bloodstream. However, the prevalence of other cardiac and vascular disease, especially atherosclerotic disease, predisposing to brain infarcts (confounders) is high in patients with mitral annular or aortic valve calcification. The hypothesis was investigated that mitral annular and aortic valve calcification are a marker or an expression of atherosclerosis, the latter being responsible for an increased stroke risk. Therefore, any observed relative stroke risk should be adjusted for confounding, which has not been done in previous studies.

Chapter 3 describes the association of clinical and echocardiographic risk factors for cardiac and vascular disease with mitral annular calcification, aortic valve calcification, and aortic valve calcification with stenosis as dependent variables, with the hypothesis that the three conditions are different expressions of cardiac or vascular disease, sharing risk factors. The study population of this and subsequent studies described in later chapters was formed by 8.160 consecutive patients with echocardiograms registered in a five year period. 
Chapter 4 describes the relative risk of stroke in a follow up of the cohort formed by the 815 patients with stenotic or non stenotic aortic valve calcification, compared with 562 controls. To identify specific patterns of cerebral infarction arguing in favour of a probable cardioembolic stroke mechanism, territorial, lacunar, and multiple or single symptomatic and silent brain infarcts were included in the analysis. Results were adjusted for the generally accepted clinical and echocardiographic risk factors for stroke, and for protective measures like aspirin or warfarin use, and for cardiac valve replacement.

Chapter 5 reports the results of an analysis of the risk of stroke in a cohort of 657 patients with mitral annular caicification, compared with 562 control patients. The results are discussed in relation to those of recent epidemiological studies that suggest a more than twofold increase in the risk of stroke in such patients.

\section{Aims}

In conclusion, the aims of this thesis are as follows:

11. To describe the concept of silent ("asymptomatic") cerebral infarction and to discuss in a review of the literature the possible role of a potential cardioembolic stroke source (Chapter 1).

3. To explain and illustrate mitral annular and aortic valve calcification and their presumed relation with cerebral embolic phenomena (Chapter I).

4. To discuss why confounding is one of the causes of the higlh risk of stroke found in patients with mitral annular or aortic valve calcification in previous studies (Chapter 1).

5. To study the occurrence of silent cerebral infarcts in patients with a first supratentorial infarct, whether they are associated with the presence of a confirmed potential cardiac source of emboli, and whether or not they are associated with specific clinical or CT scan patterns of cerebral infarction that may suggest an underlying cardioembolic stroke mechanism (Chapter 2). 
6. To test the hypothesis, that mitral annular and aortic valve calcification are both age related markers of generalised cardiovascular disease, and may represent a manifestation or even a form of atherosclerosis (Chapter 3).

7. To study the risk of stroke in patients with calcification of the aortic valve with or without stenosis (Chapter 4), or mitral annular calcification (Chapter 5), and to test the hypothesis that stroke in patients with mitral annular or aortic valve calcification is the result of atherosclerotic disease unless another, established potential cardioembolic source of stroke is identified. 


\section{References}

1. Cerebral-Embolism-Task-Force. Cardiogenic Brain Embolism. Arch Neurol 1986;43:71-84

2. Cerebral-Embolism-Task-Force Cardiogenic brain embolism. The second report of the Cerebral Embolism Task Force [published arratum appears in Arch Neurol 1989 Oct;46(10):1079] [see comments]. Arch Neurol 1989;46:727-743.

3. Hart RG. Cardiogenic embolism to the brain. Lancet 1992,339:589594.

4. Belkin $R N$, Hurwitz $B J$, Kisslo $J$. Atrial septal aneurysm: association with cerebrovascular and peripheral embolic events. Stroke $1987 ; 18: 856-862$.

5. Ringelstein $\mathbb{E B}$, Koschorke $\mathrm{S}$, Holling $\mathrm{A}$, Thron $\mathrm{A}$, Lambertz $\mathrm{H}$, Minale $C$. Computed tomographic patterns of proven embolic brain infarctions. Ann Neurol 1989;26:759-765.

6. Bogousslavsky J, Cachin C, Regli F, Despland PA, Van-Melle G, Kappenberger $\mathrm{L}$. Cardiac sources of embolism and cerebral infarction-clinical consequences and vascular concomitants: the Lausanne Stroke Registry. Neurology 1991;41:855-859.

7. Kitner SJ, Sharkness CM, Sloan MA, Price TR, Dambrosia JM, Tuhrim S, Wolf PA, Mohr JP, Hier DB. Features on initial computed tomography scan of infarcts with a cardiac source of embolism in the NINCDS Stroke Data Bank. Stroke 1992;23:1748-1751.

8. Petersen P, Pedersen F, Johnsen A, Madsen EB, Brun B, Boysen G, Godtfredsen J Cerebral computed tomography in paroxysmal atrial fibrillation. Acta Neurol Scand 1989;79:482-486.

9. Tratemichi TK. How acute brain failure becomes chronic: A view of the mechanisms of dementia related to stroke. Neurology $1990 ; 40: 1652-1659$.

10. Tatemichi TK, Foulkes MA, Mohr JP, Hewitt JR, Hier DB, Price TR, Wolf PA. Dementia in Stroke Survivors in the Stroke Data Bank Cohort. Stroke 1990;21:858-866.

11. Easton DD, Sherman DG. Management of Cerebral Embolism of Cardiac Origin. Stroke 1980;11:433-441.

12. Feinherg WM, Seeger JF, Camody RF, Anderson DC, Hart RG, Pearce LA. Epidemiologic features of asymptomatic cerebral infaretion in patients with nonwalvular atrial fibrillation. Arch Intern Med $1990 ; 150: 2340-2344$.

13. Orgogozo NM, Aupy M, Levy S. Unsuspected Cardiac Origin of Cerebral Embolism. Cerebrovasc Dis 1981;6:319-322.

14. Kempster PA, Gerraty RP, Gates PC. Asymptomatic cerebral infarc- 
tion in patients with chronic arral fibrillation. Stroke 1988;19:955-7.

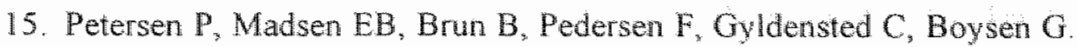
Silent Cerebral Infarction in Chronic Atrial Fibrillation. Stroke 1987; 18:1098-1100.

16. Petersen P. Thromboembolic complications of atrial fibrillation and their prevention: a review. Am I Cardiol 1990;6524C-28C.

17. Sasaki W, Yanagisawa S, Maki K, Onodera A, Awaji T, Kanazawa T. High Incidence of Silent Small Cerebral Infarction in the Patients with Atrial Fibrillation. Circulation 1987,76, Supp IV:IV-104.

18. Wilson JH, Cranley JJ. Recurrent calcium emboli in a patient with aortic stenosis. Chest 1989,96:1433-4.

19. Vernhet H, Torres GF, Laharotte JC, Toumut P, Bierme T, Froment JC, Duquesnel J. Spontaneous calcific cerebral emboli from calcified aortic valve stenosis. I Neuroradiol 1993;20:19-23.

20. Rubin DC, Plotnick GD, Hawke MW. Intraaortic debris as a potential source of embolic stroke. Am J Cardiol 1992;69:819-20.

21. Brockmeier LB, Adolph RJ, Gustin BW, Holmes JC, Sacks JG. Calcium emboli to the retinal artery in calcific aortic stenosis. Am Heart J 1981,101:32-35.

22. Rancurel $G$, Marelle $L$, Vincent $D$, Catala M, Arzimanoglou A, Vacheron A. Spontaneous calcific cerebral embolus from a calcific aortic stenosis in a middle cerebral artery infarct. Stroke 1989,20:691. 693.

23. De Bono DP, Warlow CP. Mitral-annulus callification and cerebral or retinal ischemia. The Lancet 1979;:383-385.

24. Fulkerson PK, Beaver BM, Auseon JC, Graber HL. Calcification of the Mitral Annulus. Etiology, Clinical Associations, Complications and Therapy, Am J Med 1979,66:967-977.

25. Furtan AJ, Craciun AR, Salcedo EE, Mellino M. Risk of stroke in patients with mitral annulus calcification. Stroke 1984; 15:801-803.

26. Jespersen $\mathrm{CM}$, Egeblad $\mathbb{H}$. Calcified mitral ring. Incidence and complications]. Ugeskr Laeger 1987,149:3394-3397.

27. The Boston Area Anticoagulants for Atral Fibrilation Trial Investigators. The effect of low-dose warfarin on the risk of stroke in patients with nonrheumatic atrial fibrillation. N Engl J Med 1990;323:15051511

28. Aronow WS, Schoenfeld MR, Gutstein H. Frequency of thromboembolic stroke in persons greater than or equal to 60 years of age with 
extracranial carotid arterial disease and/or mitral annular calcium. Am J Cardiol 1992;70:123-124.

29. Nair CK, Thomson W, Ryschion $K_{n}$, Cook C, Hee TT, Sketch MH. Long-term follow-up of patients with echocardiographically detected mitral anular calcium and comparison with age- and sex-matched control subjects. Am J Cardiol 1989;63:465-470.

30. Benjamin EJ, Plehn JF, D'Agostino RB, Belanger AJ, Comai $\mathrm{K}$, Fuller DL, Wolf PA, Levy D. Mitral annular calcification and the risk of stroke in an elderly cohort. N Engl J Med 1992;327:374-379. 


\section{Introduction}

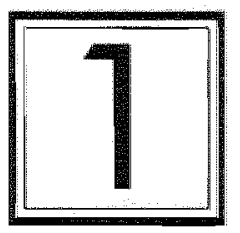





\section{Silent (asymptomatic) brain infarcts}

Q ilent brain infarcts, also called asymptomatic brain infarcts are $D$ defined as hypodense lesions on brain CT scan or MRI, compatible with brain infarction in patients without a history of stroke. ${ }^{1.16}$ Although one must doubt whether silent infarcts are really asymptomatic, they indeed represent a relatively symptom poor and probably an early stage of ultimately severe brain damage.

Since the discussion of Hachinski" about "multiple thromboembolic infarcts, which are too small individually to produce a major clinical incident, but which may in combination impair mental function", numerous CT scan and MRI studies on silent infarcts and their clinical significance have been done on healthy volunteers and on patients with cardiac, vascular and cerebrovascular disease.

In patients with a stroke, the presence of silent infarcts has been associated with worse stroke outcome ${ }^{518.27}$ In patients with a stroke or TIA, a correlation of silent infarcts with vascular risk factors was found, such as smoking, age, male sex, hypertension, and glucose intolerance ${ }^{471328}$ In patients with or without overt cerebrovascular disease a cardiac source of embolism especially atrial fibrillation is reported to be associated with silent brain infarcts. ${ }^{521-2.529-34}$ Patients with or without stroke or TIA but with an obstructive carotid lesion show more silent infarcts than patients without carotid lesions. ${ }^{135-38}$ Patients with a stroke and silent infarcts have an increased risk of recurrent stroke, and the accumulation of many silent infarcts may cause vascular dementia ${ }^{13.1725}$ 39-45. The prevalence of silent brain infarcts depends on the detection method and the studied patients, and varies from 10 to $92 \%{ }^{46}$ In all studies, they were predominantly small deep (lacunar) infarcts. If silent cerebral infarcts suggest incipient progressive cerebral damage, it would be of interest to know whether there is a common underlying pathogenetic pathway for silent infarcts and their symptomatic equivalent. Studying sepaw rate brain infarct subgroups could be relevant because they may differ in stroke cause, clinical presentation, and outcome. ${ }^{10.7748}$ Therefore, to determine the significance of silent infarcts, they should be prospectively studied in unselected, consecutive patients with stroke, but most studies on silent brain infarcts were done in selected patients, such as those with a carotid stenosis, or with only atrial fibrillation. 22233336374950 


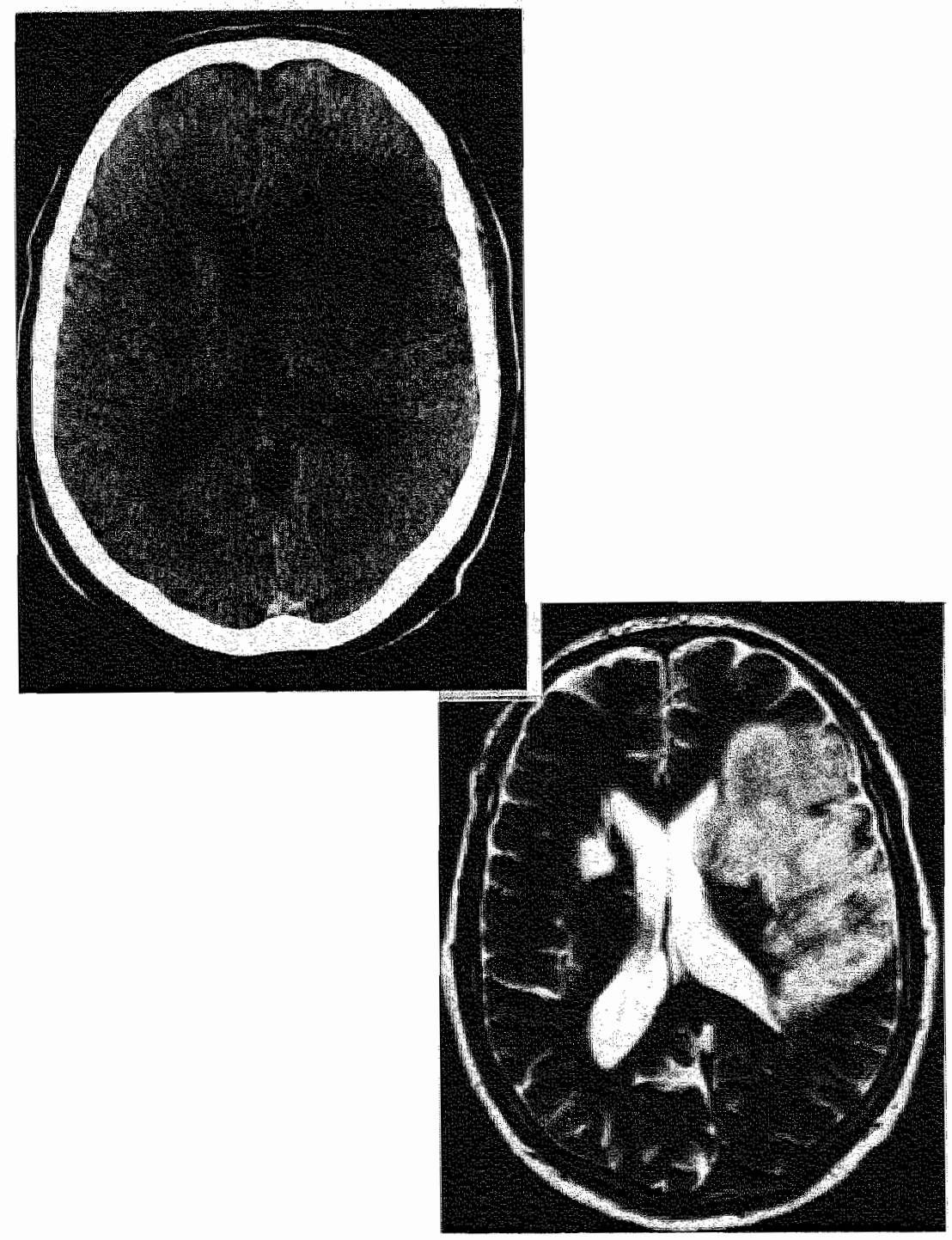

Above: CTscan showing a symptomatic left territorial infarct and a silent right lacunar infarct in the internal capsule. Below and next page: Brair MRl of the same patient showing corresponding hyperintense $T 2$-weight lesions, but in addition small asymptomatic right temporal subcortical and insular lesions not visible on CT. Are these latter lesions infards? 


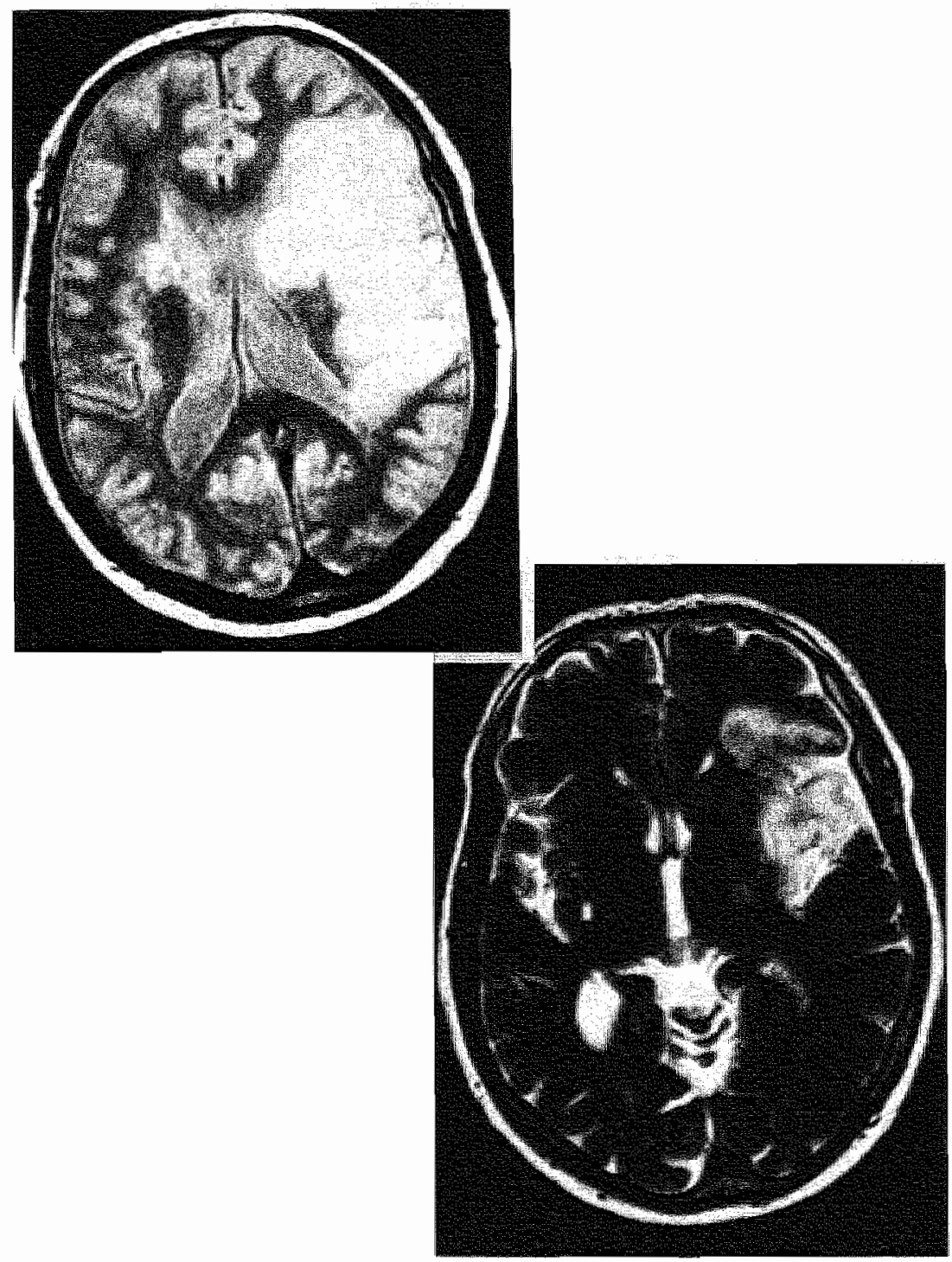


-shlent infarcts, comimued - In one large population based study, TIA or minor stroke patients with atrial fibrillation were excluded, restricting conclusions to a subgroup of patients with cerebrovascular disease ${ }^{13}$ Other studies - on unselected stroke patients - were small or retrospective..$^{335152}$

Five prospective studies discuss various aspects of silent brain infarcts in patients with a stroke..$^{2-478}$ However, two of these studies were rather small comprising 124 and 209 patients, respectively. ${ }^{47}$ The number of silent infarcts may have been underestimated due to early generation CT scanners in some studies, ${ }^{34}$ or because a considerable number of patients did not hawe $\mathrm{CT} .^{34}$ ? Others selected only a subgroup of stroke patients who had ancillary investigations, or included patients with TIA in a stroke series. ${ }^{8}$ None of the prospective studies analysed the independent association of clinical and CT scan features with silent infarcts. ${ }^{3478}$ Only one study ${ }^{2}$ used multivariate analysis of silent infarct related factors in 500 patients with a stroke, but in this study and in others no subgroup analysis according to symptomatic infarct types was done. Moreover, risk factors were not known in a number of patients, and infarcts and hemorrhages were not distinguished separately. ${ }^{2}$ A significant association between carotid stenosis and silent infarction (lesions equal to or larger than $5 \mathrm{~mm}$ ) on MRI was found in 117 asymptomatic patients, but those with a confirmed potential cardiac source of emboli were excluded, resulting in a selection bias towards more patients with carotid disease. ${ }^{35}$

The prospective study presented in Chapter 3 , of 755 consecutive patients with a first, supratentorially located ischaemic stroke, analysed associations of various clinical, prognostic and CT scan features with the presence of silent brain infarcts, and established the differential significance of silent infarcts depending on the index $(=$ presenting) stroke subtype.

\section{Aortic Valve Calcification}

\section{A. Causes}

By mechanisms still poorly understood, the aortic valve leaflets may become affected by infiltrations of mineral deposits, consisting mainly of calcium and phosphorus, ${ }^{5.7}$ ultimately leading to increased stiffness and ballooning of the valve tissue with consequent dysfunction of the valve and narrowing of its orifice. One of the causes of 
aortic valve calcification may be disturbed calcium metabolism observed in patients with long standing uremia or renal dialysis, ${ }^{54}$ or primary oxalosis. ${ }^{35}$ Another observed cause of aortic valve calcification is radiation damage. ${ }^{56}$

However, as the prevalence of aortic valve calcification is higher in elderly patients, in patients with hypercholesterolemia, or those with hypertension, it is suspected that it is an expression of atherosclerotic disease progressive with age ${ }^{57}$ Increased stress on the valve apparatus directly or indirectly resulting from hypertension, rheumatic valvular damage, or a congenitally abnormal aortic valve, may accelerate this process. ${ }^{57-61}$ This view is supported by observations in patients without rheumatic valvular disease: chronic abnormal valvular stress or motion imposed on congenital bicuspid aortic valves is associated with aortic valve calcification and subsequent stenosis in relatively young patients, whereas tricuspid aortic valve calcification without stenosis occurs more often in elderly, atherosclerotic patients. ${ }^{59}$

Thus, there is discussion whether aortic valve calcification is a primary degenerative disorder or a form or marker of atherosclerosis.

A study of 815 patients with aortic valve calcification with or without stenosis, determined risk factors associated with the lesion, in comparison with 562 control patients. The results are presented in Chapter 3.

\section{B. Symptoms}

When symptoms occur secondary to aortic valve calcification they are angina pectoris, exertional syncope, and congestive heart failure. They appear when calcification has led to aortic valve stenosis of an advanced degree. Angina pectoris may occur as a result of insufficient coronary flow because of increased left ventricular wall thickness and elevated left intraventricular pressure. Exertional syncope occurs when during exercise peripheral vasodilation is not compensated by increased cardiac output, causing arterial hypotension and subsequent reduced cerebral blood flow. Also, cardiac rhythm disturbances caused by infiltration of conductive tissue by calcified material may lead to syncope ${ }^{6162} \mathrm{Left}$ ventricular congestive failure is a late complication and an ominous sign. 
Except for situations in which the valve can be damaged, such as during cardiac surgery or cardiac catheterisation, ${ }^{6263}$ stroke is generally not considered to be a direct consequence of aortic valve calcification, but a number of case and pathological reports justify further evaluation of aortic valve calcification as a potential cardioembolic stroke cause. In patients with aortic valve calcification, calcified emboli were demonstrated at surgery or at autopsy in systemic and peripheral arteries. ${ }^{63.65}$ Postoperative embolic events may accompany aortic valve surgery, ${ }^{56}$ but the prevalence of aortic valve calcification in patients with TIA or stroke is low. ${ }^{3031}$ Of four patients with aortic valve calcification and retinal infarcts, two of them had calcium-like embolic material at examination of the ocular fundus; one of these patients had carotid anglography. ${ }^{67}$ Although stroke and TIA were reported in four patients with bicuspid aortic valves, of whom at least three had normal carotid arteries, two cases of stroke in a patient with aortic valve calcification demonstrated by CT scan and carotid angiography were presented later ${ }^{6869}$ However, emboli with the appearance of calcified material may also come from plaques in the carotid arteries or aorta. ${ }^{70}$ Follow up data from three series of patients with aortic valvular disease show no association between aortic valve disease and stroke..$^{62} 7_{1} 72$ These studies did not adjust for other risk factors for stroke.

In conclusion, if aortic valve calcification with or without stenosis can be a form of atherosclerosis, ${ }^{57}$ we need to perform an analysis of prospectively collected data from patients with that condition, with the analysis adjusted for the generally accepted risk factors and for protective measures for stroke.

We therefore studied a cohort of 815 patients with stenotic or non stenotic aortic valve calcification, and a random control group to determine the risk of stroke adjusted for traditional risk factors for stroke and for risk lowering therapies like aspirin, warfarin, and cardiac surgery. Those results are presented and discussed in Chapter 4. As previous reports suggested an association between aortic valve calcification and silent cerebral lesions ${ }^{6768}$ it was also analysed whether aortic valve calcification with or without stenosis is associated with silent infarcts in general, or only with territorial or small deep silent infarcts. 


\section{Mitral Annular Calcification}

\section{A. Causes}

Like aortic valve calcification, mitral annular calcification is an agerellated degenerative process, ${ }^{73-76}$ aggravated by increasing mitral valve stress or motion. Increased valvular stress or motion can be the result of hypertension, left atrial and ventricular enlargement, atrial fibrillation, hypertrophic cardiomyopathy, aortic valve stenosis, mitral valve prolapse, mitral valve prosthesis, whereas direct infiltration of the mitral annular apparatus may be the result of metabolic disturbances ${ }^{7476-83}$ This may even lead to bone or bonemarrow formation or inflammation. ${ }^{7544}$ The calcification may be located in a part or the whole of the mitral annulus. By direct influence on its surroundings, mitral annular calcification may cause cardiac conduction disorders or mitral stenosis. ${ }^{85} 86$ Prevalence varies considerably between 5 and $27 \%$, frequency increasing with age.

Like aortic valve calcification, which often coexists, mitral annular calcification may be a form of atherosclerotic disease, and is often associated with underlying risk factors, such as hypertension, general atherosclerosis, advanced age, congestive heart failure, atrial fibrillation or diabetes. ${ }^{207374768788}$

Chapter 3 tests the hypothesis that mitral annular calcification is an expression of atherosclerosis and presents risk factors for mitral annular calcification in an analysis of 657 patients with this condition, compared with 562 control patients.

\section{B. Mitral annular calcification and stroke}

In contrast to aortic valve calcification, case reports and prospective epidemiological studies suggest a high risk of stroke in patients with mitral annular calcification, ${ }^{76}{ }^{89-95}$ possibly by direct embolisation. ${ }^{76.96}$ ${ }^{97}$ There is also clinical and pathological evidence of calcific cerebral, retinal, or systemic emboli in otherwise normal patients with mitral annular calcification. ${ }^{7696}$

In two studies mitral annular calcification was more prevalent in patients with systemic or cerebral ischemia than in age and sex matched controls, ${ }^{89}{ }^{91}$ but patients with the lesion also had a high frequency of other vascular risk factors. In three reports of a follow up of patients with mitral annular calcification systemic or cerebral ischemic signs were associated with the condition. Control patients, however, were only age and sex matched. ${ }^{76} 9694$ 


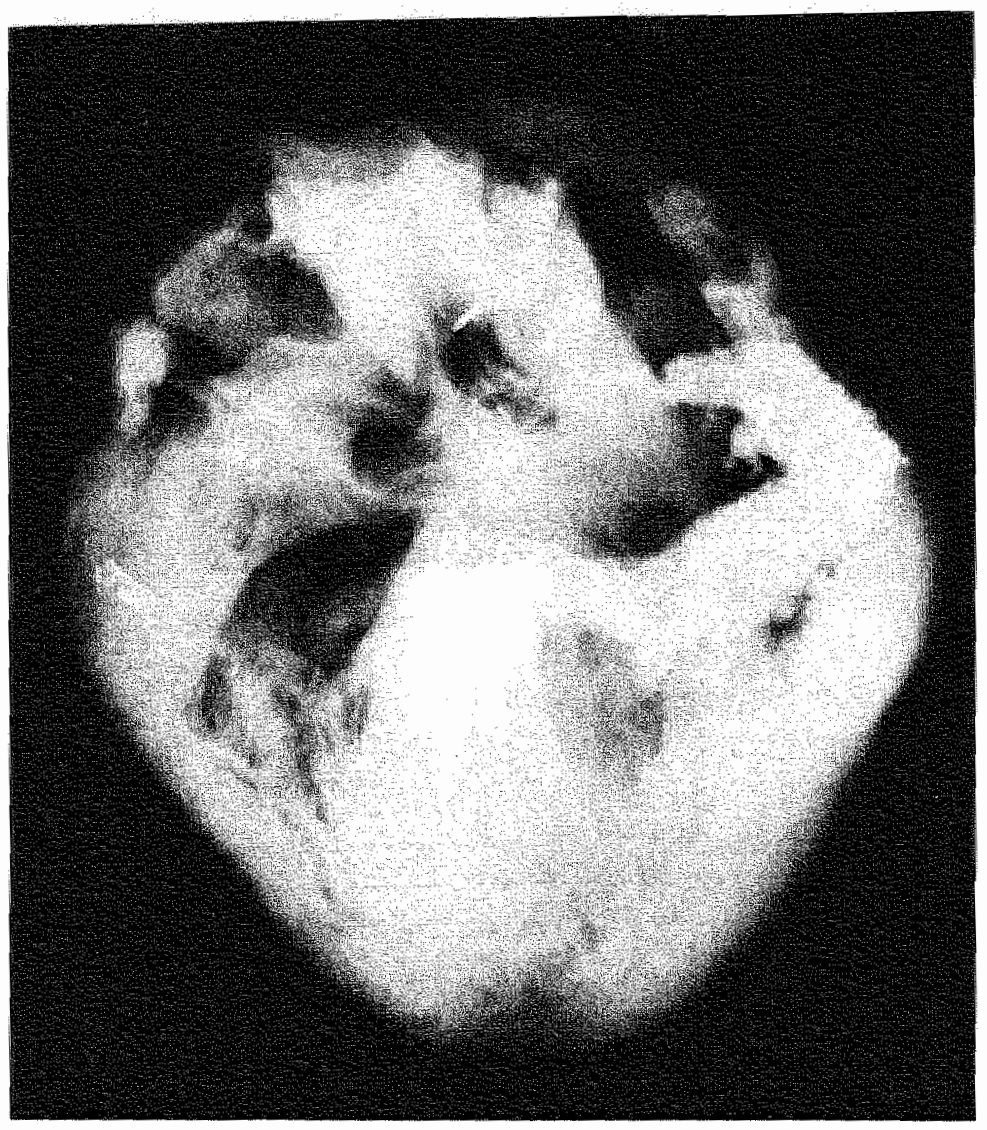

X-Roy picture fextensive posterion mitral anmular calcification 

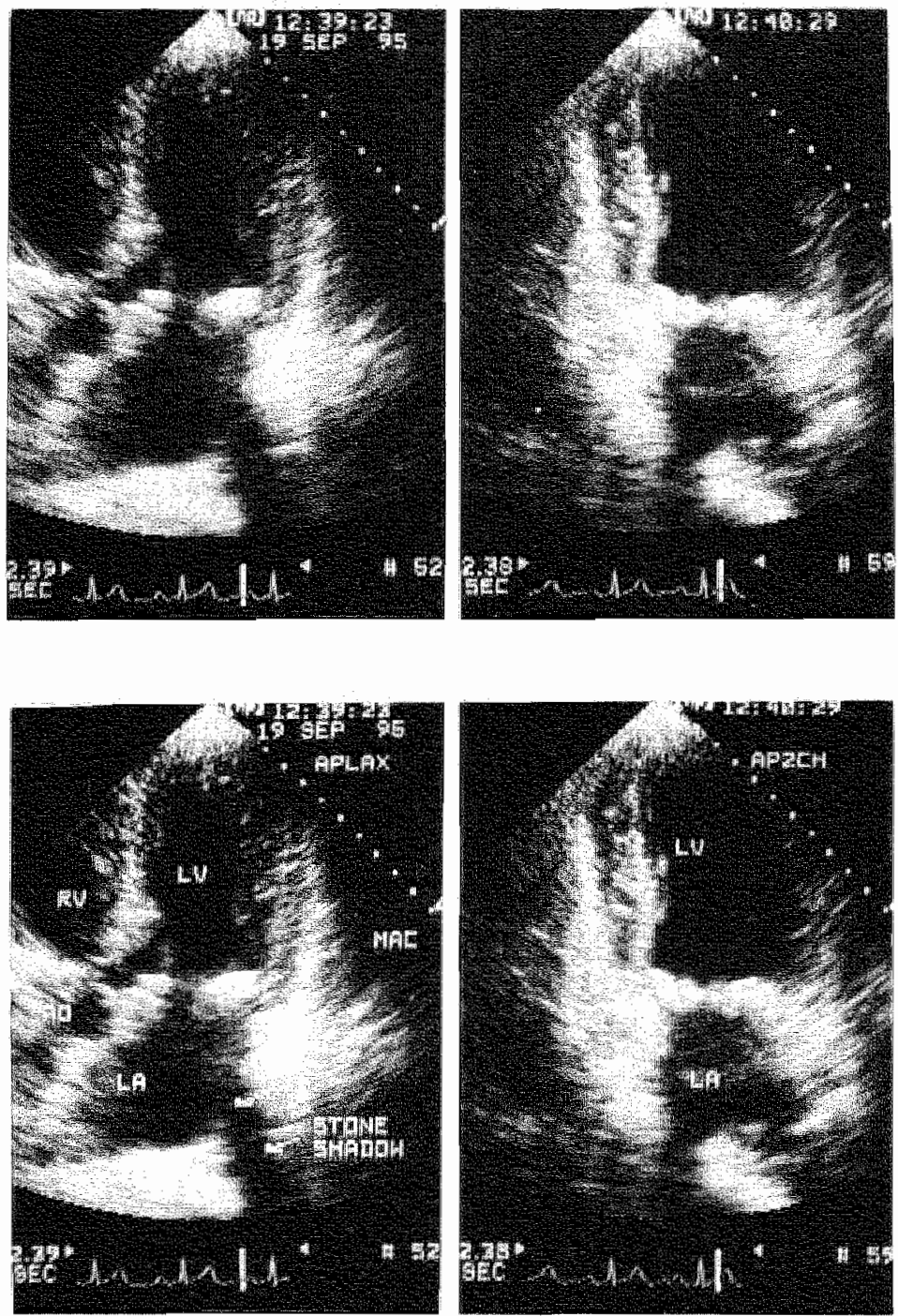

Three dimensionall echocardiogram of mifral antulal calcification. RV, right veniricle; $L V$, left ventricle; $\angle A$, lieft atrium; $A O$, corta; $M A C$, mitral annular calcificalion. 
Stronger evidence of a two to four times increased risk of stroke attributed to mitral annular calcification comes from two epidemiological studies. The first one (BAATAF) studied the effect of warfarin in atrial fibrillation patients. ${ }^{9 / 2}$ However, in BAATAF relative risk referred to therapeutic effects of warfarin in patients with atrial fibrillation, and allow no conclusions as to the risk of stroke in all patients with mitral annular calcification. The second study was especially designed to analyse prospectively the risk of stroke in patients with mitral annular calcification. ${ }^{95}$ Although in both studies other risk factors for stroke were also tested, this was done mainly with univariate models. In both studies, and also in the study of Aronow et al ${ }^{93}$ the results were likely influenced by confounders like carotid atheromatosis, the use of anti-platelet drugs or warfarin, or by cardiac risk factors for stroke.

As in aortic valve calcification, analysis of the relative risk of stroke in patients with mitral annular calcification should adjust for strong confounders. Chapter 5 is a study of a prospectively followed cohort of 657 patients with mitral annular calcification and a control group of 562 patients, adjusted for clinical, therapeutic and echocardiographical factors which might influence the risk of stroke. We also studied the association of mitral annular calcification with stroke subtypes and with the presence of silent brain infarcts, which could suggest an underlying cardioembolic mechanism in stroke patients with mitral annular calcification. This thesis also tries to give an answer on whether the decision on carotid surgery should be influenced or not by the presence of silent brain infarcts, and what should be the therapy of choice in patients with or without stroke having mitral annulus or aortic valve calcification. In Chapter 7 the therapeutic consequences of this thesis are discussed. 


\section{References}

1. Brott T, Tomsick T, Feinberg W, Johnson C, Biller J, Broderick J, Kelly M, Frey J, Schwartz S, Blum C, Nelson JJ, Chambless L, Toole $\mathrm{J}$, for the ACAS investigators. Baseline silent cerebral infarction in the asymptomatic carotid atherosclerosis study. Stroke 1994;25: 11221129

2. Jorgensen HS, Nakayama H, Raaschou HO, Gam J, Olsen TS. Silent Infarction in Acute Stroke Patients. Prevalence, Localization, Risk Factors, and Clinical Significance: The Copenhagen Stroke Study. Stroke 1994;25:97-104.

3. Chodosh EH, Foulkes MA, Kase CS, Wolf PA, Mohr JP, Hier DB, Price TR, Furtado J Jr. Silent stroke in the NINCDS Stroke Data Bank. Neurology 1988;38:1674-1679.

4. Kase CS, Wolf PA, Chodosh EH, Zacker HB, Kelly-Hayes M, Kannel WB, D'Agostino RB, Scampini L. Prevalence of silent stroke in patients presenting with initial stroke: the Framingham Study. Stroke $1989 ; 20: 850-852$.

5. Kittner SJ, Sharkness CM, Sloan MA, Price TR, Dambrosia JM, Tuhrim S, Wolf PA, Mohr JP, Hier DB. Features on initial computed tomography scan of infarcts with a cardiac source of embolism in the NINCDS Stroke Data Bank. Stroke 1992;23:1748-1751.

6. Laloux $\mathrm{P}$, Ossemann $M$, Jamart J. Prevalence and Significance of Silent Stroke in Patients With Initial Cerebral Ischemialabstr. 2nd Eur Stroke Conf, 1992]. Cerebrovase Dis 1992;2:201.

7. Ricci S, Celani MG, La-Rosa F, Righetti E, Duca E, Caputo N. Silent Brain Infarctions in Patients With First-Ever Stroke. Stroke 1993,24:647-651.

8. Mounier-Vehier F, Leys D, Rondepierre P, Godefroy O, Pruvo IP. Silent Infarcts in Patients With Ischemic Stroke Are Related to Age and Size of the Left Atrium. Stroke 1993;24:134.7-1351.

9. Foulkes MA, Wolf PA, Price TR, Mohr JP, Hier DB. The Stroke Data Bank: Design, Methods, and Baseline Characteristics. Stroke 1988:19:547-554.

10. Ricci $S$, Celani MG, Guercini $G$, Rucireta P, Vitali R, La-Rosa F, Duca E, Ferraguzzi R, Paolotti M, Seppoloni D, Caputo N, Chiurulla C, Scaroni R, Signorini E. First-Year Results of a Community-Based Study of Stroke Incidence in Umbria, Italy. Stroke 1989;20:853-857.

11. Ricci S, Celani MG, La-Rosa F, Vitali R, Duca E, Ferraguzzi R, Paolloti M, Seppoloni D, Caputo N, Chiurulla C, Scaroni R, Signorini E SEPIVAC: a community-based study of stroke incidence in Umbria, Italy. J Neurol Neurosurg Psychiatry 1991;34:695-698.

12. Bogousslavsky J, Regli F. Cerebral infarct in apparent transient 
ischemic attack. Neurology 1985,35:1501-1503

13. Herderschee D, Hijdra A, Algra A, Koudstal PJ, Kappelle LJ, vanGijn J. Silent stroke in patients with transient ischemic attack or minor ischemic stroke. The Dutch TLA Trial Study Group. Stroke $1992 ; 23: 1220-1224$.

14. Murros KE, Evans GW, Toole JF, Howard G, Rose LA Cerebral infarction in patients with transient ischemic attacks. I Neurol $1989 ; 236: 182-184$

15. Awad JA, Modic M, Little JR, Furlan AJ, Weinstein M. Focal Parenchymal Lesions in Transient Ischemic Attacks: Correlation of Computed Tomography and Magnetic Resonance Imaging. Stroke $1986 ; 17: 399-403$.

16. Kobayashi $\mathrm{S}$, Okada $\mathrm{K}$, Yamashita $\mathrm{K}$. Incidence of silent lacunar lesion in normal adults and its telation to cerebral blood flow and risk factors. Stroke 1991;22:1379-1383.

17. Hachinski VC, Lassen NA, Marshall J Multi-infarct dementia. A cause of mental health deterioration in the elderly. Lancet $1974 ;$ if: $207-210$

18. Adams H Jr., Bendixen BH, Kappelle LJ, Biller J, Love BB, Gordon DL, Marsh E3. Classification of subtype of acute ischemic stroke. Definitions for use in a multicenter clinical trial. TOAST. Trial of Org 10172 in Acute Stroke Treatment. Stroke 1993;24:35-41.

19. Sima S, Biller J, Skorton DJ, Seabold JE. Cardiac evaluation of the patient with stroke. Stroke 1990;21:14-23

20. Davis PH, Hachinski VC. The cardiac factor in stroke. Curr Opin Neurol Neurosurg 1992;5:39-43.

21. Easton JD, Sherman DG. Management of Cerebral Embolism of Cardiac Origin. Stroke 1980;11:433-441.

22. Feimberg WM, Seeger JF, Carmody RF, Anderson DC, Hart RG, Pearce LA. Epidemiologic features of asymptomatic cerebral infarction in patients with nonvalvular atrial fibrillation. Arch Intern Med $1990 ; 150: 2340-2344$.

23. Petersen P, Madsen EB, Brun B, Pedersen F, Gyldensted C, Boysen $G$. Silent Cerebral Infarction in Chronic Atrial Fubrillation. Stroke 1987:18:1098-1100.

24. Petersen P, Pedersen F, Johnsen A, Madsen EB, Brun B, Boysen G, Godttiedsen J. Cerebral computed tomography in paroxysmal atrial fibrillation. Acta Neurol Scand 1989;79:482-486.

25. Petersen $P$. Thromboembolic complications of atrial fibrillation and their prevention a review. Am J Cardiol 1990;65:24C-28C.

26. Ringelstein EB, Koschorke $\mathrm{S}$, Holling $A$, Thron A, Lambertz $\mathbb{H}$, Minale C. Computed tomographic patterns of proven embolic brain infarctions. Ann Neurol 1989;26:759-765. 
27. Sherman DG. Cardiac Embolism: The Neurologist's Perspective. Am J Cardiol 1990;65:32C-37C.

28. Boiten J, Lodder J, Kessels F. Two Clinically Distinct Lacunar Infuret Entities? A Hypothesis. Stroke 1993;24:652-656.

29. Bogousslavsky J, Cachin C, Regli F, Despland PA, Van-Melle G, Kappenberger L. Cardiac sources of embolism and cerebral infarction-clinical consequences and vascular concomitants: the Lausanne Stroke Registry. Neurology 1991;41:855-859.

30. Cerebral-Embolism-Task-Force. Cardiogenic Brain Embolism. Arch Neurol 1986;43:71-84.

31. Cerebral-Embolism-Task-Force. Cardiogenic brain embolism. The second report of the Cerebral Embolism Task Force [published erratum appears in Arch Neurol 1989 Oct; 46(10):1079] [see comments]. Arch Neurol 1989;46:727-743.

32. Orgogozo JM, Aupy M, Levy S. Unsuspected Cardiac Origin of Cerebral Embolism. Cerebrovasc Dis 1981;6:319-322.

33. Kempster PA, Gerraty RP, Gates PC. Asymptomatic cerebral infarction in patients with chronic atrial fibrillation. Stroke 1988;19:955957.

34. Sasaki W, Yanagisawa S, Maki K, Onodera A, Awaji T, Kanazawa T. High Incidence of Silent Small Cerebral Infarction in the Patients with Atrial Fibrillation. Circulation 1987;76, Supp IV:IV-104.

35. Hougaku $H$, Matsumoto $M$, Handa $N$, Maeda $H$, Itoh $T$, Tsukamoto $Y$, kamada T. Asymptomatic Carotid Lesions and Silent Cerebral Infarction. Stroke 1994,25:566-570.

36. Norris JW, Zhu CZ. Silent stroke and carotid stenosis. Stroke 1992;23:483-485,

37. Sise MJ, Sedwitz MM, Rowley WR, Shackford SR. Prospective analysis of carotid endarterectomy and silent cerebral infarction in 97 patients. Stroke 1989;20:329-332.

38. Siebler M, Sitzer M, Rose G, Bendfeldt D, Steinmetz H. Silent cerebral embolism caused by neurologically symptomatic high-grade carotid stenosis. Brain 1993;116:1005-1015.

39. Hier DB, Foulkes MA, Swiontoniowski M, Sacco RL, Gorelick PB, Mohr JP, Price TR, Wolf PA. Stroke recurrence within 2 years after ischemic infarction. Stroke 1991;22:155-161.

40. Gorelick PB, Chatterjee A, Patel D, Flowerdew G, Dollear W, Taber $\mathrm{J}$, Harris Y. Cranial computed tomographic observations in multiinfarct dementia. A controlled study. Stroke 1992;23:804-811.

41. Loeb C, Gandolfo C, Bino G. Intellectual Impairment and Cerebral Lesions in Multiple Cerebral Infarcts. Stroke 1988;19:560-565.

42. Loeb C, Gandolfo C, Croce R, Conti M. Dementia associated with lacunar infarction. Stroke 1992;23:1225-1229. 
43. Ratcliffe PJ, Wilcock GK Cerebrovascular disease in dementia: the importance of atrial fibrillation. Postgraduate Medical Journal $1985 ; 61: 201-204$.

44. Tatemichi TK. How acute brain failure becomes chronic: $A$ view of the mechanisms of .dementia related to stroke. Neurology $1990 ; 40: 1652-1659$

45. Tatemichi TK, Foulkes MA, Mohr JP, Hewitt JR, Hier DB, Price TR, Wolf PA. Dementia in Stroke Survivors in the Stroke Data Bank Cohort. Stroke 1990:21:858-866.

46. Awad IA, Spetzler RF, Hodak JA, Awad CA, Carey R. Incidental Subcortical Lesions Identified on Magnetic Resonance Imaging in the Elderly. I. Correlation With Age and Cerebrovascular Risk Factors. Stroke 1986;17:1084-1089.

47. Bamford J, Sandercock P, Dennis M, Burn J, Warlow C. Classification. and natural history of clinically identifyable subtypes of cerebral infarction. Lancet 1991;337:1521-1526.

48. Boiten J, Lodder J. Prognosis for Survival, Handicap and Recurrence of Stroke in Lacunar and Superficial Infarction. Cerebrovasc Dis $1993 ; 3: 221-226$.

49. Ricotta $J_{y}$ Ouriel $\mathbb{K}$, Green RM, DeWeese $\mathbb{J A}$. Use of Computerized tomography in selection of patients for elective and urgent carotid endarterectomy. Ann Surg 1985;202:783-787.

50. Brust JCM. Vascular Dementia-Still Overdiagnosed. Stroke 1983; 14:298-300.

51. Harrison MI, Marshall J. The variable clinical and CT findings after carotid occlusion: the role of collateral blood supply. I Neurol Neurosurg Psychiatry 1988;51:269-272.

52. Harrison MJ, Marshall J. Cerebral infarction on CT scans in patients with transient ischemic attacks relates to severity of angiographic disease at the carotid bifurcation[letter]. J Neurol Neurosurg Psychiatry 1988;51:305.

53. Foreman DW, Fulkerson PK. Crystallochemical characteristics of the inorganic phase of human calcific aortic valvar stenosis. Cardiovasc Res $1987 ; 21: 761-765$.

54. Maher ER, Curtis IR. Calcific aortic stenosis in chronic renal failure [letter]. Lancet 1985;2:1007.

55. Di-Pasquale G, Ribani $M$, Andreoli $A$, Zampa GA, Pinelli G. Cardioembolic stroke in primary oxalosis with cardiac involvement. Stroke 1989;20:1403-1406.

56. Carlson RG, Mayfield WR, Normann S, Alexander JA. Radiationassociated valvular disease. Chest 1991;99:538-545

57. Roberts WC. The Senile Cardiac Calcification Syndrome. Am J Cardiol $1986,58: 572-574$ 
58. Stapleton JF. Natural history of chronic valvular disease. Cardiovasc Clin 1986;16:105-147.

59. Normand J, Loire $\mathrm{R}$, Zambartas $\mathrm{C}$. The anatomical aspects of adult aortic stenosis. Eur Heart J 1988;9:31-36.

60. Rose AG. Etiology of acquired valvular heart disease in adults. A survey of 18,132 autopsies and 100 consecutive valve-replacement operations. Arch Pathol Lab Med 1986;110:385-388.

61. Wren C, Petch MC. Calcific aortic stenosis. J R Coll Physicians Lond 1983; 17:192-195.

62. Rotman M, Morris JJ, Behar VS, Peter RH, Kong Y. Aortic Valvular Disease: Comparison of Types and Their Medical and Surgical Management. Am J Med 1971;51:241-257.

63. Auriol M, Chomette G, Jaussoin D. Systemic calcific emboli in calcified aortic valve diseases. Apropos of an anatomical case Sem Hop Paris 1983;59:2195-2198.

64. Wilson JH, Cranley JJ. Recurrent calcium emboli in a patient with aortic stenosis. Chest 1989;96:1433-144.

65. Holley KE, Bahn RC, MoGoon DC, Mankin HT. Spontaneous calcific embolization associated with calcific aortic stenosis. Circulation 1963;27: 197-202.

66. Kapila A, Hart R. Calcific cerebral emboli and aortic stenosis: Detection of computed tomography. Stroke 1986;17:619-621.

67. Brockmeier LB, Adolph RJ, Gustin BW, Holmes JC, Sacks JG. Calcium emboli to the retinal artery in calcific aortic stenosis. Am Heart J 1981,101:32-35.

68. Rancurel $G_{s}$ Marelle L, Vincent $D$, Catala $M$, Arzimanoglou A, Vacheron A. Spontaneous calcific cerebral embolus from a calcific aortic stenosis in a middle cerebral artery infarct. Stroke 1989;20:691. 693.

69. Vernhet H, Torres GF, Laharotte JC, Tournut P, Bierme T, Froment JC, Duquesnel J. Spontaneous calcific cerebral emboli from calcified aortic valve stenosis. J Neuroradiol 1993;20:19-23.

70. Yock DH. CT demonstration of cerebral emboli. J Comput Assist Tomogr 1981;5:190-196.

71. Kumpe CW, Bean WB. Aortic stenosis: A study of the clinical and pathologic aspects of 107 proved cases. Medicine 1948;27:139-185.

72. Dry TJ, Willius FA. Calcareous disease of the aortic valve: A study of two hundred twenty-eight cases. Am Heart J 1939;17:138-157.

73. Usher BW. Cardiac valvular disease and stroke. Neurol Clin 1993;11:391-398

74. Aronow WS. Mitral annular calcification: significant and worth acting upon. Geriatrics 1991;46:73-75.

75. Oka M, Onur N, Gross S. Mitral anulus and valvular calcification. N 
Y State J Med 1983,83:837-842.

76. Fulkerson PK, Beaver BM, Auseon JC, Graber HL Calcification of the Mitral Annulus. Etiology, Clinical Associations, Complications and Therapy. Am J Med 1979;66:967-977.

77. Bigi A, Compostella L, Fichera AM, Foresti E, Gazzano M, Ripamoni. A. Roveri N. Structural and chemical characterization of inorganic deposits in calcified human mitral valve. J Inorg Biochem $1988,34: 75-82$

78. Cacciapuoti F, Perrone N, Diaspro R, Galzerano D, Gentile S, Lapiello B. Slowing of Mitral Valve Annular Calcium in Systemic Hypertension by Nifedipine and Comparisons with Enalapril and Atenolol Am J Card 1993; 72:1038-1042.

79. Dessault $O$, Toussaint M, Cabrol $C_{x}$ Fouchard J. [Tight mitral stenosis caused by calcifications of the ring extending to the valves]. Ann Cardiol Angeiol Paris 1988;37:309-311.

80. Sommer $K$, Lajos $T Z$, Visco JP. Intramyocardial calcification in the elderly. A diagnostic and therapeutic puzzle. Chest $1992 ; 102: 317-319$

81. Motamed HE, Roberts WC. Frequency and significance of mitral anular calcium in hypertrophic cardiomyopathy: analysis of 200 necropsy patients. Am J Cardiol 1987;60:877-884.

82. Forman MB, Virmani $R$, Robertson RM, Stone WJ Mitral anular calcification in chronic renal failure. Chest 1984;85:367-371.

83. Maher $\mathbb{E R}$, Young G, Smyth-Walsh B, Pugh S, Curtis JR. Aortic and mitral valve calcification in patients with end-stage renall disease. Lancet $1987 ; 2: 875-877$.

84. Giampalmo A, Buffa D, Caponnetto S, Chiarella F, Pesce C, Sacchetti R. Myxoid degeneration with prolapse and dystrophic calcification of the annulus fibrosus of the mitral valve. Pathological and clinical survey. Appl Pathol 1983;1:194-208.

85. Iga $\mathrm{K}$. Hori $\mathrm{K}$. Left ventricular outflow obstruction caused by mitral ring calcification. Am Heart J 1990;119:418-419.

86. Kelly RP, Kuchar DL, Thorburn CW. Subvalvular mitral calcium as a cause of surgically correctable ventricular tachycardia. Am J Cardiol $1986,57: 884-886$

87. Hart RG. Cardiogenic embolism to the brain. Lancet $1992 ; 339: 589-$ 594.

88. Jespersen CM, Egeblad H. Mitral annulus calcification and embolism. Acta Med Scand 1987;222;37-41.

89. De Bono DP, Warlow CP. Mitral-annulus calcification and cerebral or retinal ischemia. The Lancet 1979;383-385.

90. Furlan AJ, Craciun AR, Salcedo EE, Mellino M. Risk of stroke in patients with mitral anmulus calcification. Stroke 1984;15:801-803.

91. Jespersen CM, Egeblad H. [Calcified mitral ring. Incidence and 
complications]. Ugeskr Laeger 1987;149:3394-3397.

92. The Boston Area Anticoagulants for Atrial Fibrilation Trial Investigators. The effect of low-dose warfarin on the risk of stroke in patients with nonrheumatic atrial fibrillation. N Engl J Med 1990;323:15051.511 .

93. Aronow WS, Schoenfeld MR, Gutstein H. Frequency of thromboembolic stroke in persons greater than or equal to 60 years of age with extracranial carotid arterial disease and/or mitral annular calcium. Am J Cardiol 1992; 70:123-124.

94. Nair CK, Thomson W, Ryschon K, Cook C, Hee TT, Sketch MH. Long-term follow-up of patients with echocardiographically detected mitral anular calcium and comparison with age- and sex-matched control subjects. Am J Cardiol 1989;63:465-470.

95. Benjamin EJ, Plehn JF, D'Agostino RB, Belanger AJ, Comai K, Fuller DL, Wolf PA, Levy D. Mitral annular calcification and the risk of stroke in an elderly cohort. $\mathrm{N}$ Engl J Med 1992,327:374-379.

96. Lin CS, Schwartz IS, Chapman I. Calcification of the mitral annulus fibrosus with systemic embolization. A clinicopathologic study of 16 cases. Arch Pathol Lab Med 1987;111:411-414.

97. Nestico PF, Depace NL, Morganroth J, Kotler MN, Ross J. Mitral annular calcification: clinical, pathophysiology, and echocardiographic review. Am Heart J 1984;107:989-996. 



\section{Silent Brain Infarcts}

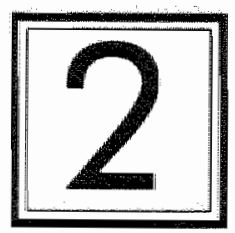

Silent brain infarcts in 755 consecutive patients with a first-ever supratentorial ischemic stroke; the relationship with index stroke subtype, vascular risk factors, and mortality. 



\section{Abstract}

Background and Purpose: to establish associations of various clinical variables, CT scan features, presenting stroke subtypes, and outcome with the presence of silent infarcts on brain CT scan.

Methods: 755 consecutive patients were studied in a prospective registration of patients with a first supratentorial atherothrombotic, cardioembolic, or lacunar stroke, or stroke with an undetermined cause, by multiple logistic regression analysis.

Results: Two hundred and six patients $(27 \%)$ with a first symptomatic territorial or small deep ischemic stroke had one or more silent infarcts on CT. Of all silent lesions, $169(82 \%)$ were small and deep. Silent infarcts were significantly more strongly associated with a lacunar than atherothrombotic (OR:1.59;95\% Cl:1.02-2.47;P=0.039) or cardioembolic (OR:1.89;95\% CI:1.2-2.99; $\mathrm{P}=0.005$ ) index stroke. Silent territorial lesions were more strongly associated with cardioembolic stroke compared with lacunar stroke but not when compared with atherothrombotic stroke. No differences were found in the association of silent infarcts with atherothrombotic strokes compared with strokes of undetermined cause. High age and hypertension were the only risk factors significantly associated with silent infarcts (OR:1.76;95\%Cl:1.14-2.71;P=0.011 and OR: $1.58 ; 95 \% \mathrm{Cl}: 1.13-$ $2.21 ; \mathrm{P}=0.007$, respectively). This was mainly because of a strong independent association of these risk factors with silent small deep infarcts (OR:1.75;95\% $1.1 .10-2.79 ; \mathrm{P}=0.018$ and $\mathrm{OR}: 1.57$;$95 \% \mathrm{Cr}: 1.09-2.24 ; \mathrm{P}=0.014$, respectively). A cardioembolic source, or atrial fibrillation in specific were not associated with any type or number of silent infarcts, when adjusted for other risk factors. Significant carotid stenosis (a diameter reduction of more than $50 \%$ ) was not significantly associated with any type of silent lesion. Initial severe handicap (Rankin score greater than three), 30-days case fatality rate, and one-year mortality, were not affected by the presence of silent infarcts.

Conclusions: The strong association of silent small deep lesions with first symptomatic small deep infarcts suggests a common underlying mechanism, presumably small-vessel vasculopathy, whereas cardiogenic embolism or large vessel thromboembolism are the most likely 
cause in both silent and first symptomatic territorial infarcts. Single or multiple silent infarcts do not predict a cardioembolic stroke mechanism in first symptomatic supratentorial brain infarcts. As silent infarcts do not predict carotid embolic stroke cause in first symptomatic brain infarcts, their presence should not influence the decision on carotid desobstruction. Silent infarcts do not affect the degree of initial handicap, 30-days case fatality or one-year mortality. The significance of silent infarcts for possible future cognitive decline and the risk of recurrent stroke awaits further study. 
B rain CT scanning may detect one or more hypodense lesions compatible with brain infarction without a history of prion stroke. Such lesions are often called silent brain infarcts. ${ }^{1-15}$ Their presence has been associated with worse stroke outcome, vascullar risk factors, ${ }^{361226}$ a cardiac source of embolism especially

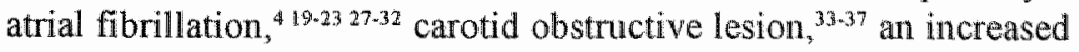
risk of recurrent stroke, and the development of vascular dementia. is 23 38-4.5 However, most studies on silent brain infarcts were done in selected patients, such as those with a carotid stenosis, or with only atrial fibrillation, not allowing conclusions on the significance of silent infarcts for stroke patients in general. 2021313935.364647 One large study included a control group for comparison, but selected only TIA or minor stroke patients without atrial fibrillation, restricting conclusions to this subgroup. ${ }^{12}$ Some studies on unselected stroke patients were small or retrospective, not allowing any firm conclusions. $^{31} 48$ There are five prospective studies that analysed different aspects of silent brain infarcts in consecutive stroke patients. ${ }^{1.30}$. 3 However, these studies can be criticized for several reasons: two were rather small; 36 early generation CT scanners may have missed silent infarcts; ${ }^{23}$ approximately $25 \%$ of patients or more did not have $\mathrm{CT} ;{ }^{236}$ only a certain age cohort was included; ${ }^{3}$ only a subgronp was selected based on whether or not certain ancillary investigations were performed ${ }^{7}$ patients with TIA were included in a stroke series; 7 multiple logistic regression analysis allowing for collinearity between silent infarct associated factors was not performed. ${ }^{237} \mathrm{No}$ studies did subgroup analysis. One prospective series of 500 stroke patients had a high rate $(85 \%)$ of CT scanning and performed multivariate comparisons. However, risk factors could not be studied in all patients, infarct and hemorrhages were not considered separately, whereas no prospectively well-defined separation of different infarct subtypes was performed. 'One prospective study established a significant association between carotid stenosis and silent infarction (lesions equal to or larger than $5 \mathrm{~mm}$ ) on MRI in 117 patients free of stroke, increasing the a priori chance of such an association by excluding all patients with a potential cardioembolic source and possibly excluding some with small deep silent infarcts. ${ }^{34}$ Studying separate brain infarct subgroups could be relevant because they may differ in stroke cause, clinical presentation, and outcome. 9051 Thus, the significance of finding silent brain infarcts may differ between index stroke subtypes. Also, similarity in silent and symptomatic brain infarct type may point at a consistency in underlying stroke cause. These considerations led us to conclude that so far several aspects of silent brain infarcts have not fully been clarified. There- 
fore, in a prospective study of 755 consecutive patients with a first, supratentorially located ischaemic stroke, we studied adjusted associations of various clinical and CT scan features with the presence of silent brain infarcts. Especially we wondered whether silent infarcts would influence stroke outcome in terms of 30-days case fatality rate and one-year mortality, and whether they are small deep or territorial in symptomatic small deep, respectively territorial strokes.

\section{Patients and Methods}

Patients were registered between July 1987 and August 1992 in an ongoing prospective registry at the University Hospital of Maastricht, including all patients with a first-ever supratentorial brain infarct with symptoms lasting longer than 24 hours. Twenty-five of 813 consecutive patients were exluded because of a rare cause like fibromuscular dysplasia, carotid dissection, vasculitis etc, leaving 788 patients, of whom 755 had CT scan and were included in the study. The University Hospital is the only hospital in the Maastricht region with an adherent population of approximately 190.000 people. All patients were examined as soon as possible after admission or at the first out-patient clinic visit. They had routine investigations including standard blood and urine tests, electrocardiography, chest radiography, carotid studies, and CT scan. Echocardiography, 24 hours ECG monitoring and cerebral angiography were performed in selected cases. A brain infarct was defined as rapidly developing clinical signs of focal disturbance of cerebral function, lasting longer than 24 hours or leading to death, with no other apparent cause than that of vascular origin, while CT scan showed an area of low attenuation compatible with the clinical signs and symptoms or was without specific lesion. For symptomatic infarcts, when no CT scan was available, we used the Guy's Hospital Stroke Diagnostic Score (Allen Score) that predicts with a probability of more than $90 \%$ that the stroke was due to infarction when the score is lower than $4 .{ }^{52} \mathrm{~A}$ small deep infarct was defined as a CT lesion compatible with the occlusion of a single perforating artery, i e. a subcortical, small, sharply marginated hypodense lesion with a diameter less than 20 $\mathrm{mm}$, or clinically a lacunar syndrome if no specific lesion was visible $^{3.3}$ on CT. A patient with a cortical syndrome and a lacunar infarct on CT was classified as having a symptomatic lacunar infarct, unless symptoms were incompatible, ${ }^{26} 53$ but were also analysed separately. We distinguished four lacunar syndromes: pure motor stroke, pure sensory stroke, sensorimotor stroke and ataxic hemiparesis including dysarthria-clumsy hand cases. A territorial infarct was 
defined as CT findings compatible with infarction involving the cortex, or clinically a cortical syndrome, i.e. a unilateral motor or sensory deficit, or both, in combination with signs of contical dysfunction (e.g. aphasia, visual field deficit, visual spatial disturbances, apraxia, neglect or agnosia) if no specific lesion was visible on $\mathrm{CT}$. Patients with a large subcortical infarct were included in this group, because of probable similar pathogenesis. ${ }^{54}$ Territorial infarcts were divided into three groups by presumed cause: atherothrombotic, cardioembolic, or undetermined cause. Infarcts were considered of undetermined origin in the absence of carotid studies (duplex scan, continuous wave doppler, multigate pulse Doppler, or angiography), any compatible carotid lesion (more than $5-15 \%$ stenosis on multigate pulse Doppler, duplex scanning or angiography, or more than $15-50 \%$ stenosis on continuous wave Doppler), or cardiac source of embolism. A cardioembolic infarct was defined as a territorial infarct in the presence of one or more of the following cardiac sources of embolism: chronic and paroxysmal atrial fibrillation, myocardial infarction less than 6 weeks old, prosthetic aortic or mitral valve, endocarditis, cardiomyopathy, mitral stenosis, left-ventricular aneurysm, and intraventricular thrombus. Four patients with a cardioembolic stroke cause but with significant ipsilateral carotid stenosis were included in this group. Atherothrombotic infarction was defined as a territorial infarct with no other apparent cause than presumed large vessel disease, i.e. atherothrombosis or artery-toartery embolism, fullfilling the criteria of compatible carotid lesions as mentioned above. A silent brain infarct was defined as a lowdensity area on CT compatible with infarction but without a history of stroke, as taken from the patient's history, from the family, or any other accessible information. Identification of silent lesions was based on incompatibility of such lesion and index stroke symptoms, such as location in different hemisphere or otherwise anatomical incompatibility (e.g. a small deep infarct in the anterior leg of the internal capsule on $\mathrm{CT}$ in a patient with sudden hemianopia). Furthermore, old lesions are more hypodense, or may show signs of surrounding tissue loss like retraction of brain structures towards the lesion. Sometimes a repeated CT showed the recent infarct. We distinguished two types of silent brain infarcts: small deep lesions and silent territorial infarcts, defined as CT lesions described above. Besides age and sex the following risk factors were recorded: hypertension (known hypertension treated with anti-hypertensive medication, two or more blood pressure recordings higher than $160 / 90 \mathrm{~mm} \mathrm{Hg}$ before stroke or at least one week after stroke), diabetes mellitus (known diabetes treated with diet and/or medica- 
tion; or either a fasting serum glucose higher than $7 \mathrm{mmol} / \mathrm{l}$, or a postprandial serum glucose level higher than $11 \mathrm{mmol} / \mathrm{lmeasured}$ on at least two separate occasions before or after stroke, but not in the acute phase (the first 72 hours)), a history of ischaemic heart disease (myocardial infarction, angina pectoris), carotid stenosis of more than $50 \%$ on carotid tests. Handicap on admission was measured using the modified Rankin-scale. ${ }^{35}$ Categorical variables were analysed in an univariate analysis by means of Chi-square test and crude odds ratios ((c)OR) with $95 \%$ confidence intervals (CI) ${ }^{96}$ Subsequent multiple logistic regression analysis determined the independent association of age, sex, hypertension, diabetes mellitus, a history of ischaemic heart disease, significant carotid stenosis (more than 50\% stenosis), stroke subtypes (lacunar, atherothrombotic, cardioembolic, or undetermined cause) with any type of silent infarct, silent small deep infarct, or with silent territorial infarct, as dependent variables. Statistical analysis was performed with odds ratios, adjusted for age, sex, hypertension, diabetes mellitus, ischaemic heart disease, atrial fibrillation, carotid stenosis, and symtpomatic stroke subtype, ((a)OR), with $95 \% \mathrm{Cl}$. Risk factor profiles for silent infarcts were also determined with symptomatic stroke subtypes added to the model. Models with different subsets of variables in subgroups of patients were tested to look for collinearity, of which only relevant results are reported.

\section{Results}

There were 398 men (53\%) and 357 women (47\%), with a median age of 71 (range 24-96) years. The median delay until CT scan was 5 (range 0-912) days; $490 \mathrm{CT}$ scans $(65 \%)$ were done within the first week, $638(85 \%)$ within two weeks, and $681(90 \%)$ within three weeks after stroke onset. There were 210 stroke patients without an infarct on CT, of which 34 infarcts were atherothrombotic, 46 cardioembolic, 95 lacunar, and 35 of undetermined cause. Two hundred and six patients $(27 \%, 95 \% \mathrm{Cl}: 24-30)$ had one or more silent infarcts on $\mathrm{CT}$. There were 145 patients with undetermined stroke cause. These had a similar frequency of $\mathrm{CT}$ confirmed infarcts and silent infarct subtypes as thad the atherothrombotic group. Therefore, and because of the absence of any specific stroke cause, and regarding their ages (mean: 71 years) the most likely cause was considered to be generalised atherosclerosis, but they were analysed separately. Table 1 shows the frequency of patients with silent infarcts among the four presenting stroke subtypes. Hundred and thirty-nine patients had one silent infarct, 67 more than one. Hundred and sixty-nine patients had one or more silent small deep, and 48 one or more silent 
territorial infarcts. Of all silent lesions, $164(49 \%)$ were right hemispheric; 22 of these, and 30 of 169 left hemispheric silent lesions were territorial. In the patients with multiple silent infarcts, 177 lesions were small deep ( 83 in the right hemisphere), and 17 territorial ( 7 in the right hemisphere). Multiple silent infarcts did not occur more often in patients with $(10 / 178)$ than without $(57 / 577)$ a cardioembolic stroke ((c)OR:0.54,95\%Cl:0.26-1.15; $\mathrm{P}=0.11$ ). Multiple logistic regression comparison (Table 2) showed that silent infarcts were significantlly more prevalent in patients with a small deep index stroke than in those with an atherothrombotic or cardioembolic index stroke. This association was mainly due to a significant preponderance of silent small deep infarcts with a small deep index stroke as compared to those with an atherothrombotic or cardioembolic index stroke. Silent infarcts were equally prevalent in atherothrombotic or cardioembolic index stroke groups. Silent territorial infarcts were significantly less strongly associated with small deep than cardioembolic infarcts. The undetermined cause group behaved like the atherothrombotic group in its association with silent infarcts, when compared with the other index stroke groups. Because the type of index stroke in patients with a cortical syndrome but a small deep infarct on CT may be uncertain, in a separate analysis we also looked at this group of patients. This group was strongly and much more associated with silent small deep infarcts than atherothrombotic ((a)OR:5.12;95\%CI:2.30-11.4; $\mathrm{P}=0.000)$, lacunar ((a)OR:3.06;95\%Cl:1.42-6.56; $\mathrm{P}=0.003$ ), cardioembolic strokes ((a)OR:6.95;95\%CI:3.08-15.7; $\mathrm{P}=0.000)$, or strokes with undetermined cause ( (a)OR:5.68;95\% Cl:2.50-12.9:P=0.000). Associations of this group with silent territorial infarcts were the same as in the other stroke groups. Table 3 shows the frequencies of risk factors among patients with a silent infarct, which we compared between the different groups by crude odds ratios. Higher age and hypertension were significantly more frequent in patients with one or more silent (small deep) infarcts. Atrial fibrillation and a more severe initial handicap (Rankin score higher than 3 ) were significantly more frequent in patients with than without a silent territorial lesion. Significant carotid stenosis on either side was less frequent in patients with than without a silent small deep infarct. Figure 1 displays the association of risk factors, also shown in Table 4, with the presence of one or more silent infarcts as resulted from multiple logistic regression analysis. Age above 65 years and hypertension were significantly associated with the presence of a silent small deep infarct, or with the presence of any type of silent brain infarct, but not with silent territorial infarcts. 


\begin{tabular}{|c|c|c|c|c|c|}
\hline \multirow[b]{2}{*}{ Silent infarcts } & \multicolumn{5}{|c|}{ Index brain infart cause } \\
\hline & Atherothrombotic & Undetermined & Cardioembolic & $\begin{array}{l}\text { Small } \\
\text { deep }\end{array}$ & Total \\
\hline$I$ mall deep & $21(12)$ & $20(14)$ & $21(12)$ & $42(16)$ & $104(13)$ \\
\hline $\begin{array}{l}2 \text { or more small } \\
\text { deop }\end{array}$ & $8(4)$ & $6(4)$ & $6(3)$ & $34(13)$ & $54(7)$ \\
\hline 1 Tarritorial & $10(6)$ & $6(4)$ & $13(7)$ & $6(2)$ & $35(4)$ \\
\hline $\begin{array}{l}2 \text { or mope } \\
\text { ferritarial }\end{array}$ & 0 & 0 & $\mathrm{~T}$ & 1 & 2 \\
\hline $\begin{array}{l}\text { Small deep and } \\
\text { torritorial }\end{array}$ & $4(2)$ & 1 & $3(2)$ & $3(1)$ & 11 \\
\hline None & $133(76)$ & $112(77)$ & $134(75)$ & $170(66)$ & $549(73)$ \\
\hline Total & 176 & 145 & 178 & 256 & 755 \\
\hline
\end{tabular}

Numbers of patients; percentages of column fotals between brackets. 


\begin{tabular}{|c|c|c|c|c|c|c|c|c|}
\hline \multirow[b]{3}{*}{$\begin{array}{l}\text { Index stroke } \\
\text { cause }\end{array}$} & \multicolumn{8}{|c|}{ Silent infarcts } \\
\hline & \multicolumn{3}{|l|}{ All } & \multicolumn{3}{|c|}{ Small deep } & \multicolumn{2}{|l|}{ Territorial } \\
\hline & OR & $95 \% \mathrm{Cl}$ & $P$ & OR & $95 \% \mathrm{Cl}$ & $P$ & $\mathrm{OR} 95 \% \mathrm{Cl}$ & $P$ \\
\hline $\begin{array}{l}\text { Small deep vs } \\
\text { atherothrombotic }\end{array}$ & 1.59 & $1.02-2.47$ & 0.04 & 1.97 & $1.23-3.16$ & 0.005 & $0.46 \quad 0.20 \cdot 1.07$ & ns \\
\hline $\begin{array}{l}\text { Small deep vs } \\
\text { cardioembolic }\end{array}$ & 1.89 & $1.20-2.99$ & 0.005 & 2.71 & 1.64 .44 .48 & 0.000 & $0.43 \quad 0.19 \cdot 0.99$ & 0.04 \\
\hline $\begin{array}{l}\text { Cardioembolic vs } \\
\text { atherothrombotic }\end{array}$ & 0.84 & 0.50 .11 .40 & $n s$ & 0.73 & $0.41 \cdot 1.29$ & ns & $1.08 \quad 0.49-2.35$ & ns \\
\hline $\begin{array}{l}\text { Undetermined ws } \\
\text { ather othrombotic }\end{array}$ & 0.81 & $0.47-1.38$ & $n s$ & 0.89 & $0.50-7.59$ & $n s$ & $0.530 .20-1.38$ & ns \\
\hline $\begin{array}{l}\text { Undetermined ws } \\
\text { small deep }\end{array}$ & 0.51 & $0.32-0.83$ & 0.006 & 0.45 & $0.27-0.75$ & 0.002 & $1.14 \quad 0.42-3.12$ & $n s i$ \\
\hline $\begin{array}{l}\text { Undetermined vs } \\
\text { cardioembolic }\end{array}$ & 0.97 & $0.57 \cdot 1.63$ & ms & 1.23 & $0.69-2.20$ & ns & $0.49 \quad 0.201 .23$ & ns \\
\hline
\end{tabular}

Associations of silent infards with index stroke subtypes with multiple logistic regression analysis. $\mathrm{OR}$, adjusted odds ratio; $95 \% \mathrm{Cl}, 95$ percent confidence interval; $\mathrm{P}$, $\mathrm{P}$-value. 


\section{Table 3. Silent infarcts, risk factors, unadjusted.}

\section{Silent infarcts}

All types Small deep Territorial

Risk factor $n$ OR $95 \% \mathrm{Cl} P$ P OR $95 \% \mathrm{Cl} P \quad \mathrm{P}$ OR $95 \% \mathrm{Cl} P$ $\begin{array}{llllllllllllll}65<\mathrm{Age}<76 & 78 & 1.69 & 1.09-2.62 & 0.02 & 66 & 137 & 1.66 & 1.04 \times 2.66 & 0.03 & 17 & 1.62 & 0.60 .4 .39 & 0.3\end{array}$

$\begin{array}{lllllllllllllll}\text { Age }>75 / & 84 & 1.85 & 1.20-2.84 & 0.00 & 66 & 1.63 & 1.02 .2 .62 & 0.04 & 22 & 2.12 & 0.89-5.04 & 0.09\end{array}$

age $<66 \quad / 44 \quad 1.85 \quad 1.20 .2 .840 .00 \quad 137 \quad 1.631 .022 .620 .04 \quad 19 \quad 2.120 .89-5.040 .09$

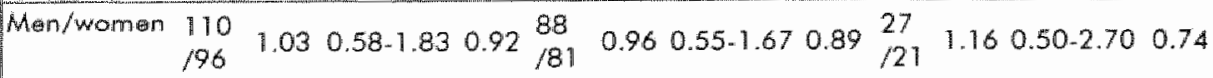

$\begin{array}{llllllllllllll}\text { Hypertension } 113 & 1.58 & 1.13-2.19 & 0.00 & 94 & 1.59 & 1.12 & 2.27 & 0.01 & 23 & 1.06 & 0.05-2.12 & 1.0\end{array}$

ischemic

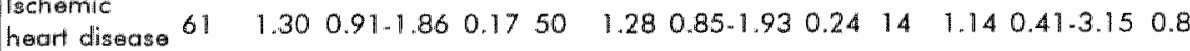

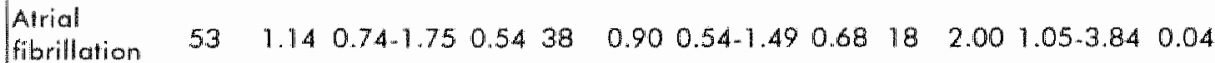

\begin{tabular}{llllllllllllllllllll}
\hline $\begin{array}{l}\text { Diabat } \\
\text { mellitus }\end{array}$ & 39 & 1.24 & $0.78-7.98$ & 0.36 & 31 & 1.16 & $0.67-2.00$ & 0.59 & 11 & 1.53 & $0.66-3.54$ & 0.32
\end{tabular}

\begin{tabular}{|llllllllllllllllll}
\hline $\begin{array}{l}\text { Any caratid } \\
\text { stenosis }\end{array}$ & 29 & 0.74 & $0.46-1.21$ & 0.23 & 20 & 0.59 & $0.35-1.02$ & 0.06 & 12 & 1.70 & $0.78-3.69$ & 0.18 \\
\hline $\begin{array}{l}\text { Rankin scor } \\
>3\end{array}$ & 108 & 1.12 & $0.78-1.61$ & 0.53 & 82 & 0.91 & $0.60-1.37$ & 0.65 & 32 & 2.06 & $1.08-3.95$ & 0.03 \\
\hline
\end{tabular}

Risk factors far silent brain infarcts. Crude analysis. OR, crude odds ratio: $95 \% \mathrm{Cl}, 95$ percent confidence interwal: P, P-yalue 
Table 4. Risk factors for silent infarcts, adjusted

\begin{tabular}{|c|c|c|c|c|c|c|c|c|c|}
\hline \multirow[b]{3}{*}{ Risk factor } & \multicolumn{9}{|c|}{ Silent infarcts } \\
\hline & \multicolumn{3}{|l|}{ All } & \multicolumn{3}{|c|}{ Small deep } & \multicolumn{3}{|c|}{ Territorial } \\
\hline & OR & $95 \% \mathrm{Cl}$ & $\mathrm{p}$ & OR & $95 \% \mathrm{Cl}$ & $p$ & OR & $95 \% \mathrm{Cl}$ & $p$ \\
\hline $\begin{array}{l}65<A g \theta<76 \\
\text { age } 666\end{array}$ & 1.76 & $1.14-2.71$ & 0.01 & 1.75 & $1.10-2.79$ & 0.02 & 1.55 & $0.67-3.61$ & 0.30 \\
\hline $\begin{array}{l}\text { Aga }>75 / \\
\text { Aga }<66\end{array}$ & 2.18 & $1.39-3.43$ & 0.000 & 2.01 & $1.24-3.27$ & 0.005 & 1.92 & $0.82 \cdot 4.46$ & 0.13 \\
\hline Men/women & 0.79 & $0.56-1.12$ & 0.19 & 0.90 & $0.66 \cdot 1.31$ & 0.59 & 0.66 & $0.35-1.25$ & 0.20 \\
\hline Hypertansion & 1.58 & $1.13-2.21$ & 0.007 & 1.57 & $1.09-2.24$ & 0.01 & 1.11 & 0.60 .2 .03 & 0.74 \\
\hline $\begin{array}{l}\text { Ischemic heart } \\
\text { disease }\end{array}$ & 1.29 & $0.89-1.87$ & 0.18 & 1.35 & $0.90-2.01$ & 0.14 & 0.98 & 0.50 .1 .90 & 0.46 \\
\hline Atrial fibrillation & 0.96 & $0.65-1.43$ & 0.85 & 0.79 & $0.50-1.23$ & 0.29 & 1.85 & $0.96-3.57$ & 0.06 \\
\hline Diabetes mellitus & 1.13 & $0.73-1.75$ & 0.58 & 1.03 & $0.65-1.65$ & 0.89 & 1.58 & $0.76-3.27$ & 0.22 \\
\hline $\begin{array}{l}\text { Any carolid } \\
\text { stenosis }\end{array}$ & 0.61 & $0.35 \cdot 1.06$ & 0.08 & 0.80 & $0.52-1.23$ & 0.31 & 1.91 & 0.85 .4 .28 & 0.11 \\
\hline Rankin score $>3$ & 0.99 & $0.71-11.40$ & 0.9 & 0.83 & $0.58-1.20$ & 0.32 & 1.76 & $0.92-3.37$ & 0.09 \\
\hline
\end{tabular}

Risk factors for silent brain infarcts. Multiple lagistic regiression analysis. OR, adjusted odds ratio; $95 \% \mathrm{Cl}, 95$ percent confidence interval, $\mathrm{P}, \mathrm{P}$-value. 
Fig. 1 Multiple logistic regresision analysis of patients with or without silent infairets. Odds ratio $>1$ : the riskfactor is more strongly associlated with sillent Infarct. A lower limit of the $95 \%$ confidence interval $<1$ implies a P-value<0.05. Cs: carotid stenosis; *, all silent infarets; *, silent territorial infarct (sti); : sllent small deep infarct.

$65<$ age $\leq 75$ vs age $\leq 65$

age $>75$ vs age $\leq 65$

sex male/female

ischemic heart disease

hypertension

diabetes mellitus

atrial tibrillation

Flght $C S$ and right STI

Left CS and left STI

Fankin $>3$

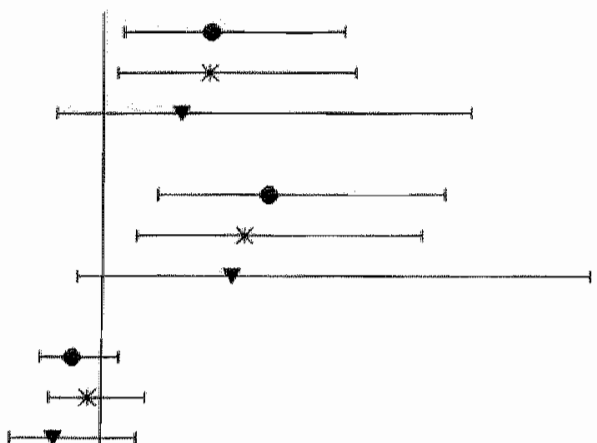

any CS

One month mortality One year mortalifty

\section{0}

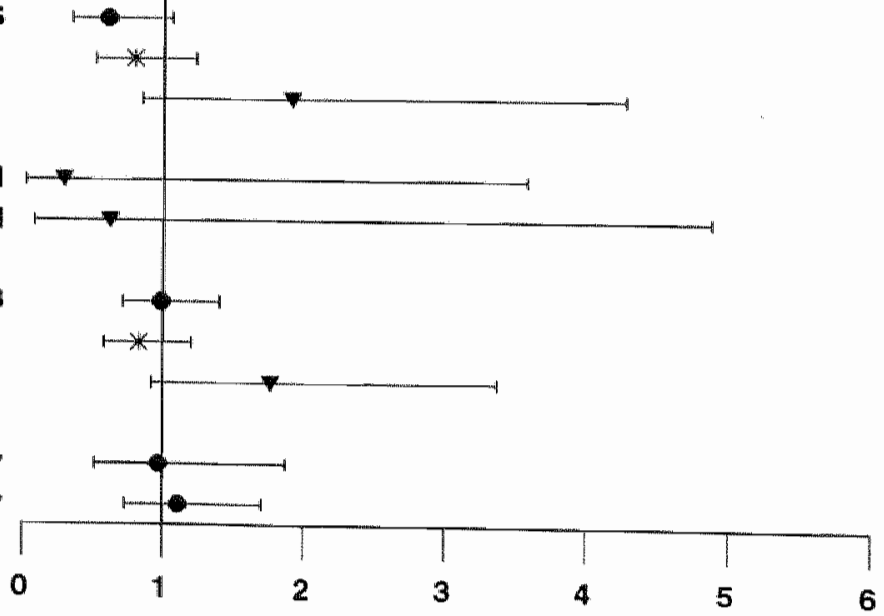

odds ratio with $95 \%$ confidence interval 
Only when small deep index strokes were excluded from the analysis with silent territorial infarcts as dependent variable, atrial fibrillation became just significant ((a)OR:2.11;95\% CI: $1.01-4.40 ; \mathrm{P}=0.046)$ Diabetes mellitus was significantly associated with silent teritorial infarcts only when the analysis was restricted to patients with noncardioembolic territorial index strokes ((a)OR:3.31; 95\%Cl:1.10$9.95 ; \mathrm{P}=0.03)$. Restricting the analysis to other stroke subtypes did not significantly change associations. A tendency for silent territorial cortical infarcts to be associated with a significant carotid stenosis either ipsilateral or contralateral to the silent infarct was not significant; this tendency was lost when analysing only carotid stenosis ipsilateral to silent territorial lesion (right carotid stenosis:

(a) OR:0.29;95\% Cl:0.02-3.58;P=0.45; left carotid stenosis:

(a) OR:0.62;95\%CI:0.08-4.88; $\mathrm{P}=0.87$ ). Thirty-days case fatality rate and one-year mortality did not significantly differ between patients with or without a silent infarct ((a)OR:0.97;95\% Cr:0.51-1.87; $\mathrm{P}=0.11$, and (a)OR: $1.11 ; 95 \% \mathrm{Cl}: 0.73-1.70 ; \mathrm{P}=0.63$, respectively). A more severe initial handicap (Rankin score higher than 3) was not significantly associated with the presence of one or more silent infarcts ((a)OR:0.96;95\%CI:0.71-1.40).

\section{Discussion}

The 27 per cent of patients with one or more silent brain infarcts is more than reported by others. ${ }^{238} \mathrm{CT}$ scanning rate in this study was higher compared to other series. Especially for very old patients when not admitted to hospital, CT scan may be less easily accessible. Because higher age is related with the presence of silent infarcts, both high $\mathrm{CT}$ scanning rate and the higher age of the patients may explain the higher frequency of silent infarcts in this study. "High age might explain the even higher percentage (38\%) in the community-based SEPIVAC.6910

As others found in this study most silent infarcts appeared to be small deep lesions. ${ }^{1-371220}$ Depending on the lesion site a small deep infarct may more often go unnoticed by the patient than infarction involving the cortex. ${ }^{57}$ None of the prospective studies on consecutive patients with ischaemic stroke reported multivariate analysis accounting for collinearity between features related with silent infarcts, ${ }^{2367}$ except a recent one ${ }^{1}$ in which, however, different indexstroke subtypes were not distinguished. Although predominant in all of the four index stroke subgroups, silent small deep infarcts were significantly more frequent in first-ever lacunar stroke in this study. Silent territorial infarcts, on the other hand, were underrepresented in 
lacunar index stroke. These findings suggest similarity in the type of underlying mechanism in symptomatic and silent infarcts: small vessel vasculopathy in most small deep infarcts, and cardiogenic embolism or large vessel thromboembolism in territorial infarcts. ${ }^{57}$ Some patients may suffer both, because silent small infarcts are common among stroke patients with cardiogenic or large vessel thromboembolism. This may reflect hypertension related small vessel wasculopathy, since beside age hypertension was the only risk factor significantly associated with silent small deep, but not territorial infarcts. This small vessel vasculopathy may be small vessel hyalinosis rather than small vessel atherothrombosis as was argued before. ${ }^{26}$ In contrast, The Copenhagen Stroke study' reported lower mean symptomatic infarct size in a crude comparison of patients with and without silent infarcts, concluding that the underlying stroke mechanism might be different. However, the study presented here indicates that those findings merely reflected differences in the frequency of silent small infarcts among symptomatic stroke subtypes. It should be kept in mind that some lesions considered as silent infarcts may be sequelae of small hemorrhages. Also, some patients with a lacunar syndrome but without a visible compatible lesion on CT may have an infarct in the brainstem, but it has been recently discussed that CT-negative cases resemble those with visible symptomatic lacunar infarctions. ${ }^{53}$ The presumed lacunar index strokes with a cortical syndrome resembled the lacunar strokes in this study. The chance that a lacunar stroke is erroneously diagnosed as a territorial infarct increases with the presence of one or more silent small deep infarcts, as has been discussed elsewhere ${ }^{53}$ As others found, increasing age was strongly related to the presence of silent brain infarcts, mainly due to age dependency of the silent small deep lesions. Thus, with increasing age hypertensive patients may be at increased risk for silent small deep infarcts probably due to hypertension related small vessel lipohyalinosis. ${ }^{31}$

Like The Copenhagen study but as opposed to other studies, most of which lacked non-cardioembolic stroke patients for comparison, neither a cardiac source of embolism in general nor atrial fibrillation in specific were significantly associated with any type of silent stroke in this series. ${ }^{419.23} 77.32475859$ Only when small deep index strokes were excluded from the analysis with silent territorial infarcts as dependent variable, atrial fibrillation became just significant. That concurs with the above-mentioned consistency in underlying stroke mechanism in prior silent and first symptomatic stroke. However, these data, nor those of Jorgensen et al. ${ }^{1}$ concur with the general 
statement, that finding silent brain infarcts increases the risk that the symptomatic stoke was caused by cardiogenic embolism. Other studies on consecutive stroke patients also did not find atrial fibrillation to be associated with silent infarcts, ${ }^{36}$ as opposed to studies restricted to patients with atrial fibrillation. ${ }^{20 \cdot 22.32}$

Diabetes mellitus was an associated risk factor only with silent territorial infarcts, and only when the analysis was restricted to the atherothrombotic index stroke subgroup. The Framingham study found glucose intolerance as the only risk factor for silent infarcts. There was a tendency for carotid stenosis to be associated with silent territorial lesions but this was not statistically significant. These findings do not confirm suggestions by others on the significance of carotid obstructive lesions for the presence of silent infarcts, even when the analysis was restricted to the atherothrombotic subgroup or included stenosis compatible with the side of the silent lesion, or side of the index stroke. The relationship of silent infarcts with carotid stenosis in other studies may be explained by the lack of adjusting for collinearity with other associated factors, ${ }^{35}{ }^{36}$ or by selection bias ${ }^{34}$ Therefore, the decision on carotid surgery should not be influenced by the presence of prior silent infarcts.

Prior silent infarcts may increase functional deficit when a symptomatic stroke occurs. ${ }^{12}$ However, more severe initial handicap as indicated by a Rankin score of 4 or 5 was not associated with silent infarcts. Also, 30-days case fatality rate and one-year mortality were not affected by the presence of silent infarcts. Obviously, silent brain infarcts do not have a deleterious effect on stroke outcome, a finding that contrasts with the suggestions of others, which, however, were mostly based on data from series of selected patients. ${ }^{416.25}$ In the SEPIVAC, the NINCDS Stroke Data Bank, and The Copenhagen Stroke studies the presence of silent infarcts also did not affect stroke outcome. ${ }^{126}$ An increased risk of cognitive decline or even dementia has often been related to the presence of silent brain infarcts. However, this view was more often based on flawed inferences than on the results of prospective evaluation of patients in comparison with those without silent brain infarcts. ${ }^{470}$ Patients with multiple asymptomatic lesions in the NINCDS study were "free of overt symptoms in cognitive or behaviourial spheres" ${ }^{245}$ Jorgensen et al found silent infarcts to have no effect on MMSE ratings. ${ }^{.}$Until follow-up evaluation of prospectively included stroke patients comparing those with and without silent lesions, that also accounts for collinearity of factors that may influence cognitive decline such as leukoaraiosis or 
brain atrophy has not been achieved, it remains unclear whether silent lesions present an independent factor threatening stroke patients' cognition, or whether they indicate an increased risk for future (silent) stroke. This study illustrates that the significance of silent brain infarcts may depend on silent infarct subtype and on index infarct subtype. Evaluating the brain by imaging techniques in patients at risk, specially those with hypertension, should be considered to document the degree of cerebral "end organ damage" in terms of silent infarcts, although the precise significance of eventual detected lesions for future risk of stroke and cognitive decline deserves further study. 


\section{References}

1. Jorgensen HS, Nakayama H, Raaschou HO, Gam J, Olsen TS Silent Infarction in Acute Stroke Patients. Prevalence, Localization, Risk Factors, and Clinical Significance: The Copenhagen Stroke Study. Stroke 1994;25:97-104.

2. Chodosh EH, Foulkes MA, Kase CS, Wolf PA, Mohr JP, Hier DB, Price TR, Furtado J Jr. Silent stroke in the NINCDS Stroke Data Bank. Neurology 1988;38:1674-1679.

3. Kase CS, Wolf PA, Chodosh EH, Zacker HB, Kelly-Hayes M, Kannel WB, D'Agostino RB, Scampini L. Prevalence of silent stroke in patients presenting with initial stroke: the Framingham Study. Stroke $1989 ; 20: 850-852$.

4. Kittner SJ, Sharkness CM, Sloan MA, Price TR, Dambrosia JM, Tuhrim S, Wolf PA, Mohr JP, Hier DB. Features on initial computed tomography scan of infarcts with a cardiac source of embolism in the NINCDS Stroke Data Bank. Stroke 1992;23:1748-1751.

5. Laloux $P$, Ossemann $M$, Jamart J. Prevalence and Significance of Silent Stroke in Patients With Initial Cerebral Ischemia[abstr. 2nd Eur Stroke Conf, 1992]. Cerebrovasc Dis 1992;2:201.

6. Ricci S, Celani MG, La-Rosa F, Righetti E, Duca E, Caputo N. Silent Brain Infarctions in Patients With First-Ever Stroke. Stroke $1993 ; 24: 647-651$.

7. Mounier-Vehier F, Leys D, Rondepierre P, Godefroy O, Pruvo JP. Silent Infarcts in Patients With Ischemic Stroke Are Related to Age and Size of the Left Atrium. Stroke 1993;24:1347-1351.

8. Foulkes MA, Wolf PA, Price TR, Mohr JP, Hier DB. The Stroke Data Bank: Design, Methods, and Baseline Characteristics. Stroke $1988 ; 19: 547-554$

9. Ricci $\mathrm{S}$, Celani MG, Guercini $G$, Rucireta P, Vitali $R$, La-Rosa $F_{\text {, }}$ Duca E, Ferraguzzi $R$, Paolotti M, Seppoloni $D$, Caputo N, Chiurulla C, Scaroni R, Signorini E. First-Year Results of a Community-Based Study of Stroke Incidence in Umbria, Italy. Stroke 1989;20:853-857.

1.0. Ricci $S$, Celani $M G$, La Rosa $F$, Vitalli $R$, Duca $\mathbb{E}$, Ferraguzzi $R$, Paolotti M, Seppoloni D, Caputo $N$, Chiurulla $C$, Scaroni $R$, Signorini E. SEPIVAC a community-based study of stroke incidence in Umbria, Italy. J Neurol Neurosurg Psychiatry 1991;34:695-698

11. Bogousslavsky $\boldsymbol{J}$, Regli $F$. Cerebral infanct in apparent transient ischemic attack. Neurology 1985;35:1501-1503.

12. Herderschee D, Hijdra A, Algra A, Koudstaal PJ, Kappelle LJ, vanGijn J. Silent stroke in patients with transient ischemic attack or minor ischemic stroke. The Dutch TIA Trial Study Group. Stroke $1992 ; 23: 1220-1224$. 
13. Murnos KE, Evans GW, Toole JF, Howard G, Rose LA. Cerebra] infarction in patients with transient ischemic attacks. INeurol $1989 ; 236: 182-184$.

14. Awad IA, Modic M, Little JR, Furlan AJ, Weinstein M. Focal Parenchymal Lesions in Transient Ischemic Attacks: Correlation of Computed Tomography and Magnetic Resonance Imaging. Stroke $1986,17: 399-403$

15. Kobayashi $\mathrm{S}$, Okada $\mathrm{K}$, Yamashita $\mathrm{K}$. Incidence of silent lacunar lesion in normal adults and its relation to cerebral blood flow and risk factors. Stroke 1991;22:1379-1383.

16. Adams H Jr, Bendixen BH, Kappelle LJ, Biller J, Love BB, Gordon DL, Marsh E3. Classification of subtype of acute ischemic stroke. Definitions for use in a multicenter clinical trial. TOAST. Trial of Org 10172 in Acute Stroke Treatment. Stroke 1993;24:35-41.

17. Sirna $S$, Biller $J$, Skorton DJ, Seabold JE. Cardiac evaluation of the patient with stroke. Stroke 1990;21:14-23.

18. Davis $\mathrm{PH}$, Hachinski VC. The cardiac factor in stroke. Curr Opin Neurol Neurosurg 1992;5:39-43

19. Easton JD, Sherman DG. Management of Cerebral Embolism of Cardiac Origin. Stroke 1980;11:433-441.

20. Feimberg WM, Seeger JF, Carmody RF, Anderson DC, Hart RG, Pearce LA. Epidemiologic features of asymptomatic cerebral infarction in patients with nonvalvular atrial fibrillation. Arch Intern Med $1990 ; 150: 2340-2344$

21. Petersen P, Madsen EB, Brun B, Pedersen F, Gyldensted C, Boysen G. Silent Cerebral Infarction in Chronic Atrial Fibrillation. Stroke 1987; 18:1098-1100.

22. Petersen P, Pedersen F, Johnsen A, Madsen EB, Brun B, Boysen G, Godtfredsen 1 Cerebral computed tomography in paroxysmal atrial fibrillation. Acta Neurol Scand 1989;79:482-486.

23. Petersen $\mathbf{P}$. Thromboembolic complications of atrial fibrillation and their prevention: a review. Am J Cardiol 1990,65:24C-28C.

24. Ringelstein $\mathbb{E B}$, Koschorke $\mathrm{S}$, Holling $\mathrm{A}$, Thron $\mathrm{A}$, Lambertz $\mathbb{H}$, Minale C. Computed tomographic patterns of proven embolic brain infarctions. Ann Neurol 1989;26:759-765.

25. Sherman DG. Cardiac Embolism: The Neurologist's Perspective. Am $\mathrm{J}$ Cardiol $1990,65: 32 \mathrm{C}-37 \mathrm{C}$.

26. Boiten J, Lodder J, Kessels F. Two Clinically Distinct Lacunar Infarct Entities? A Hypothesis. Stroke 1993;24:652-656.

27. Bogousslavsky $J_{\text {, Cachin }} C$, Regli F, Despland PA, Van-Melle $G_{\text {, }}$ Kappenberger L. Cardiac sources of embolism and cerebral infarction-clinical consequences and vascular concomitants: the Lausanne Stroke Registry. Neurology 1991;41:855-859. 
28. Cerebral-Embolism-Task-Force. Cardiogenic Brain Embolism. Arch Neurol 1986;43:71-84.

29. Cerebral-Embolism-Task-Force. Cardiogenic brain embolism. The second report of the Cerebral Embolism Task Force [published erratum appears in Arch Neurol 1989 Oct;46(10): 1079] [see comments]. Arch Neurol 1989,46:727-743.

30. Orgogozo JM, Aupy M, Levy S. Unsuspected Cardiac Origin of Cerebral Embolism. Cerebrovasc Dis 1981;6319-322.

31. Kempster PA, Gerraty RP, Gates PC. Asymptomatic cerebral infarction in patients with chronic atrial fibrillation. Stroke 1988;19955957.

32. Sasaki W, Yanagisawa S, Maki $\mathrm{K}$, Onodera A, Awaji $\mathrm{T}$, Kanazawa $\mathrm{T}$. High Incidence of Silent Small Cerebral Infarction in the Patients with Atrial Fibrillation. Circulation 1987;76, Supp IV.IV-104.

33. Brott $T$, Tomsick $T$, Feinberg W, Johnson C, Biller J, Broderick J, Kelly M, Frey J, Schwartz S, Blum C, Nelson JJ, Chambless L, Toole $J$, for the ACAS investigators. Baseline silent cerebral infarction in the asymptomatic carotid atherosclerosis study. Stroke 1994,25 . 1122 1129 .

34. Hougaku $\mathrm{H}$, Matsumoto $\mathrm{M}$, Handa $\mathrm{N}$, Maeda $\mathrm{H}$, Itol $\mathrm{T}$, Tsukamoto $\mathrm{Y}$, kamada T. Asymptomatic Carotid Lesions and Silent Cerebrall Infarction. Stroke 1994,25:566-570.

35. Norris JW, Zhu CZ. Silent stroke and carotid stenosis. Stroke $1992 ; 23: 483-485$.

36. Sise MJ, Sedwitz MM, Rowley WR, Shackford SR. Prospective analysis of carotid endarterectomy and silent cerebral infarction in 97 patients. Stroke 1989;20;329-332.

37. Siebler M, Sitzer M, Rose $G$, Bendfeldt D, Steinmetz H. Silent cerebral embolism caused by neurologically symptomatic high-grade carotid stenosis. Brain 1993;116:1005-1015.

38. Hier DB, Foulkes MA, Swiontoniowski M, Sacco RL, Gorelick PB, Mohr JP, Price TR, Wolf $\mathbb{P} A$. Stroke recurrence within 2 years after ischemic infarction. Stroke 1991;22:155-161.

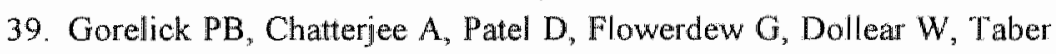
$\mathrm{J}$, Harris Y. Cranial computed tomographic observations in multiinfarct dementia. A controlled study. Stroke 1992:23:804-811.

40. Hachinski VC, Lassen NA, Marshall J. Multi-infarct dementia. A cause of mental health deterioration in the elderly. Lancet 1974, ii $207-210$.

41. Loeb C, Gandolfo C, Bino G. Intellectual Impairment and Cerebral Lesions in Multiple Cerebral Infarcts. Stroke 1988;19:560-565.

42. Loeb C, Gandolfo C, Croce R, Conti M. Dementia associated with lacunar infarction. Stroke 1992;23:1225-1229 
43. Ratcliffe PJ, Wilcock GK. Cerebrovascular disease in dementia: the importance of atrial fibrillation. Postgraduate Medical Journal $1985 ; 61: 201-204$

44. "Tatemichi TK. How acute brain failure becomes chronic: A view of the mechanisms of dementia related to stroke. Neurology 1990,40 1652-1659.

45. Tatemich "TK, Foulkes MA, Mohr JP, Hewitt JR, Hier DB, Price TR, Wolf PA. Dementia in Stroke Survivors in the Stroke Data Bank Cohort. Stroke 1990;21:858-866.

46. Ricotta JJy Ouriel $\mathrm{K}$, Green RM, DeWeese JA. Use of Computerized tomography in selection of patients for elective and urgent carotid endarterectomy. Ann Surg 1985;202:783-787.

47. Brust JCM Vascular Dementia-Still Overdiagnosed. Stroke $1983 ; 14: 298-300$

48. Harrison $M J$, Marshall $\mathbb{J}$. The variable clinical and $C T$ findings after carotid occlusion: the role of collateral blood supply. I Neurol Neurosurg Psychiatry 1988;51:269-272.

49. Harrison MJ, Marshall J. Cerebral infarction on CT scans in patients with transient ischemic attacks relates to severity of angiographic disease at the carotid bifurcation[letter]. I Neurol Neurosurg Psychiatry $1988,51: 305$

50. Bamford J, Sandercock P, Dennis M, Burn J, Warlow C. Classification and natural history of clinically identifyable subtypes of cerebrall infarction. Lancet 1991;337:1521-1526.

51. Boiten J, Lodder J. Prognosis for Survival, Handicap and Recurrence of Stroke in Lacunar and Superficial Infarction. Cerebrovasc Dis $1993 ; 3: 221-226$.

52. Allen CMC. Clinical diagnosis of the acute stroke syndrome. Q J Med $1983 ; 208: 515-523$.

53. Lodder $\mathrm{J}$, bamford $\mathrm{J}$, kappelle $\mathrm{J}$, Boiten $\mathrm{J}$. What causes false clinical prediction of small deep infarcts? Stroke $1994 ; 25: 86-91$.

54. Boiten $J$, Lodder J. Large striatocapsular infarcts: clinical presentation and pathogenesis in comparison with lacunar and cortical infarcts. Acta Neurol Scand 1992;86:298-303.

55. Bamford J, Sandercock PAG, Warlow CP, Slattery J. Interobserver agreement for the assessment of handicap in stroke patients[letter] Stroke 1989;20:828

56. Sandercock P. The odds ratio: a usefull tool in neurosciences. J Neurol Neurosurg. Psychiatry 1989;52:817-820.

57. Caplan LR. Silent Brain Infarcts. Cerebrowasc Dis 1994;4(suppl 1) $32-39$.

58. Kittner SJ, Sharkness CM, Price TR, Plotnick GD, Dambrosia JM, Wolf PA, Mohr JP, Hier DB, Kase CS, Tuhrim S. Infarcts with a 
cardiac source of embolism in the NINCDS Stroke Data Bank. historical features. Neurology 1990;40:281-284.

59. Broderick JP, Phillips SJ, O'Fallon WM, Frye RL, Whisnant JP. Relationship of cardiac disease to stroke occurrence, recurrence, and mortality. Stroke 1992;23:1250-1256.

60. Lambert CD. Neurological Manifestations of Acquired Cardiac Disease and Dysrhythmias. In: Aminoff MIJ, ed. Neurology and General Medicine. New York: Churchill Livingstone, 1989: 69-83. 



\section{Cardiac Valve Calcification}

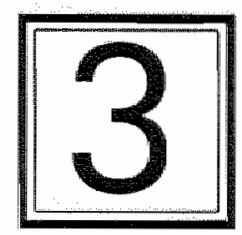

Characteristics of Patients with

Calcification of the Mitral Annulus or

Aortic Valve. 



\section{Abstract}

Background and Purpose: There is discussion about mitral annular calcification and aortic valve calcification with or without stenosis being expressions of atherosclerotic disease.

Methods: Therefore, incidence of atherosclerotic risk factors was analysed in patients with these diseases and control patients from an echocardiographic database of 8.160 consecutive patients. $657(8 \%)$ Patients were identified with mitral annular calcification and 815 $(9 \%)$ patients with a calcified aortic valve, of which $515(6.3 \%)$ patients had stenosis with a minimal aortic valve gradient of $16 \mathrm{~mm}$ $\mathrm{Hg}$. In these patients, the atherosclerotic risk profile was compared with 568 control patients using multiple logistic regression analysis.

Results: Age, female sex, hypertension, diabetes mellitus, and hypercholesterolemia were strongly associated with aortic valve calcification without stenosis, and with mitral annular calcification. These risk factors were almost similar for stenotic aortic valve calcification except for female sex and diabetes mellitus.

Conclusions: Mitral annular calcification, and stenotic or non stenotic aortic valve calcification have a high incidence of atherosclerotic risk factors, suggesting they should be considered as manifestations of generalized atherosclerosis. 
$\mathrm{C}$ alcification of the mitral annulus and aortic valve occurs as a degenerative process mainly in the elderly. Calcific deposits in the neighbouring atrioventricular conduction system can lead to cardiac conduction disturbances in patients with mitral annular calcification and aortic valve calcification. ${ }^{12}$ An other potential complication of valvular stenosis is embolism due to dislodgement of calcified material in the blood stream. The degenerative mechanism underlying mitral annular calcification and aortic valve calcification may accelerate when mechanical stress imposed on the valvular apparatus increases, like in hypertension and congenital or acquired valvular disorders.

Prevalence of mitral annular calcification and aortic valve calcification increases with age and often exist together. ${ }^{3}$ Therefore, the question arises whether the valvular calcifications are the result of increased valvular stress (as is the case in hypertension), an expression of more generalized atherosclerosis, or reflect a primary degenerative process, progressing with advancing age. Among the reports that suggest an association of mitral annular calcification or aortic valve calcification with cardiac and vascular risk factors is one population based study of 162 patients with mitral annular calcification, which describes a multiple logistic regression model containing few clinical and no echocardiographic variables. We analysed whether there is a specific risk factor profile for patients with mitral annular calcification or aortic valve calcification in multivariate logistic regression models, adjusting for clinical and echocardiographic risk factors for cardiac and vascular disease.

This analysis is relevant in the context of this thesis, because MAC and CAS may be risk factors for stroke, or merely markers of atherosclerotic disease, which is discussed in the following chapters which report the results of studies on stroke risk in patients with MAC or CAS.

\section{Patients and Methods}

From a prospective echocardiographic database ${ }^{4}$ of 8.160 consecutive patients examined between 1985 and 1990, all patients with mitral annular calcification or aortic valve calcification where selected. Furthermore, 568 randomly selected patients without cardiac valve calcification from the same database formed a control group. 
The following clinical risk factors were recorded: age, sex, hypertension (known hypertension treated or not treated with anti-hypertensive medication; or two or more blood pressure recordings higher than $160 / 90 \mathrm{~mm} \mathrm{Hg}$ ), diabetes mellitus (known diabetes treated with diet and/or medication; or either a fasting serum glucose higher than $7 \mathrm{mmol} / 1$, or a postprandial serum glucose level higher than 11 mmol/1 measured on at least two separate occasions), a history of ischaemic heart disease (myocardial infarction, angina pectoris), a history of coronary artery bypass grafting, the use of oral anticoagulants or salicylates, cholesterol (the mean of all available values with or without lipid lowering therapy), a history of hypercholesterolemia (known treated hypercholesterolemia or fasting or non-fasting cholesterol level higher than $6.5 \mathrm{mmol} / \mathrm{L}$ ), peripheral atherosclerotic disease, atrial fibrillation, and date and type of cardiac valve replacement.

The following echocardiographic parameters were registered: mitral annular calcification (defined as a dense, localized, highly reflective area at the base of the (mainly posterior) mitral valve on twodimensional echocardiogram; if these calcifications are large enough stone-shadows can be discerned), mitral stenosis (defined as a hemodynamic important increase in velocities over the mitral valve leading to gradients in combination with a calculated functional valve orifice of less than $2.5 \mathrm{~cm}^{2}$ ), the degree of mitral insufficiency, the presence of calcified aortic sclerosis, (defined as bright echo's on one or more cusps more than $1 \mathrm{~mm}$ in anteroposterior direction and a maximal pressure gradient below $16 \mathrm{~mm} \mathrm{Hg}$ ), aortic stenosis (defined as a pressure gradient exceeding $16 \mathrm{~mm} \mathrm{Hg}$ ), mitral, tricuspid or aortic valve prosthesis or bioprothesis, enlarged left atrium (45 mm or more), atrial-septal aneurysm, atrial septal defect, reduced (to less than $40 \%$ ) left-ventricular ejection fraction, presence of a reduced (to less than 28\%) fractional shortening, increased left-ventricular mass, ${ }^{5}$ posterior-, inferior-, anterior wall infarction, wallmotion score, and presence of apical aneurysm, cardiac thrombus, and a dilated cardiomyopathy. Wall-motion score was a semiquantitative measure of left ventricular wall motion. For this purpose, the left ventricle was divided into thirteen segments. Wall motion in each segment was scored from 0-4 (normokinesis, hypokinesis, hypokinesis to akinesis, akinesis, and dyskinesis). As cut off point between small and larger asynergy of the left ventricle was chosen a wall motion score of 12 . Fractional shortening was defined as the difference between left ventricular enddiastolic and endsystolic diameter. Left ventricular wall mass was determined echocardi- 
ographically as a measure of left wentricular wall thickness reflecting long standing hypertension, independent of left ventricular chamber size ${ }^{67}$ Left ventricular wall mass cutpoints were 175,200 and $225 \mathrm{~g}$ for men, and 165,190 , and $215 \mathrm{~g}$ for women ${ }^{5}, 225$ and $215 \mathrm{~g}$ being defined as the upper limits of normal in men and women, respectively. All diameters used were measured according to the recommendations of the American Society of Echocardiography. ${ }^{8-10}$

Despite the expected age differences between patients and controls we deliberately designed the study for multiple logistic regression analysis as opposed to matching in order to: 1 . Avoid the introduction of confounding by matching, 2 . measure the attribution of each stratum, impossible after matching, 3. prevent reduction of study group size with consequent larger confidence intervals, and therefore improve reliability of point estimates. In addition: 1. matching for e.g. age and sex would raise the question why not match for many other variables (multiple regression analysis), and 2. matching was unnecessary concerning the large group sizes.

Statistical analysis was done with stepwise multiple logistic regression analysis with mitral annular calcification, aortic valve calcification, and calcified aortic valve with stenosis, respectively as dependent variables, and the control group as reference. The above mentioned registered clinical and echocardiographic variables could be entered into the model when the P-value of entrance was 0.10 or lower.

\section{Results}

Mitral annular calcification was present in 657 patients, aortic valve calcification in 815 , leading to stenosis in 515 . Aortic valve calcification occurred in 289 , and aortic valve calcification with stenosis in 113 patients with mitral annular calcification. Characteristics of the groups are shown in Table 1 . The results of stepwise multiple logistic regression analysis for aortic valve calcification, aortic valve calcification with stenosis and mitral annular calcification are shown in Table 2, 3 and 4, respectively, and in Figure 1. Of the tested model indicated in the methods section only those variables are shown which passed the P-level of significance for entry in the model. 


\begin{tabular}{|c|c|c|c|c|}
\hline & MAC 657 & AVC 300 & CAS 515 & Controls 562 \\
\hline $\begin{array}{l}\text { Mean age [median] } \\
\text { Range }\end{array}$ & $\begin{array}{l}72+1 / 10[74] \\
21-96\end{array}$ & $\begin{array}{l}7.4+1.10[75] \\
21-92\end{array}$ & $\begin{array}{l}67+1-15[71] \\
7-96\end{array}$ & $\begin{array}{l}53+/ .18[58] \\
0.90\end{array}$ \\
\hline age $<45$ & 8 & 4 & 42 & 163 \\
\hline $45<=$ age $<55$ & 26 & 6 & 30 & 86 \\
\hline $55<=$ age $<65$ & 97 & 35 & 101 & 132 \\
\hline age $>=65$ & 526 & 255 & 342 & 181 \\
\hline Men/women & $220(33) / 437$ & $106(35) / 194$ & $242(47) / 273$ & $338 / 60 / / 224$ \\
\hline Hypertension & $290(44)$ & $136(45)$ & $154(30)$ & $96(17)$ \\
\hline Ischemic heart disease & $382(58)$ & $179(59)$ & $248(48)$ & $225(40)$ \\
\hline Diabetes mellitus & $124(19)$ & $68(23)$ & $51(10)$ & $43(8)$ \\
\hline Hyperchollesterolemia & $36(5)$ & $18(6)$ & $22(4)$ & $10(2)$ \\
\hline Mean serum cholesterol & 6.6 & 6.5 & 6.6 & 5.9 \\
\hline $\begin{array}{l}\text { Peripheral atherasderotic } \\
\text { disease }\end{array}$ & $55(8)$ & $30(10)$ & $37(7)$ & $28(5)$ \\
\hline Afrial fibrillation & $32(4)$ & $14(5)$ & $36(7)$ & $30(5)$ \\
\hline Dilated cardionyopathy & $30(4)$ & $19(6)$ & $12(2)$ & $38(7)$ \\
\hline Rheumatic mitral stenosis & $18(2)$ & $6(2)$ & $59(11)$ & $19(3)$ \\
\hline Mitral regurgitation & $220(33)$ & $95(31)$ & $27 !(52)$ & $218(39)$ \\
\hline Aortic/ mitral prosthesis & $6 / 0$ & $0 / 0$ & $2 / 19$ & $26 / 39$ \\
\hline $\begin{array}{l}\text { Anterior wall } \\
\text { infaret/Apicall } \\
\text { anaurysm/Cardiac } \\
\text { thrombus/Atrial septal } \\
\text { anourysm/Atrial septal } \\
\text { defect }\end{array}$ & $80 / 3 / 5 / 0 / 0$ & $34 / 1 / 4 / 0 / 0$ & $24 / 0 / 2 / 0 / 0$ & $82 / 10 / 16 / 3 / 7$ \\
\hline Coronary bypass surgery & $67(10)$ & $26(9)$ & $61(12)$ & $60(11)$ \\
\hline
\end{tabular}

Baseline data. $+/-10$ means a standard deviation of 10 . Percentage between brackets, median between square brackets. 


\section{Table 2. Non-stenotic aortic valve calcification, characteristics}

\begin{tabular}{|lll|}
\hline Risk Factors & OR(95\%Cl) & $P$ \\
\hline $45<=a g e<55$ vage $<45$ & $5.78(1.13-30.6)$ & 0.03 \\
\hline $55<=0 g e<65$ va age $<45$ & $23.3(5.33-102)$ & 0.00 \\
\hline Age $>=65$ va age $<45$ & $104(24.6-440)$ & 0.00 \\
\hline Men/women & $0.57(0.38-0.68)$ & 0.00 \\
\hline Hypertension & $2.38(1.55-3.65)$ & 0.00 \\
\hline Diabetes mellitus & $2.85(1.58-5.13)$ & 0.00 \\
\hline Hypercholesterolemia & $2.95(0.99-8.82)$ & 0.05 \\
\hline Enlarged left atrium & $2.29(1.5-3.51)$ & 0.00 \\
\hline Anterior myocardial infarct & $0.47(0.26-0.85)$ & 0.01 \\
\hline Apical aneurysm & $0.15(0.02-1.42)$ & 0.09 \\
\hline Atrial fibrillation & $0.41(0.16-1.02)$ & 0.05 \\
\hline Mitrat regurgitation & $0.48(0.31-0.74)$ & 0.00 \\
\hline
\end{tabular}

Multiple lagistic regression analysis of the riskfactors associated with aortic vallwe calcification withoul stenosis ("AVC" in lext). OR, adjusted adds ratio, $95 \% \mathrm{Cl}_{*} 95$ percent confidence interval; $P$, $P$-value. 


\begin{tabular}{|c|c|c|}
\hline & OR(95\%CI) & $\mathrm{p}$ \\
\hline $45<=$ age $<55 /$ age $<45$ & $1.11(0.56-2.14)$ & 0.70 \\
\hline $55<=$ age $<65 /$ age $<45$ & $2.28(1.30-4.0)$ & 0.00 \\
\hline Age $>=65 / a g e<45$ & $7.7(4.68-12.7)$ & 0.00 \\
\hline Hypertension & $1.91(1.31-2.78)$ & 0.00 \\
\hline Hypercholesterolemia & $2.55(0.90-7.17)$ & 0.07 \\
\hline Enlarged left atrium & $2.01(1.4-2.87)$ & 0.00 \\
\hline Anterior myocardial infarct & $0.18(0.10-0.34)$ & 0.00 \\
\hline Dilaied cardiomyopathy & $0.23(0.10 \cdot 0.51)$ & 0.00 \\
\hline Rheumatic mitral stenasis & $2.29[1.11-4.74]$ & 0.02 \\
\hline
\end{tabular}

Multiple logistic regression analysis of the risk foctors associated with aartic valve calcification with stenosis ("CAS" in the text). OR, adjusted adds ratio; $95 \% \mathrm{Cl}, 95$ percent confidence interval; $P$, P-wallue. 


\begin{tabular}{|c|c|c|}
\hline Risk factor & $\mathrm{OR}(95 \% \mathrm{Cl})$ & $P$ \\
\hline 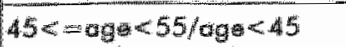 & $8.82(3.37 .23 .1)$ & 0.00 \\
\hline 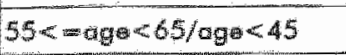 & $18.6(7.54 .45)$ & 0.00 \\
\hline$A g=-65 / \mathrm{cge}<45$ & $67(27-161)$ & $0 . \overline{00}$ \\
\hline Men/wamen & $0.45(0.33-0.63)$ & 0.00 \\
\hline Hypentrits & $2.72(1.92-3.86)$ & 0.00 \\
\hline Diobetes mellitus & $2.49(1.49-4.14)$ & 0.00 \\
\hline Hyparcholesterolemia & $2.86(1.16-7.08)$ & 0.02 \\
\hline Enlarged left atrium & $2.22(1.58 .3 .10)$ & 0.00 \\
\hline Anterior myocardial infarct & $0.65(0.41-1.03)$ & 0.06 \\
\hline Apical cineurysm & $0.2(0.04-0.92)$ & 0.03 \\
\hline Mitral ragurgitation & $0.45(0.32-0.63)$ & 0.00 \\
\hline
\end{tabular}

Multiplo logistic regression analysis of the risk factors associated with mitral annular calcification ("MAC" in the textf). OR, adjusted adds ratio; $95 \% \mathrm{Cl}, 95$ percent confidence interval; $\mathrm{P}, \mathrm{P}$-value. 
Fig 1. Riskfactors associated with aortic valve calcillication without $(1)$ or with (E) stenosis, and with mitral annular calcification (*). Multiple logistic regression analysis.

$45 \leq$ age $<55 /$ age $<45$

$55 \leq$ age $<65 /$ age $<45$

age $\geq 65 /$ age $<45$

male/female

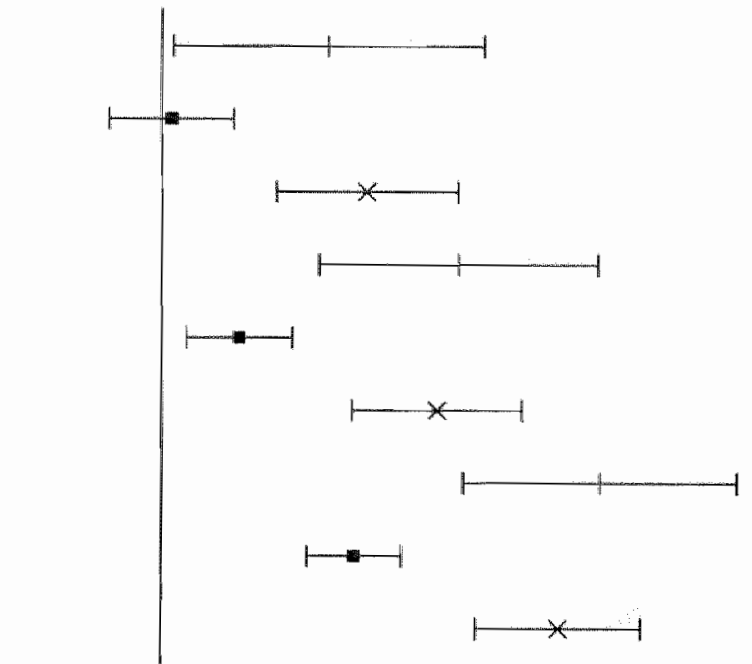

male/female

(1)

hypercholesterolemia

diabetes mellitus

hypertension

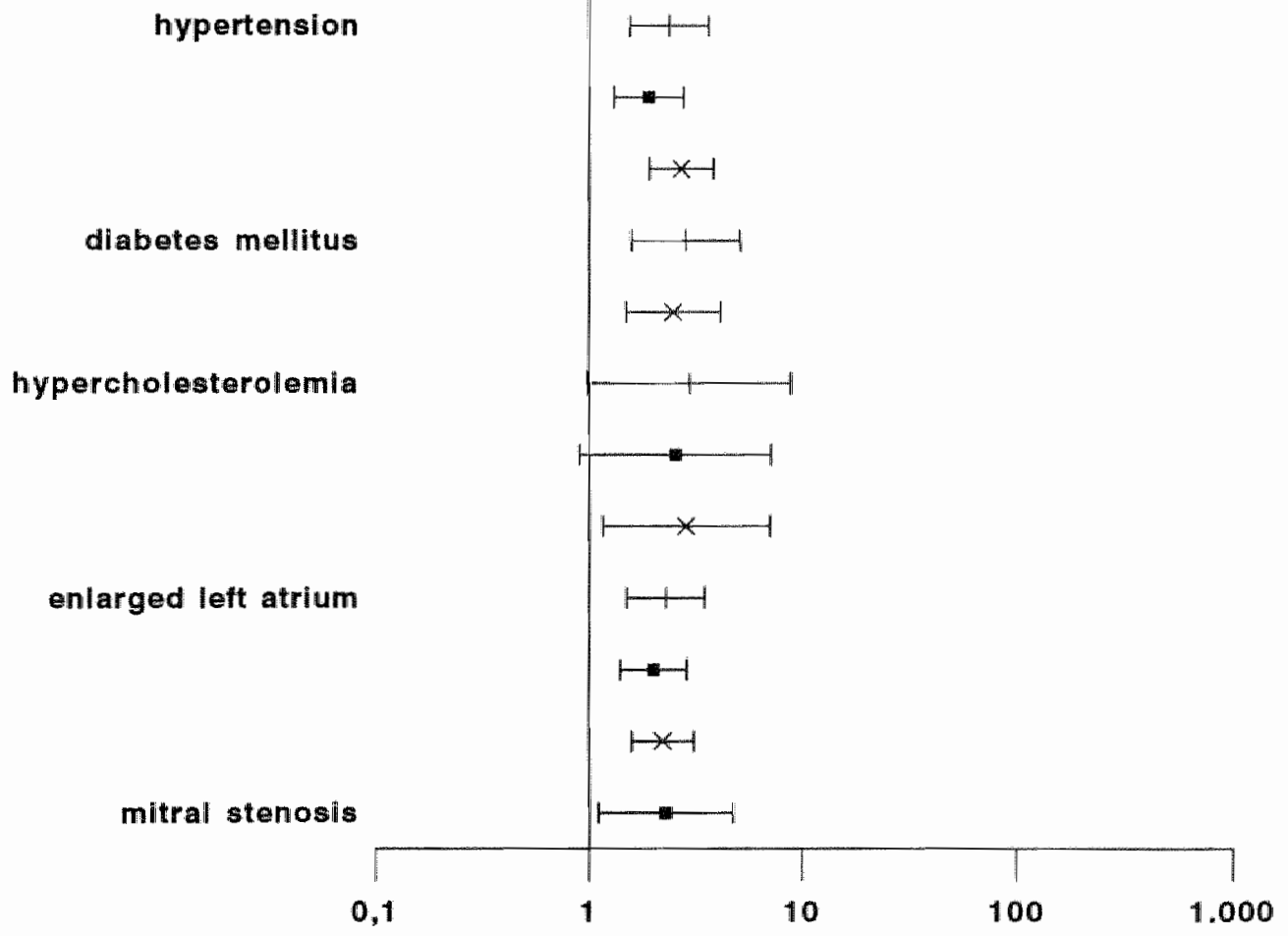

odds ratio; $95 \%$ confidence interval - Logarithmic scale 
Increasing age, hypertension and enlarged left atrium were strongly associated with each of the valvular calcifications. Also, hypercholesterolemia was associated with each of the valvular calcifications, although just significantly only with mitral annular calcification.

Female sex and diabetes mellitus were significantly associated with aortic valve calcification and mitral annular calcification, but not with aortic valve calcification with stenosis. Some conditions were negatively associated with the valve calcifications: echocardiographic anterior wall infarction, and apical aneurysm with aortic valve calcification and mitral annular calcification, atrial fibrillation with aortic valve calcification, and dilated cardiomyopathy with aortic valve calcification with stenosis. The reason for this may be, that both patients and controls are selected from a cardiologic population.

\section{Discussion}

We found that associated variables were almost similar for all three valvular calcification types: A) for mitral annular calcification and aortic valve calcification: age, female gender, hypertension, diabetes mellitus, hypercholesterolemia, enlarged left atrium; B) for aortic valve calcification with stenosis: age, hypertension, hypercholesterolemia, enlarged left atrium.

\section{Mitral annular calcification}

One study on mitral annular calcification and its correlates, using multivariate analysis, " showed an association with age, female sex, hypertension, and enlarged left atrium, but in contrast to this study also with atrial fibrillation and aortic stenosis. However, atrial fibrillation, aortic stenosis (and enlarged left atrium) were analysed univariately in age and sex-matched patients. The high prevalence of aortic valve calcification without $(43 \%)$ or with $(17 \%)$ stenosis in patients with mitral annular calcification in the study presented here was not a significant association between aortic valve calcification and mitral annular calcification after adjusting for other risk factors, which suggests common vascular risk factors for both mitral annular and aortic valve calcification. As expected, atrial fibrillation was less frequent in the control group of the population based Framingham study than in this study, which may explain that in the latter no association between mitral annular calcification and atrial fibrillation was found. However, the higher percentage of atrial fibrillation in mitral annular calcification patients in the former study may represent a higher incidence of concomitant cardiovascular risk factors, especially enlarged left atrium, ${ }^{11}$ and possibly age, which was not 
adjusted for in the analysis. That hypercholesterolemia and diabetes mellitus were significantly associated with mitral annular calcification in this study and not in the Framingham study will in part be due to different definitions, causing treated patients to be considered as having the condition. There are six other studies in patients with mitral annular calcification using age- and sex-matched controls. ${ }^{12-17}$ Associated risk factors were hypertension and diabetes mellitus, atrial fibrillation, sudden cardiac death, myocardial infarction, coronary heart disease and congestive heart failure, enlarged left atrium, enlarged left ventricle, cardiac conduction defects and cardiomegaly, but these were not adjusted for concomitant cardiovascular risk factors. Whether increased levels of parathyroid hormone resulting in hypovitaminosis $\mathrm{D}$ causes the association of female gender with mitral annular calcification was discussed elsewhere. ${ }^{18}$

\section{Aortic valve calcification}

No epidemiological studies are available about risk factors for aortic valve calcification. Two studies described conduction defects in patients with aortic stenosis with or without mitral annular calcification, but made no comparison with patients without aortic stenosis. ${ }^{12}$ Clinical characteristics of patients with calcified aortic stenosis were described by Wren, ${ }^{19}$ who found angina pectoris, hypertension and sudden death more often in those patients, than in controls. The findings presented here of a cardiovascular risk factor profile for aortic valve calcification with or without stenosis agrees with the view of Roberts, ${ }^{320}$ who stated that factors predisposing to atherosclerosis also predispose to aortic valve calcification.

In conclusion, this study demonstrated that patients with aortic valve and mitral annular calcification have similar cardiac and vascular risk factors. Therefore, mitral annular and aortic valve calcification should be considered as comparable expressions of underlying age related cardiac manifestations of atherosclerosis. These findings question whether these cardiac valve conditions should be regarded as risk factors for, or even causes of embolic complications, or merely as markers of generalized atherosclerosis. 


\section{References}

1. Nair CK, Sketch MH, Ahmed I, Thomson W, Ryschon K, Woodruff MP, Runco V. Calcific valvular aortic stenosis with and without mitrall anular calcium. Am J Cardiol $1987 ; 60: 865-870$.

2. Nair CK, Aronow WS, Stokke K, Mohiuddin SM, Thomson W, Sketch MH. Cardiac conduction defects in patients older than 60 years with aortic stenosis with and without mitral anular calcium. Am J Cardiol 1984;53:169-172.

3. Roberts WC. Morphologic features of the normal and abnormal mitral valve. Am J Cardiol 1983;51:1005-1028.

4. Mulleneers $R$, Cheriex $E$, Dassen $W$, Bleijlevens $B$, Wellens $H$. CAESARS; The cardiac storage and retrieval network system. In: Computers in Cardiology. IEEE Computer Society Press 1990, 1990: $211-214$.

5. Devereux R, Reichek N. Echocardiographic determination of left ventricular mass in man. Circulation 1977;55:613-618.

6. Laver MS, Anderson KM, Levy D. Influence of contemporary versus 30-year blood pressure levels on left ventricular mass and geometry: the Framingham Heart Study [see comments]. I Am Coll Cardiol $1991 ; 18: 1287-1294$.

7. Kitzman DW, Scholz DG, Hagen PT, Ilstrup DM, Edwards WD. AgeRelated Changes in Normal Human Hearts During the First 10 Decades of Life. Part II (Maturity): A Quantitative Anatomic Study of 765 Specimens From Subjects 20 to 99 Years Old. Mayo Clin Proc $1988 ; 63: 137-146$.

8. Sahn DJ, DeMaria AN, Kisslo J, Weyman A. Recommendations regarding quantitation in M-mode electrocardiography: The results of a survey of echocardiographic measurements. The committee on $\mathrm{M}$ mode standardization on the American Society of Echocardiography. Circulation 1978,58:1072-1083.

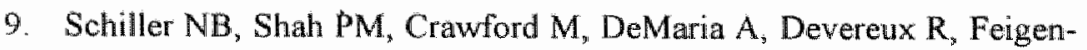
baum H, Gutgesell H, Reicher N, Sahn D, Schnittger I, Silverman NH, Tajik $\mathrm{AJ}$. Recommendations for quantitation of the left ventricle by two-dimensional echocardiographs. J Am Soc Echo 1989;5:358-367.

10. Teicholz LE, Kreulen T, Herman MV, Gorlin R. Problems in echocardiographic volume determinations: Echocardiographic - angiographic correlations in the presence or absence of asynergy. Am J Cardiol $1976 ; 37: 7-11$.

11. Savage D, Garrison RJ, Castelli WP, McNamara PM, Anderson SJ, Kannel WB, Feinleib M. Prevalence of Submitral (Anular) Calcium and Its Correlates in a General Population-Based Sample (The Framingham Study). Am J Cardiol 1983;51:1375-1378. 
12. Nair CK, Sudhakaran C, Aronow WS, Thomson W, Woodruff MP, Sketch MH. Clinical characteristics of patients younger than 60 years with mitral anular calcium: comparison with age- and sex-matched control subjects. Am J Cardiol 1984;54:1286-1287.

13. Aronow WS, Schwartz KS, Koenigsberg M. Correlation of atrial fibrillation with presence or absence of mitral anular calcium in 604 persons older than 60 years. Am I Cardiol 1987;59:1213-1214.

14. Nair CK, Thomson W, Ryschon K, Cook C, Hee TT, Sketch MH Long-term follow-up of patients with echocardiographically detected mitral anular calcium and comparison with age- and sex-matched control subjects. Am J Cardioll 1989;63:465-470.

15. Aronow WS, Koenigsberg M, Kronzon I, Gutstein H. Association of mitral anular calcium with new thromboembolic stroke and cardiac events at 39-month follow-up in elderly patients. Am J Cardiol 1990;65:1511-1512.

16. Benjamin EJ, Plehn JF, D'Agostino RB, Belanger AJ, Comai K, Fuller DL, Wolf PA, Levy D. Mitral annular calcification and the risk of stroke in an elderly cohort. N Engl J Med 1992;327:374-379.

17. Nair CK, Aronow WS, Sketch MH, Mohiuddin SM, Pagano T, Esterbrooks. DJ, Hee TT. Clinical and echocardiographic characteristics of patients with mitral anular calcification. Comparison with ageand sex-matched control subjects. Am II Cardiol 1983;51:992-995.

18. Shiraki M, Miyagawa A, Akiguchi I, Ito $H$, Ohkawa $S$, Sugiura $M$. Evidence of hypovitaminosis $D$ in patients with mitral ring calcification. .Jpn Heart J 1988;29:801-808.

19. Wren C, Petch MC. Calcific aortic stenosis. J R Coll Physicians Lond 1983;17:192-195.

20. Roberts WC. The Senile Cardiac Calcification Syndrome. Am J Cardiol $1986 ; 58$ 572-574 



\section{Aortic Valve Calcification and Stroke}

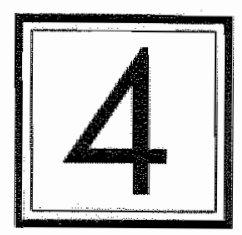

The Risk of Stroke in a Cohort of 815 Patients With Calcification of the Aortic Valve with or without Stenosis 


\section{Abstract}

Background and Purpose: To establish a possible role of a calcified aortic valve with or without stenosis as a risk factor for stroke.

Methods: Occurrence of stroke, stroke subtypes, and concomitant cardiovascular risk factors were prospectively analysed in 300 patients with echocardiographic evidence of aortic valve calcification, 515 patients with calcified aortic valve stenosis, and 562 controls. Silent brain infarcts were studied in patients with a stroke during follow up.

Results: Twenty-four patients with aortic valve calcification, 24 patients with calcific aortic valve stenosis, and 27 controls had a stroke during follow up. Using Cox proportional hazards models, strokes did not occur significantly more often in patients with aortic valve calcification with or without stenosis. Only hypertension and any carotid atheromatosis were strongly associated with stroke. Furthermore, on multivariate logistic regression analysis, we did not find any association between one of the two valve conditions and indirect indications of cardiogenic embolism such as territorial as opposed to small deep brain infarcts, or the presence of silent brain infarcts. There was no inverse association between one of the valve lesions and small deep brain infarcts.

Conclusion: Aortic valve calcification with or without stenosis is not a risk factor for stroke. This finding argues against the use of anticoagulation in these patients to lower the risk of embolic stroke 
$\mathrm{C}$ alcification of an aortic valve may result from increased stress and motion in conditions like hypertension, congenital bicuspid aortic valves, congenital aortic valve stenosis, aortic valve damage from theumatic fever or radiation, or a combination of these. ${ }^{1-6}$ It may lead to calcified aortic stenosis." Primary oxalosis, disturbed calcium metabolism in hemodialysis, and chronic uremia may cause calcium infiltration in aortic valves. ${ }^{810}$ Neurologic sequelae of aortic valve disease could result from global brain ischemia due to reduced cardiac output in severe aortic valve stenosis and cardiac arrhythmias. ${ }^{511}$ An important point is whether aortic valve calcification and calcified aortic valve stenosis should be considered as sources of embolism, with the possible consequence of anticoagulant therapy in patients with aortic valve calcification or calcified aortic valve stenosis. To determine the risk of a minor risk factor, a study with a sufficiently large population, which also takes into account the effect of concomitant risk factors for stroke, is required. Such a study has not been done before. In three series, that did not adjust for cardiovascular risk factors for stroke, no association was found between aortic valve callcification and stroke, ${ }^{11-13}$ but case reports provide some evidence of brain infarction, retinal ischemia, or peripheral vascular occlusion due to release of calcified material from the aortic valve. ${ }^{1-1}$ This study was done to answer the question whether aortic valve calcification and calcified aortic valve stenosis are risk factors for stroke, or markers of generalised atherosclerosis. It was also analysed whether strokes in patients with calcified aortic valves had characteristics of cardioembolic strokes.

\section{Patients and Methods}

\section{Design}

The study population was recruited from a prospective database of 8,160 consecutive patients who had 11,924 echocardiograms made at the Department of Cardiology of the University Hospital of Maastricht between january 1st, 1985 and jan 1st, 1990. ${ }^{19}$ Three hundred and four patients had echocardiographic evidence of aortic valve calcification and 526 additional patients showed calcified artic valve stenosis, and entered the study. The reference group was a random sample of 568 patients from 7,600 patients without aortic valve calcification or calcified aortic valve stenosis. Four patients with aortic valve calcification, 11 with calcified aortic valve stenosis, and 6 controls, were lost to follow up for geographic reasons. The 
cohort therefore consisted of 815 patients with and 562 patients without aortic valve calcification. For each patient the date of the first echocardiogram after january 1st, 1985 with or without aortic valve calcification was the start of the follow up.

\section{Clinical risk factors at the start of the follow up}

The following risk factors were recorded: age, sex, the presence of hypertension (known hypertension treated with anti-hypertensive medication, two or more blood pressure recordings higher than $160 /$ $90 \mathrm{~mm} \mathrm{Hg}$ ), diabetes mellitus (known diabetes treated with diet and or medication; or either a fasting serum glucose bigher than $7 \mathrm{mmol}$ 1 , or a postprandial serum glucose level higher than $11 \mathrm{mmol} / \mathrm{L}$ measured on at least two separate occasions), a history of ischaemic heart disease (myocardial infarction, angina pectoris), a history of coronary artery bypass grafting, the use of oral anticoagulants or salicylates, prior stroke or TIA, serumcholesterol (the mean of all available measurements with or without treatment with cholesterol lowering drugs), hypercholesterolemia (known treated hypercholesterolemia or fasting or non-fasting cholesterol level higher than 6.5 $\mathrm{mmol} / \mathrm{L}$ ), peripheral arterial disease, electrocardiographic documentation of atrial fibrillation, and date and type of any cardiac valve replacement.

\section{Echocardiographic parameters at the start of follow up}

Aortic valve calcification was defined as bright dense echo's on one or more cusps with a size of at least more than $1 \mathrm{~mm}$ (in general decreasing the mobility of the involved cusp). Doppler velocity measured with Continuous Doppler less than $2 \mathrm{~m} / \mathrm{s}$ was regarded as flow within normal limits. Besides this, calcified aortic stenosis (defined as having a maximal systolic pressure gradient exceeding $16 \mathrm{~mm} \mathrm{Hg}$ ), and other echocardiographic parameters were registered which might influence cardioembolic potential: mitral annular calcification (defined as bright echo's in mitral annulus on twodimensional echocardiogram with "stone-shadow"), mitral stenosis (defined as rheumatic mitral stenosis with increased velocities over the valve and a mitral valve area of equal or less than $2.5 \mathrm{~cm}^{2}$, or non-rheumatic valvular disease if mitral annular calcification and fibrosis of the mitral valve apparatus caused a gradient and a mitral valve orifice smaller than or equal $\left.2.5 \mathrm{~cm}^{2}\right)$, the degree of mitral regurgitation, enlarged left atrium (diameter $45 \mathrm{~mm}$ or more), atrial septal aneurysm and atrial septal defect, cardiac valve prosthesis or bioprothesis, myocardial infarct location, apical aneurysm, intracardiac thrombus, dilated cardiomyopathy, a left ventricular 
ejection fraction of $40 \%$ or less, and fractional shortening reduced to $28 \%$ or less, wall-motion score, left ventricular mass in patients without anterior wall myocardial infarction and with successive cutpoints of 175,200 and $225 \mathrm{~g}$ for men, and 165,190 and $215 \mathrm{~g}$ for women. ${ }^{20}$

Increased left ventricular wall thickness due to long standing hypertension was defined as a left ventricular wall mass greater than $225 \mathrm{~g}$ for men, or $215 \mathrm{~g}$ for women. Wall mass is independent of chamber size and hence a better indication of increased chronic cardiac work load than heart size. ${ }^{21} 22$

Wall-motion score was a semi-quantitative measure of left ventricular wall motion. For this purpose, the left ventricle was divided in thirteen segments. Wall motion in each segment was scored from 0-4 (normokinesis, hypokinesis, hypokinesis to akinesis, akinesis, and dyskinesis). A wall motion score of more than 12 was regarded as cut off point between small and larger asynergy of the left ventricle. Fractional shortening was defined as the difference between left ventricular enddiastolic and end systolic diameter. All diameters used were measured according to the recommendations of the American Society of Echocardiography. ${ }^{23-25}$

\section{Outcome definitions}

Stroke was defined as a supra- or infratentorial brain infarct or intracerebral hematoma. A brain infarct was defined as rapidly developing clinical signs of focal disturbance of cerebral function, lasting longer than 24 hours or leading to death, with no other apparent cause, while $\mathrm{CT}$ scan showed an area of low attenuation compatible with the clinical signs and symptoms or without a specific lesion. CT scan had been performed in $92 \%$ of patients with stroke. For symptomatic infarcts, when no CT was available, the Guy's Hospital Stroke Diagnostic Score (Allen Score) was applied. ${ }^{26}$

Symptomatic infarcts were divided into small-deep and territorial infarcts. A small deep infarct was defined as a CT lesion compatible with the occlusion of a single perforating artery, i.e. a subcortical, small, sharply marginated hypodense lesion with a diameter less than $20 \mathrm{~mm}$, or clinically a lacunar syndrome if no specific lesion was visible on CT. Four lacunar syndromes were distinguished: pure motor stroke, pure sensory stroke, sensorimotor stroke and ataxic hemiparesis including dysarthria-clumsy hand cases. A territorial infarct was defined as CT findings compatible with infarction in- 
volving the cortex, or clinically a cortical syndrome, i.e. a unilateral motor or sensory deficit, or both, in combination with signs of cortical dysfunction (e.g. aphasia, visual field deficit, visual spatial disturbances, apraxia, neglect or agnosia) if no specific lesion was visible on $C T$. Patients with a large subcortical infarct were included in this group. ${ }^{27}$ Territorial infarcts were divided into two groups by presumed cause: cardioembolic and remaining infarcts. A cardioembolic infarct was defined as a territorial infarct in the presence of one or more of the following possible cardiac sources of embolism: chronic and paroxysmal atrial fibrillation, anterior myocardial infarction less than 6 weeks old, prosthetic aortic or mitral valve, endocarditis, dilated cardiomyopathy, mitral stenosis, left ventricular aneurysm, and intraventricular thrombus. Aortic valve calcification and calcified aortic valve stenosis were not a priori considered potential cardioembolic sources, because they were the subject of the present study.

Brain CT scan of patients presenting with a stroke sometimes showed signs of prior unpercieved (silent) brain infarcts, defined as a low-density area on CT compatible with an infarct but without a history of stroke. Silent small deep lesions and silent territorial infarcts were distinguished.

At the time of stroke, beside age and sex, the following risk factors were recorded: hypertension present before stroke or at least one week after stroke, diabetes mellitus (not measured in the acute phase of stroke (the first 72 hours)), a history of ischaemic heart disease, and symptomatic or asymptomatic carotid stenosis of more or less than $50 \%$ on Doppler or Duplex scan. No carotid studies were done in patients without stroke.

\section{Patient selection and analysis}

All patients except those lost to follow up were included. Two types of analysis were done: a primary analysis including patients who suffered a stroke later than an arbitrary number of 70 days before the index echocardiogram, and a secondary analysis including patients with stroke or a history of stroke (all in a lifetime stroke).

Follow up was censored when stroke occurred after the index echocardiogram, or at the last follow up date in patients without stroke. Patients with callified aortic valve stenosis who had aortic valve replacement were considered to be out of risk from that moment on. Although most patients with a stroke were referred to the 
university hospital of Maastricht, this was checked in january I991. by sending three questions to the general practitioners of all patients: 1. whether or not the patient had a cerebrovascular accident in the study period, as judged by the general practioner, 2 . whether or not the patient liad been admitted to hospital and where, and 3. time, place and cause of death.

\section{Analysis}

The scope of primary analysis were strokes occurring later than 70 days before echocardiographic detection of AVC or CAS in patients who did not have a history of stroke. Secondary analysis was done including patients having a stroke before that period, or patients with TIA. The association was determined of aortic valve calcification or calcified aortic valve stenosis and the registered cofactors mentioned above with stroke by proportional hazards analysis. Crude analysis expressing risk in person years was done with Incidence Density Ratios (IDR) and $95 \%$ confidence intervals (CI), and the Cox proportional hazards model was used with hazard ratios (HR) for analysis of different subsets of the registered (risk) factors. Stroke subtypes, conditional to the occurrence of stroke, were regarded as independent of exposure time. Therefore, multivariate logistic regression analysis was used with odds ratios (OR) to determine the association of either of the two valve lesions with symptomatic small deep, symptomatic territorial, silent small deep, silent territorial, and multiple silent cerebral infarcts, as dependent variables.

We used multiple logistic regression analysis instead of matching to: 1. A void confounding by matching, due to the fact that independent variables such as age and sex are associated with the exposition factor, 3 . determine effect parameters for each stratum, which would have been impossible with matching, 4 . optimize group size with consequent larger confidence intervals, and therefore improve the reliability of point estimates. In addition, matching for e.g. age and sex would not be sufficient because there are many other confounders, and was unnecessary concerning the large group sizes.

\section{Results:}

\section{Baseline data}

Of the 815 patients with calcification of the aortic valve 348 were men and 467 women. Of 562 control patients 338 were men and 224 women. Hundred forty-eight study patients ( 5 patients with aortic valve calcification, 143 with calcified aortic valve stenosis) and 19 
controls had some form of open heart surgery in the follow up period. Eighty-five patients with calcified aortic valve stenosis had their aortic valve replaced during operation. Two patients with CAS were still at risk after heart surgery, and had a territorial brain infarct within 8 days after surgery, probably due to perioperative dislodgment of remaining calcified material from the aortic valve annulus. Of patients with aortic valve calcification, $61(20 \%)$ used aspirin and $57(19 \%)$ anticoagulants at the start of the follow up. For calcified aortic valve stenosis these numbers were $55(11 \%)$ and $97(18 \%)$, respectively, and for controls $64(11 \%)$ and $150(16 \%)$. Baseline data are shown in Table 1. Details about aspirin and anticoagulant therapy are given in Table 2.

\section{Outcome}

Twenty-four ( $8 \%$ ) patients with aortic valve calcification, $24(5 \%)$ patients with calcified aortic valve stenosis and $27(4 \%)$ controls had a stroke in the followup period. Seven of those patients had a prior stroke as defined before ( 4 with aortic valve calcification, 2 with calcified aortic valve stenosis, and one control), and one control patient had prior TIA. Mean delay until CT was 8 days (range 0 to 87).

Of the strokes in the aortic valve calcification group, $18(7 \%)$ were territorial and $4(17 \%)$ small deep infarcts. There was one intracerebral hematoma, and one unspecified supratentorial infarct. In the calcified aortic valve stenosis group, there were $12(50 \%)$ territorial and $4(17 \%)$ small deep infarcts, $3(12 \%)$ unspecified supratentorial infarcts, $4(17 \%)$ infratentorial infarcts, and 1 intracerebral hematoma. Among controls, there were $13(48 \%)$ territorial and $5(19 \%)$ small deep infarcts, $4(15 \%)$ unspecified infarcts, 1 infratentorial infarct, $3(11 \%)$ intracerebral hematomas, and one with multiple cerebral infarcts, not further specified. Carotid studies were done in 10 patients with aortic valve calcification and stroke, 6 patients with calcified aortic stenosis and stroke, and 8 controls with stroke.

Of patients with aortic valve calcification, $47(16 \%)$ died after a mean follow up of 547 days, $64(12 \%)$ of patients with calcified aortic valve stenosis died after a mean follow up of 504 days, and $77(13 \%)$ of the concrols after a mean follow up of 524 days. The most common cause of death was heart failure $(47 \%, 68 \%$ and $33 \%$ respectively). 


\section{Table 1. Baseline Data}

\begin{tabular}{|c|c|c|c|}
\hline & $\begin{array}{l}\text { AVC } \\
300\end{array}$ & $\begin{array}{l}\text { CAS } \\
515\end{array}$ & $\begin{array}{l}\text { Controls } \\
562\end{array}$ \\
\hline Marn ago & 74 & 67 & 53 \\
\hline Men/women & $106(35) / 194$ & $242(46) / 273$ & $338(60) / 224$ \\
\hline Hypertencion & $136(45)$ & $54(30)$ & $96(17)$ \\
\hline Ischamic heart disedse & $179(59)$ & $249(48)$ & $225(40)$ \\
\hline Dicabets mellitus & $68(23)$ & $51(10)$ & $43(8)$ \\
\hline Hypercholesterolemia & $18(6)$ & $22(4)$ & $10(2)$ \\
\hline Moan serum cholesterol(mmol/L) & 6.5 & 6.6 & 5.9 \\
\hline Peripheral atherosclerotic disease & $30(10)$ & $37(7)$ & $28(5)$ \\
\hline Atrial fibrillation & $14|5\rangle$ & $36(7)$ & $30(5)$ \\
\hline Previcus stroke (definition) & $16(5)$ & $23(4)$ & $20(4)$ \\
\hline TIA & $9(3)$ & $11(2)$ & $17(3)$ \\
\hline Stroke and pirvious stroke & $4(1)$ & 2 & 1 \\
\hline Dilated cardiomyapathy & $19(6)$ & $12(2)$ & $38(7)$ \\
\hline Rhoumatic mitral stenosis & $6(2)$ & $59(11)$ & $19(3)$ \\
\hline Mitral regurgitation & $95(31)$ & $271(52)$ & $218(39)$ \\
\hline Mitral annular calcification & $289(96)$ & $113(21)$ & 0 \\
\hline Aortic/mitral valve prosthesis & $0 / 0$ & $2 / 19$ & $26 / 39$ \\
\hline $\begin{array}{l}\text { Anterior wall infard/ } \\
\text { aneurysm/cardiac } \\
\text { thrombus/atrial septum } \\
\text { aneurysm/atrial septum defect }\end{array}$ & $34 / 7 / 4 / 0 / 0$ & $24 / 0 / 2 / 0 / 0$ & $82 / 10 / 16 / 3 / 7$ \\
\hline Coronary artery bypass surgery & $26(9)$ & $61(12)$ & $60(11)$ \\
\hline
\end{tabular}
brackets.

Baseline data. AVC, contic valve calcification without; CAS, with stemosis. Percentages between 


\section{Table 2. Aspirin and anticoggulants}

\begin{tabular}{|lllll|} 
Patienis & Aspirin & n Anticoagulants $n$ \\
\hline AVC & $6(1-81)$ & 61 & $6(0.03-61)$ & 57 \\
\hline CAS & $8(0.7-61)$ & 55 & $9(0.03-70)$ & 97 \\
\hline Controls & $4(0.03-65)$ & 64 & $7(0.1-82)$ & 150 \\
\hline
\end{tabular}

Mean number of manths (range) of aspirin and anticaagulant use. n, numbers of patienls. 


\section{Risk factors for stroke}

Crude analysis showed no significant association of aortic valve calcification or calcified aortic valve stenosis with stroke occurring after entry into the cohort (IDR:0.7;95\% $\mathrm{Cl}: 0.31-1.40 ; \mathrm{P}=0.28$, and IDR:0.87;95\%CI:0.44-1.7:P=0.08, respectively). Results were similar with multiple logistic and Cox regression analysis, where only hypertension and symptomatic or asymptomatic carotid stenosis were strongly associated with stroke (Tables 3 and 4 and Figures 1 and 2).

In a separate analysis strokes were included that had occurred before start of the follow up, and we therefore used odds instead of hazard ratios. Both aortic valve calcification and calcified aortic valve stenosis were not associated with all-time stroke (OR: $1.14 ; 95 \% \mathrm{Cl}: 0.76-1.69 ; \mathrm{P}=0.5$, and OR:0.67;95\%Cl:0.44$1.00 ; \mathrm{P}=0.05$, respectively). Combining aortic valve calcification and calcified aortic valve steriosis gave similar results.

\section{Risk factors associated with stroke subtypes}

Aortic valve calcification and calcified aortic valve stenosis were not significantly stronger associated with territorial than small deep infarcts (OR:0.39;95\% Cl:0.06-2.5 and OR:1.33;95\% Cl:0.13-14.2, respectively), adjusted among others for any carotid stenosis, for significant ipsilateral carotid stenosis and the presence of a potential cardioembolic source. Although included in the overall analysis of strokes, the numbers of hematoma's, hemorrhagic infarcts and infratentorial infarcts were too small for an analysis with stroke subtypes as dependent variables.

\section{Risk factors associated with silent brain infarcts in stroke patients}

Aortic valve calcification and calcified aortic valve stenosis were not significantly associated with one or more silent cerebral infarcts on

CT in patients presenting with stroke during follow up (OR: $1.26 ; 95 \% \mathrm{Cl}: 0.27-5.84 ; \mathrm{P}=0.7 ; \mathrm{OR}: 1.01 ; 95 \% \mathrm{Cl}: 0.127$ -

$8.08 ; \mathrm{P}=0.9$, respectively), with silent small deep infarcts (OR:0.88;95\% Cl: $0.14-5.55 ; \mathrm{P}=0.8 ; \mathrm{OR}: 1.95 ; 95 \% \mathrm{Cl}: 0.18-20.8 ; \mathrm{P}=0.5$, respectively), or with silent territorial infarcts (aortic valve calcification: OR: $1.27 ; 95 \% \mathrm{Cl}: 0.11-14.8 ; \mathrm{P}=0.8$; calcified aortic valve stenosis patients had too few silent territorial infarcts for analysis). 


\begin{tabular}{|c|c|c|c|}
\hline Risk foctor & OR & $95 \% \mathrm{Cl}$ & $\mathrm{P}$ \\
\hline AVC & 0.89 & $0.48 \cdot 1.63$ & mis \\
\hline CAS & 0.67 & $0.36-1.25$ & ns \\
\hline Age $>=65$ & 0.78 & 0.26 .2 .37 & ns \\
\hline Men ws women & 1.07 & $0.65 \cdot 1.75$ & $\mathrm{~ns}$ \\
\hline Ischemic heart disease & 0.76 & $0.47-1.23$ & ns \\
\hline Diabetes mellitus & 2.18 & $1.27 \cdot 3.37$ & 0.04 \\
\hline Hypertension & 3.42 & $2.1-5.55$ & 0.00 \\
\hline $\begin{array}{l}\text { Peripheral atherosclerotic } \\
\text { disease }\end{array}$ & 1.2 & $0.54-2.64$ & $n s:$ \\
\hline Hypercholesterolemia & 1.27 & $0.46 \cdot 3.5$ & ns \\
\hline Atrial fibrillation & 0.73 & $0.21 \cdot 2.54$ & ns \\
\hline Anticoagulants & 0.69 & $0.36-1.34$ & ns \\
\hline Rheumatic mitral stenosis & 0.77 & 0.17 .3 .41 & ns \\
\hline Mitral regurgitation $>$ grade 3 & 0.63 & $0.37-1.06$ & $\mathrm{~ms}$ \\
\hline Enlarged left atrium & 1.04 & $0.59-1.84$ & $m s$ \\
\hline Mitral ammular callefication & 0.88 & 0.48 .1 .62 & $\mathrm{~ms}$ \\
\hline Prosthetic cardiac valves & 2.25 & 0.78 .6 .49 & ms \\
\hline Ejection fraction< $<30 \%$ & 1.32 & 0.49 .3 .53 & $\mathrm{~ns}$ \\
\hline $\begin{array}{l}\text { increased left ventricular wall } \\
\text { mass, cotegory I }\end{array}$ & 1.75 & $0.77-3.99$ & ns. \\
\hline category II & 1.49 & $0.74 \cdot 2.99$ & nsi \\
\hline category III & 1.27 & $0.66-2.45$ & ns: \\
\hline
\end{tabular}

Multiple logistic regression analysis of the risk of stroke in patients with aortic valve calcification without (AVC) or with stenasis (CAS). OR, adjusted odds ratio; $95 \% \mathrm{Cl}, 95$ percent confidence interval; $\mathrm{P}$, Pivalue. Categories of left ventricular wall mass are defined in the methods section. 
Table 4. Stroke risk, Cox model

\begin{tabular}{|c|c|c|c|}
\hline Rask factor & HR & $95 \% \mathrm{Cl}$ & $\mathrm{P}$ \\
\hline AVC & 1.01 & 0.49 .2 .09 & 0.9 \\
\hline CAS & 0.97 & $0.49+1.95$ & 0.7 \\
\hline$A g Q>-65$ & 1.44 & $0.25-1.90$ & 0.4 \\
\hline Men/momen & 0.82 & $0.47-1.46$ & 0.5 \\
\hline Ischemic hoart diseaste & 0.78 & $0.45-1.43$ & 0.4 \\
\hline Diabetes mollitus & 1.34 & $0.69 \cdot 2.64$ & 0.3 \\
\hline Hyportension & 2.40 & $1.4-4.24$ & 0.002 \\
\hline $\begin{array}{l}\text { Paripheral atherosederotic } \\
\text { disoase }\end{array}$ & 0.50 & $0.18-1.41$ & 0.19 \\
\hline Hyperchalesterolemia & 1.96 & $0.72-5.37$ & 0.18 \\
\hline Atrial fibrillcation & 0.49 & $0.11-2.15$ & 0.34 \\
\hline Anticoagulants & 0,66 & $0.32 \cdot 1.33$ & 0.24 \\
\hline Aspirin & 0.59 & $0.26 \cdot 1.29$ & 0.18 \\
\hline History of coronary bypass & 0.89 & $0.32-2.50$ & 0.82 \\
\hline Rheurnatic mitral stenosis & 0.85 & 0.27 .2 .76 & 0.79 \\
\hline Miiral regurgitation > grade 3 & 0.72 & $0.28-1.81$ & 0.49 \\
\hline Enlarged left atrium & 1.14 & $0.60-2.17$ & 0.67 \\
\hline Mitral annular calcification & 0.77 & 0.37 .1 .58 & 0.4 \\
\hline Prosthettic cardioc volves & 1.49 & $0.45 \cdot 4.91$ & 0.5 \\
\hline Anterior wall infarction [echo] & $\pi .60$ & $0.54-3.12$ & 0.38 \\
\hline Apical aneurysm & 5.36 & $0.96-29.8$ & 0.05 \\
\hline Dilated cardiomyopathy & 0.93 & $0.20-4.24$ & 0.9 \\
\hline Eiection fraction $<30 \%$ & 0.89 & $0.3-2.5$ & 0.8 \\
\hline $\begin{array}{l}\text { Increased left ventricular wall } \\
\text { mess }\end{array}$ & 0.97 & $0.54-1.74$ & 0.9 \\
\hline Ary carotid stenosis & 9.69 & $4.2 \cdot 22.4$ & 0.0 \\
\hline
\end{tabular}

Proportional hazard analysis of the risk of strake in patients with aortic valve calcification without (AVC) or with stenosis (CAS). HR, hazard ratio; $95 \% \mathrm{CH}, 95$ percent confidence interwat; $P$, P-walue. The class of laft ventricular wall mass is the lowest one defined in the methads section, but results were similar for the higher dasses. The risk presented here is a measure of the adjusted risk in person-years. 
Fig $\#$. The risk of stroke of aortic valve calcification with (CAS) or without (AVC) stenosis, with multiple logistic regression analysis.

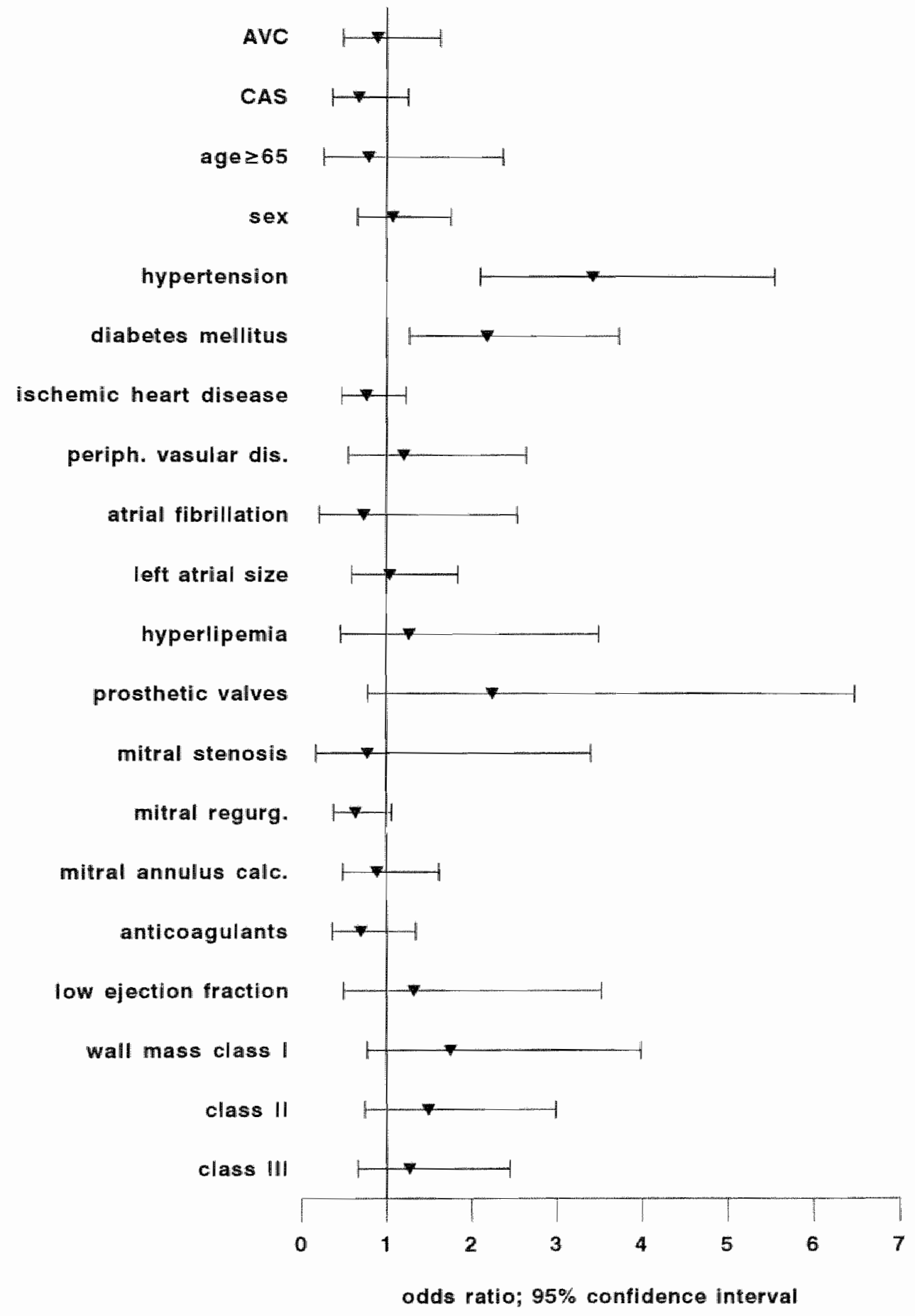


Fig 2. Aortic valve calcification with (CAS) or without (AVC) stenosis and covariates and the risk of stroke. Proportional hazard analysis. Classes of wall mass: see text.

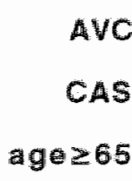

malle vs female

hypertension

diabetes mellitus

ischemic heart dilsease coronary bypass

anterior wall infarct

apical aneurysm

dilated cardiomyopathy

perph. atherosclerosis

atrial fibrillation

enlarged left atrium

hypercholesterolemia

prosthetic valves

mitral stenosis

mitral regurgitation

mitral regurg $>$ gr. 3

mitral calcification

warfarin

aspirin

low ejection fraction

increased wall mass

any carotid stenosis

prior stroke

TIA

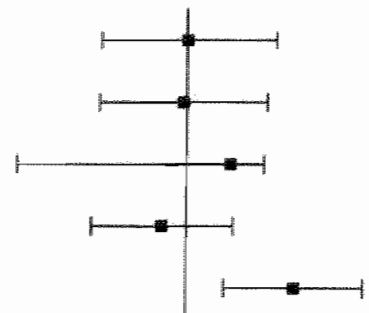

$x^{2}$ 


\section{Discussion}

Aortic valve calcification with or without stenosis was not a risk factor for stroke. The data of this study do not support the assumption that in patients with aortic valve calcification with or without stenosis a stroke should be considered as the result of this cardiac abnormality. In a separate stepwise logistic regression analysis discussed in Chapter Three age, hypertension, and enlarged left atrial size were significant risk factors for both valve lesions, female gender, diabetes mellitus, and hypercholesterolemia for aortic valve calcification, and mitral stenosis for calcified aortic valve stenosis. Hypertension and any carotid lesion on noninvasive studies were strongly associated with stroke of any type. These findings further indicate that stroke in patients with aortic valve calcification with or without stenosis is due to atherosclerosis caused by vascular risk factors rather than cardiac embolism.

Evidence that an ischemic stroke in a patient with aortic valve calcification is caused by embolism from the heart, may indirectly be suggested from an association of calcified aortic valve with territorial rather than small deep infarcts, because cardioembolic stroke source is an unlikely cause of small deep (lacunar) brain infarcts. ${ }^{28-30}$ However, the data do not support such an association. There was no significant association of aortic valve calcification, with or without stenosis, with a specific brain infarct subtype, especially not with territorial cerebral infarcts, whereas there was no negative association of aortic valve calcification with or without stenosis with small deep infarcts. This strengthens the idea that brain infarction in patients with aortic valve calcification with or without stenosis is unlikely to be due to embolism from the valve.

A possible argument in favour of cardiac embolism could come from the finding of sillent brain infarcts in stroke patients with aortic valve calcification, as several authors report asymptomatic brain infarcts to indicate cardioembolism. ${ }^{29}{ }^{31-44}$ But this idea has strongly been questioned by others ${ }^{45}{ }^{46}$ Aortic valve calcification with or without stenosis. was not associated with one or more silent small deep or territorial brain infarcts. Thus, the lack of any association with silent infarcts also does support the idea that aortic valve calcification with or without stenosis should not be considered as a potential source of cerebral emboli in stroke patients. 
Selective allocation of warfarin or aspirin to patients with aortic valve calcification or calciffed aortic valve stenosis may cause a reduction in the difference in strokes and stroke subtypes between study and control patients. Irrespective of any clinical indication, we found no association of aspirin and anticoagulant therapy with aortic valve calcification or calcified aortic valve stenosis as compared to controls, and therefore there is not such a therapeutic bias.

Theoretically, as compared to a population based design, contrast of covariates between the studygroup and controls may have been reduced by cardiology referral bias, which could lead to an underestimation of aortic valve calcification and calcified aortic valve stenosis as risk factors for stroke. However, the direct embolic potential of the valve calcification was questioned irrespective of concomitant risk factors. If aortic vallve calcification is strongly correlated with cardiovascular risk factors, then confounding can not be avoided by design. Therefore, the relationship between the available studygroup and the chosen control sample was calculated for optimal contrast as far as the study lesion was concerned, and permitted anallysis with relatively large subsets of covariates. The mean age of the study group was higher than that of the reference group. Any bias resulting from this difference would have led to an overestimation rather than underestimation of the association of aortic valve calcification and calcified aortic valve stenosis with stroke, and therefore does not influence the conclusions.

In conclusion, our study indicates that aortic valve calcification with or without stenosis is not a risk factor for stroke, but merely a marker of generalised cardiovascular disease.

Therefore, the finding of aortic valve calcification with or without stenosis is by itself not an indication for anticoagulant therapy to lower the risk of stroke. 


\section{References}

1. Stapleton JF. Natural history of chronic valvular disease Cardiovasc Clin 1986;16:105-147.

2. Roberts WC. The Senile Cardiac Calcification Syndrome. Am J Cardiol 1986;58:572-574.

3. Normand J, Loire R, Zambartas C. The anatomical aspects of adult aortic stenosis. Eur Heart J 1988;9:31-36

4. Rose AG. Etiology of acquired valvular heart disease in adults. A survey of 18,132 autopsies and 1.00 consecutive valve-replacement operations. Arch Pathol Lab Med 1986;110:385-388.

5. Wren $\mathrm{C}$, Petch $\mathrm{MC}$. Calcific aortic stenosis. I R Coll Physicians Lond $1983 ; 17: 192-195$.

6. Carlson RG, Mayfield WR, Normann $S$, Alexander JA. Radiationassaciated valvular disease. Chest 1991;99:538-545.

7. Savage D, Garrison RJ, Castelli WP, McNamara PM, Anderson SJ, Kannel WB, Feinleib M. Prevalence of Submitral (Anular) Calcium and Its Correlates in a General Population-Based Sample (The Framingham Study). Am J Cardiol 1983;51:1375-1378.

8. Di-Pasquale G, Ribani M, Andreoli A, Zampa GA, Pinelli G. Cardioembolic stroke in primary oxalosis with cardiac involvement. Stroke $1989 ; 20: 1403-1406$.

9. Maher ER, Curtis JR. Calcific aortic stenosis in chronic renal failure [letter]. Lancet 1985;2:1007.

10. Maher ER, Pazianas M, Curtis JR. Calcific antic stenosis: a complication of chronic uraemia. Nephron 1987;47:119-122.

11. Rotman M, Morris JI, Behar VS, Peter RH, Kong Y. Aortic Valvular Disease: Comparison of Types and Their Medical and Surgical Management. Am J Med 1971;51:241-257.

12. Kumpe $\mathrm{CW}$, Bean WB. Aortic stenosis: A study of the clinical and pathologic aspects of 107 proved cases Medicine 1948,27:139-185.

13. Dry TJ, Willius FA. Calcareous disease of the artic valve: A study of two hundred twenty-eight cases. Am Heart J 1939;17:138-157.

14. Wilson $\mathrm{\Omega H}$, Cranley $\mathrm{J} \mathrm{J}$. Recurrent calcium emboli in a patient with aortic stenosis. Chest 1989;96:1433-1434.

15. Vernhet $H$, Torres GF, Laharotte JC, Tournut $P$, Bierme $T$, Froment IC, Duquesnel J. Spontaneous calcific cerebral emboli from calcified aortic valwe stenosis. IN Neuroradiol 1993;20:19-23.

16. Rubin DC, Plotnick GD, Hawke MW. Intraaortic debris as a potential source of embolic stroke. Am J Cardiol 1992;69:819-820.

17. Brockmeier LB, Adolph RJ, Gustin BW, Holmes JC, Sacks JG. Calcium emboli to the retinal artery in calcific aortic stenosis. Am 
Heart J 1981;101:32-35.

18. Rancurel $G$, Marelle L, Vincent $D$, Catala M, Arzmanoglow $A$, Vacheron A. Spontaneous calcific cerebral embolus from a calcific aortic stenosis in a middle cerebral artery infarct. Stroke 1989,20:691693.

19. Mulleneers R, Cheriex E, Dassen W, Bleijlevens B, Wellens $H$. CAESARS; The cardiac siorage and retrieval nework system. In: Computers in Cardiology. IEEE Computer Society Press 1990, 1990: $211-214$.

20. Devereux R, Reichek N. Echocardiographic determination of left ventricular mass in man. Circulation 1977,55:613-618.

21. Lauer MS, Anderson KM, Levy D. Influence of contemporary versus 30-year blood pressure levels on left ventricular mass and geometry: the Framingham Heart Study [see comments]. J Am Coll Cardiol $1991 ; 18: 1287-1294$

22. Kitzman DW, Scholz DG, Hagen PT, Ilstrup DM, Edwards WD. AgeRelated Changes in Normal Human Hearts During the First 10 Decades of Life. Part II (Maturity): A Quantitative Anatomic Study of 765 Specimens From Subjects 20 to 99 Years Old. Mayo Clin Proc $1988 ; 63: 137-146$

23. Sahn DJ, DeMaria AN, Kisslo J, Weyman A. Recommendations regarding cquantitation in $\mathrm{M}$-mode electrocardiography: The tesults of a survey of echocardiographic measurements. The committee on $\mathrm{M}$ mode standardization on the American Society of Echocardiography Circulation 1978;58:1072-1083.

24. Schiller NB, Shah PM, Crawford M, DeMaria A, Devereux R, Feigenbaum $H$, Gutgesell $\mathbb{H}$, Reicher $N$, Sahn D, Schnitger I. Silverman NH, Tajik AJ. Recommendations for quantitation of the left ventricle by two-dimensional echocardiographs. J Am Soc Echo 1989;5:358-367.

25. Teicholz LE, Kreulen T, Herman MV, Gorlin R. Problems in echocardiographic volume determinations: Echocardiographic angiographic correlations in the presence or absence of asynergy. Am J Cardiol 1976;37:7-11

26. Allen CMC. Clinical diagnosis of the acute stroke syndrome. Q I Med $1983,208: 515-523$.

27. Boiten J, Lodder J. Large striatocapsular infarcts: clinical presentation. and pathogenesis in comparison with lacunar and cotical infarcts. Acta Neurol Scand 1992;86;298-303.

28. Ringelstein EB, Koschorke $S$, Holling $A$, Thron $A$, Lambertz $\mathbb{H}$, Minale $C$. Computed tomographic patterns of proven embolic brain infarctions. Ann Neurol 1989;26:759-765.

29. Kitner SJ, Sharkness CM, Price TR, Plotnick GD, Dambrosia JM, Wolf PA, Mohr IP, Hier DB, Kase CS, Tuhrim S. Infarcts with a 
cardiac source of embolism in the NDCDS Stroke Data Bank: historical features. Neurology 1990,40:281-284.

30. Luijckx GJ. Lacunar Brain Infarcts: A Clinical and Pathogenetical Study. Thesis, Maastricht, 1996.

31. Kittner SI, Sharkness CM, Sloan MA, Price TR, Dambrosia JM, Tuhrim S, Wolf PA, Mohr JP, Hier DB. Features on initial computed tomography scan of infarcts with a cardiac source of embolism in the NINCDS Stroke Data Bank. Stroke 1992;23:1748-1751.

32. Easton JD, Sherman DG. Management of Cerebral Embolism of Cardiac Origin. Stroke 1980,11:433-441

33. Feinberg WM, Seeger JF, Carmody RF, Anderson DC, Hart RG, Pearce LA. Epidemiologic features of asymptomatic cerebral infarction in patients with nonvalvular atrial fibrillation. Arch Intern Med $1990 ; 150: 2340-2344$.

34. Petersen P, Madsen EB, Brun B, Pedersen F, Gyldensted C, Boysen G. Silent Cerebral Infarction in Chronic Atrial Fibrillation. Stroke 1987;18:1098-1100.

35. Petersen $P$, Pedersen F, Johnsen A, Madsen EB, Brun B, Boysen $G$, Godtfredsen $J$. Cerebral computed tomography in paroxysmal atrial fibrillation. Acta Neurol Scand 1989;79:482-486.

36. Petersen $P$. Thromboembolic complications of atrial fibrillation and their prevention: a review. Am J Cardiol 1990;65:24C-28C.

37. Bogousslavsky J, Cachin C, Regli F, Despland PA, Van-Melle G, Kappenberger $\mathrm{L}$. Cardiac sources of embolism and cerebral infarction--clinical consequences and vascular concomitants: the Lausanne Stroke Registry. Neurology 1991;41:855-859.

38. Cerebral-Embolism-Task-Force Cardiogenic Brain Embolism. Arch Neurol 1986;43:71-84.

39. Cerebral-Embolism-Task-Force Cardiogenic brain embolism. The second report of the Cerebral Embolism Task Force Lpublished erratum appears in Arch Neurol 1989 Oct;46(10):1079]. Arch Neurol 1989;46:727-743.

40. Orgogozo JM, Aupy M, Levy S. Unsuspected Cardiac Origin of Cerebral Embolism. Cerebrovasc Dis 1981,6:319-322.

41. Kempster PA, Gerraty RP, Gates PC. Asymptomatic cerebral infarction in patients with chronic atrial fibrillation. Stroke 1988;19:955 957.

42. Sasaki W, Yanagisawa $S$, Maki K, Onodera A, Awaji T, Kanazawa $T$. High Incidence of Silent Small Cerebral Infarction in the Patients with Atrial Fibrillation. Circulation 1987;76, Supp IVIV-\|104.

43. Brust JCM. Vascular Dementia-Still Overdiagnosed. Stroke $1983 ; 14: 298-300$. 
44. Broderick JP, Phillips SJ, O'Fallon WM, Frye RL, Whisnant JP. Relationship of cardiac disease to stroke occurrence, recurrence, and mortality. Stroke 1992;23:1250-1256.

45. Boon A, Lodder J, Heuts L, Kessels F. Silent brain infarcts in 755 consecutive patients with a first ever supratentorial ischemic stroke; the relationship with index stroke subtype, vascular risk factors and mortality. Stroke 1994;25:2384-2390.

46. Jorgensen HS, Nakayama $H$, Raaschou HO, Gam J, Olsen TS. Silent Infarction in Acute Stroke Patients. Prevalence, Localization, Risk Factors, and Clinical Significance: The Copenhagen Stroke Study. Stroke $1994,25: 97-104$ 


\section{Mitral Annular Calcification and Stroke}

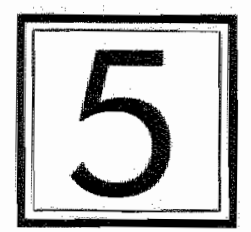

The Risk of Stroke in a Cohort of 657

Patients With Mitral Annulus

Calcification. 


\section{Abstract}

Background and Purpose. Almost all studies show a strong relative risk of mitral annular calcification for stroke, but the contribution of associated cardiac and vascular risk factors, especially carotid atheromatosis, has not been studied. This study analyses the risk of stroke in selected patients with mitral annular calcification adjusting for clinical, echocardiographic and therapeutic factors influencing stroke risk.

Methods. From an echocardiographic database of 8.160 consecutive patients, 657 patients with and 562 without mitral annular calcification were followed for a mean of $2.4(1-6.6)$ years to determine stroke risk, using proportional hazards models with the generally accepted clinical, echocardiographic, and therapentic variables that influence the risk of stroke. Also, the association was determined of mitral annular calcification with ischemic brain lesions generally considered to be specific of a cardiac embolic source, by dividing brain infarcts into territorial, small deep, and in stroke patients also asymptomatic (silent) ones.

Results. Fifty-one patients with mitral annular calcification and 27 control patients had a stroke in the follow up period. Mitral annular calcification was not statistically significant associated with stroke in proportional hazards models (hazard ratio $0.76,95$ percent confidence interval 0.42 to $1.36, P=0.3$ ), or with any of the stroke subtypes, or with the presence of silent brain infarcts. Hypertension, and carotid atheromatosis, with or without stenosis, ipsilateral or contralateral to the side of the stroke, were significantly associated with stroke in our patients.

Conclusions. Mitral annular calcification per sé was no risk factor for stroke in this study. A strong association was found between mitral anmular calcification and cardiac and vascular risk factors for stroke, indicating that the increased risk of stroke in patients with mitral annular calcification reported by others can be explained by these concomitant risk factors. Mitral annular calcification in itself is no indication for specific measures such as surgery or oral anticoagulation to lower the risk of stroke, but treating cardiovascular risk factors is a rational option. 
$\mathrm{M}$ itral annular calcification (MAC) is an age-related degenerative process within the cardiovascular fibrous skeleton, which is accelerated by conditions increasing mitral valve stress or motion, like hypertension, left atrial and ventricular enlargement, atrial fibrillation, hypertrophic cardiomyopathy, aortic valve stenosis, or mitral valve prolapse. ${ }^{1-4}$ Also, deposition of calcified material in the valve apparatus, due to metabolic disorders, may cause mitral annular calcification. ${ }^{2411}$ The pathological process is hyaline degeneration with fatty, mainly cholesterol depositions, necrosis and calcification of the mitral annulus fibrous tissue, sometimes with bone formation or inflammation. ${ }^{312}$ The magnesium content seems to play a role in the stability of these deposits. ${ }^{5}$ In a study of 87 patients on long-term haemodialysis, mitral annular calcification was associated with an increased calcium-phosphate product, although results were not adjusted for the increased cardiac output or hypertension, associated with long-term haemodialysis. ${ }^{~}$ Conditions associated with mitral annular calcification are Marfan syndrome, hyperostosis frontalis interna, vertebral disk calcification, and Paget's disease. Mitral annular calcification may occupy the whole mitral annulus. It may cause conduction disorders or mitral stenosis. ${ }^{1314}$ Prevalence of mitral annular calcification varies considerably between different studies, from 2.8 to $27 \%,{ }^{15}$ and is more frequent in women. ${ }^{12}$ The youngest patient reported with mitral annular calcification is a 14 year old boy with congenital mitral stenosis. ${ }^{16}$

Mitral annular calcification may act as a direct source of emboli or merely as a marker of other conditions associated with thromboembolism, like hypertension, generalized atherosclerosis, advanced age, congestive heart failure, atrial fibrillation and diabetes mellitus. ${ }^{124}$ 17.22 Case reports and epidemiological studies suggest a strong relation between mitral annular calcification and stroke. ${ }^{43-29}$ There is also clinical and pathological evidence of embolism by calcified material in brain, ${ }^{17}$ retina, or other organs ${ }^{4}$ in patients with mitral annular calcification. In two studies the prevalence of mitral annular calcification in patients with systemic or cerebral signs of vascular occlusion was higher than in age and sex matched controls, ${ }^{23} 2.5$ a difference, however, that also could have been caused by differences in the degree of concomitant cardiovascular disease. In three series systemic or cerebral ischemic signs occurred more often in patients with mitral annular calcification than in age and sexmatched controls. ${ }^{42428}$ 
Evidence of a more than doubled risk of stroke in mitral annular calcification patients comes from a study on the effect of warfarin on stroke risk in atrial fibrillation (The BAATAF Study), and from a study that analysed stroke risk in mitral annular calcification patients. ${ }^{26}{ }^{29}$ However, in BAATAF relative risks refer to therapeutic effects of warfarin in patients with atrial fibrillation, and not necessarily to the risk of stroke related to mitral annular calcification, whereas subgroup analysis, especially in patients selected by trial aim, could be hazardous. ${ }^{30}$ Moreover, in these and other studies the results may be influenced by confounders like carotid atheromatosis, ${ }^{27}$ the use of anti-platelet drugs or warfarin, or by cardiac factors affecting the risk of stroke.

A central problem is that vascular disease is common in patients with mitral annular calcification. Therefore, confounding cannot be prevented by design in a study of mitral annular calcification associated stroke, but can only be quantified and adjusted for. The purpose of this study was a prospective analysis of the risk of stroke in patients with mitral annular calcification, adjusted for clinical, and echocardiographical risk factors, and for treatment influencing the risk of stroke. As some subtypes of cerebral infarction may predict a cardioembolic stroke mechanism according to previous studies, the association of mitral annular calcification with specific stroke subtypes was also analysed.

\section{Patients and Methods}

\section{Patients}

Of 8,160 consecutive patients with 11,924 echocardiograms between january 1st, 1985 and jan 1st, 1990, examined in at the Department of Cardiology of the University Hospital of Maastricht, and who were registered in a specially designed prospective database, ${ }^{31} 663$ patients had echocardiographic evidence of calcification of the mitral annulus. These patients entered the study. The control group were 568 randomly chosen patients from the remaining 7,600 patients without mitral annular calcification. Six patients with and 6 without mitral annular calcification were lost to follow up. The cohort therefore consisted of 657 patients with and 562 patients without mitral annular calcification. For each patient the date of the first echocardiogram after january 1st 1985, whether with or without mitral annular calcification indicated the start of the follow up. 


\section{Clinical risk factors at entry}

The following risk factors were recorded: age, sex, hypertension (known hypertension treated with anti-hypertensive medication, two or more blood pressure recordings higher than $160 / 90 \mathrm{~mm} \mathrm{Hg}$ not measured within one week after a stroke), diabetes mellitus (known diabetes treated with diet and/or medication; or either a fasting serum glucose higher than $7 \mathrm{mmol} /{ }_{\text {, }}$ or a postprandial serum glucose level higher than $11 \mathrm{mmol} / \mathrm{l}$ measured on at least two separate occasions), a history of ischaemic heart disease (myocardial infarction, angina pectoris), a history of coronary artery bypass grafting, the use of oral anticoagulants or salicylates, prior stroke or TIA, serumcholesterol (the mean of all available values with or without lipid lowering therapy), hypercholesterolemia (known treated hypercholesterolemia, or fasting or non-fasting cholesterol levels higher than $6.5 \mathrm{mmol} / \mathrm{L}$ ), a history of peripheral atherosclerotic disease (symptomatic arteriosclerosis of extremities), electrocardiographically documented atrial fibrillation, and date and type of cardiac valve replacement.

\section{Echocardiographic data at entry}

The following echocardiographic parameters were registered: mitral annular calcification (defined as bright echo's in mitral annulus on two-dimensional echocardiogram with a "stone-shadow", mitral stenosis (defined as theumatic valvular disease with increased velocities over the valve and a mitral valve area of less than $2.5 \mathrm{~cm}^{2}$, or non-rheumatic valvular disease if mitral annular calcification and fibrosis of the mitral valve apparatus was causing a more than physiologic gradient, and a mitral valve orifice being smaller than or equal to $2.5 \mathrm{~cm}^{2}$ ), the degree of mitral regurgitation, calcified aortic valve sclerosis (bright echo's on one or more cusps of $1 \mathrm{~mm}$ or more and a maximal pressure gradient below $16 \mathrm{~mm} \mathrm{Hg}$ ), aortic stenosis (a pressure gradient exceeding $16 \mathrm{~mm} \mathrm{Hg}$ ), mitral, tricuspid or aortic valve prosthesis or bioprothesis, enlarged left atrium $(45 \mathrm{~mm}$ or more), atrial-septal aneurysm, atrial septal defect, left-ventricular ejection fraction less than $40 \%$, fractional shortening less than $28 \%$, increased left-ventricular wall mass, ${ }^{32}$ posterior-, inferior-, anterior wall infarction, wall-motion score, apical aneurysm, cardiac thrombus, and dilated cardiomyopathy. Wall-motion score was a semiquantitative measure of left ventricular wall motion. For this purpose, the left ventricle was divided in thirteen segments. Wall motion in each segment was scored from $0-4$ (normokinesis, hypokinesis, hypokinesis to akinesis, akinesis, and dyskinesis). A cut off point between small and larger asynergy of the left ventricle was 
chosen at a wall motion score of 12 . Fractional shortening was defined as the difference between lef ventricular enddiastolic and endsystolic diameter. Echocardiographically determined left ventricular wall mass is a better measure of left ventricular wall thickness than is left ventricular chamber size, and it is a reliable indicator of long standing hypertension. ${ }^{33}$ Normal men and women have a left ventricular wall mass lower than 225 and $215 \mathrm{~g} / \mathrm{m}^{2}$, respectively. In our population body surface was not measured and therefore we used the absolute values as the upper limits of normal. Left ventricular wall mass cut off points we used in our analysis were 175, 200 and $225 \mathrm{~g}$ for men, and 165,190 , and $215 \mathrm{~g}$ for women. ${ }^{32}$ All diameters used were measured according the recommendations of the American Society of Echocardiography. ${ }^{34-36}$

\section{Outcome definitions: Stroke, stroke subtypes, and silent brain infarcts in patients with stroke in the follow up}

Stroke was defined as a supra- or infratentorial brain infarct or intracerebral hematoma. A brain infarct was defined as rapidly developing clinical signs of focal disturbance of cerebral function, lasting longer than 24 hours or leading to death, with no other apparent cause than being of vascular origin, while CT scan showed an area of low attenuation compatible with the clinical signs and symptoms or no specific lesion. For symptomatic infarcts, when no CT scan was available, the Guy's Hospital Stroke Diagnostic Score was used (Allen Score) ${ }^{37}$ to differentiate between brain infarct and hemorrhage.

Symptomatic brain infarcts were divided into small deep (lacunar) and territorial infarcts. A small deep infarct was defined as a CT lesion compatible with the occlusion of a single perforating artery, i.e. a subcortical, small, sharply marginated hypodense lesion with a diameter less than $20 \mathrm{~mm}$, or clinically a lacunar syndrome if no specific lesion was visible on CT. Four lacunar syndromes were distinguished: pure motor stroke, pure sensory stroke, sensorimotor stroke, and ataxic hemiparesis including dysarthria-clumsy hand cases. A territorial infarct was defined as CT findings compatible with infarction involving the cortex, or clinically a cortical syndrome, i.e. a unilateral motor or sensory deficit, or both, in combination with signs of cortical dysfunction (e.g. aphasia, visual field deficit, visual spatial disturbances, apraxia, neglect or agnosia) if no specific lesion was visible on CT. Patients with a large subcortical infarct were included in this group, because of similar pathogenesis. 
Territorial infarcts were divided into two groups by presumed cause: cardioembolic and remaining causes. A cardioembolic infarct was defined as a territorial infarct in the presence of one or more of the following possible cardiac sources of embolism: chronic or paroxysmal atrial fibrillation, myocardial infarction less than 6 weeks prior to stroke, prosthetic aortic or mitral valve, endocarditis, dilated cardiomyopathy, mitral stenosis, left-ventricular aneurysm, and intraventricular thrombus. By study design, mitral annular calcification was not defined a potential cardioembolic stroke cause.

Some patients with a stroke had clinically unrelated low-density areas on CT scan compatible with previous unpercieved brain infarction. Such lesions were defined a silent brain infarct. Two types of silent brain infarcts were distinguished: silent small deep and silent territorial infarcts.

\section{Risk factors at time of a strake in the follow up}

Beside age and sex the following risk factors at the time of stroke were recorded: hypertension (present before or after stroke but not diagnosed within one week after stroke), diabetes mellitus (not measured in the acute phase of stroke, i.e. within 72 hours), a history of ischaemic heart disease, and more than $50 \%$ carotid stenosis (on either side) on Duplex scanning, Doppler, or angiograms. Carotid studies were performed in stroke patients only, and the results were studied as contributory and not explanatory variables.

\section{Selection}

First-ever strokes in the follow up period were the primary endpoints. There were no exclusion criteria, meaning that patients with previous stroke and any TIA were included, but analysis was also done excluding those patients. A simple questionnaire to general practitioners of all patients, was assembled to verify hospital admissions for stroke, and to trace stroke patients not admitted.

\section{Censoring}

Follow up was censored at the time of a stroke during follow up, and at the date of mitral valve replacement without residual calcification. Patients with post cardiac surgery echocardiograms still showing mitral annular calcification were considered still at risk for stroke. 
Primary endpoints were first-in-a-lifetime strokes occurring later than an arbitrary number of 70 days before the index echocardiogram. Strokes before that time were defined as previous strokes. We chose this period to optimize the number of endpoints, and because mitral annular calcification must have been present for some time before the index echocardiogram.

A subanalysis was done on stroke patients who also had a previous stroke, and chosing 0 instead of 70 days.

\section{Statistics}

Heart surgery, death, more recent patient inclusion, withdrawal, and censoring resulted in varying times of exposure to mitral annular calcification and other risk factors. The analysis assumed that these exposure times were important for the risk of stroke, but not of stroke subtypes. Therefore, crude analysis of the risk of stroke expressing risk in person years was done with Incidence Density ratios (IDR), and subsequent multivariate analysis with the Cox Proportional Hazard Model (Hazard ratios; HR). For comparisons of stroke subtypes, univariate analysis (Chi-square test; crude odds ratios (OR) with $95 \%$ confidence intervals $(\mathrm{CI})$ ), and subsequent multiple stepwise logistic regression analysis were done with adjusted odds ratios, to determine the association of mitral annular calcification with symptomatic or silent small deep or territorial infarcts, as dependent variables. Models with different patient subgroups were tested to check for the stability of the associations.

We used multiple logistic regression analysis instead of matching for e.g. age and sex because: 1 . the latter is a form of restriction reducing the preciseness of point estimates (increasing confidence intervals), 2. biologically, it can be strongly suspected that cardiovascular risk factors are associated with mitral annular calcification, which is the exposition factor. Therefore, matching could introduce confounding, 3. this would be the only method to determine effectparameters for each variable.

\section{Results}

\section{Baseline data at entry}

Among the 657 patients with mitral annular calcification were 220 men and 437 women. The 562 control patients consisted of 338 men and 224 women. Thirty-three of the mitral annular calcification patients and 19 controls had some form of open heart surgery in the 
follow up period. Six patients with mitral annular calcification were still at risk after operation (they had no mitral valve replacement), of whom one suffered a stroke, which occurred one day after the operation. Mean followup was 2.4 years (range 1-6.6). Hundred seventy patients with mitral annular calcification and 74 controls used aspirin sometime during follow up with a mean of 169 and 86 days, respectively, whereas 92 patients with mitral annular calcification and 161 controls were on anticoagulant therapy during follow up with a mean of 195 and 210 days, respectively. At the start of the follow up, 122 and 119 patients with mitral annular calcification, and 64 and 150 control patients used aspirin or anticoagulants, respectively.

Fifty-one patients with mitral annular calcification and 27 controls had a stroke in the followup period. Of those patients, 1 control and 5 patients with mitral annular calcification had previous strokes, and 1 and 2 had prior TIA, respectively. Table 1 shows baseline data, Table 2 shows details about stroke and TIA.

\section{The risk of stroke in patients with mitral annular calcification}

Crude (IDR,0.77;95\% $\mathrm{Cl}, 0.41$ to $1.41 ; \mathrm{P}=0.04$ ) as well as multiple logistic and Cox regression analysis (Tables 3 and 4 , Figures $l$ and 2) showed no significant association of mitral annular calcification with stroke. Only hypertension and any carotid stenosis measured in selected stroke patients were significantly associated with stroke. An apical aneurysm on echocardiography was just not significantly associated with stroke.

\section{Mitral annular calcification and stroke subtypes}

Mitral annular calcification was not more strongly associated with cortical than with lacunar symptomatic brain infarction (lacunar vs cortical: $\mathrm{OR}, 1.4 ; 95 \% \mathrm{Cl}, 0.18$ to $11, \mathrm{P}=0.73$ ) with or without adjustments for risk factors such as symptomatic or asymptomatic significant carotid stenosis, a potential cardioembolic stroke cause in general, and atrial fibrillation in particular. Intracerebral hematoma and infratentorially located infarcts did not occur frequently enough for a meaningfull sub analysis. 
Table 1. Baseline data

\begin{tabular}{|c|c|c|}
\hline & $\begin{array}{l}\text { MAC } \\
657\end{array}$ & $\begin{array}{l}\text { Controls } \\
562\end{array}$ \\
\hline Mean age [madian] & $72+/ 110[74]$ & $53+/-18[58]$ \\
\hline $\operatorname{gg} \theta<65 /$ age $>=65$ & $131 / 1526$ & $381 / 781$ \\
\hline Men/women & $220(33) / 437$ & $338(60) / 224$ \\
\hline Hypertension & $290(44)$ & $96(17)$ \\
\hline Ischemic heart disease & $382(58)$ & $225(40)$ \\
\hline Diabetes mallitus & $124(19)$ & $43(8)$ \\
\hline Hypercholesterolemia & $36(5)$ & $10(2)$ \\
\hline Mean serum cholesterol (mmol/L) & 6.6 & 5.9 \\
\hline Peripheral atherosclerotic disease & $55 \mid 8\}$ & $28(5)$ \\
\hline Atrial fibrillation & $32(5)$ & $30(5)$ \\
\hline Prior stroke & $40(6)$ & $20(4)$ \\
\hline Stroke and previous stroke & 5 & 1 \\
\hline TIA & $21(3)$ & $17(3)$ \\
\hline Died [average follow up in days] & $104[506]$ & $77[524]$ \\
\hline Dilated cardiomyopathy & $30(4)$ & $38(7)$ \\
\hline Rheumatic mitral stenasis & $18(3)$ & $19(3)$ \\
\hline Mitral regurgitation & $220(33) / 64(10)>$ grade 3 & $218(38) / 49(8)>\operatorname{grade} 3$ \\
\hline Aortic valve calcification/[stemotic] & $289(44) /[113(17)]$ & $0 /[0]$ \\
\hline Aortic/mitral valve prosthesis & $\begin{array}{l}6(1) / 3 \text { of whom } 0 / 1 \text { had } \\
\text { bioprosthesis }\end{array}$ & $\begin{array}{l}26(4) / 39 \text {, of which } \\
3 / 10 \text { had bioprosthesis }\end{array}$ \\
\hline $\begin{array}{l}\text { Anterior wall infarct/apical } \\
\text { aneurysm/cardiac thrombus/atrial } \\
\text { septum aneurysm/atrial septum defect }\end{array}$ & $80 / 3 / 5 / 0 / 0$ & $82 / 10 / 16 / 3 / 7$ \\
\hline Coronary bypass surgery & $67(10)$ & $60(10)$ \\
\hline
\end{tabular}

Baseline data. Percentage between brackets; numbers between square brackets are defined in the first columr. MAC, mitral annular calcification; $+1-10$ means a standard deviation of 10 . 


\begin{tabular}{|c|c|c|}
\hline & $\begin{array}{l}\text { MAC } \\
657\end{array}$ & $\begin{array}{l}\text { Controls } \\
562\end{array}$ \\
\hline Strok & $\begin{array}{l}51(7) \text { - One patient had rheumatic } \\
\text { valwular disease, one had recent } \\
\text { myocardial infarction, and } 10 \text { had } \\
\text { atrial fibrillation. }\end{array}$ & $\begin{array}{l}27(5) \text { - None with a poliential cardioembolic } \\
\text { stroke source. }\end{array}$ \\
\hline Stroke type & $\begin{array}{l}34 \text { territorial [contical], } 10 \text { small deep } \\
\text { [lacunar], } 2 \text { hematomas, } 2 \\
\text { infratentorial infarcts, and three } \\
\text { unspeacified hemispheric infares. }\end{array}$ & $\begin{array}{l}13 \text { teritorial, } 5 \text { small deep, } 4 \text { unspecified } \\
\text { hemispheral, } 3 \text { hematomas, and one } \\
\text { "multi-infarct" - dassified as unspecified } \\
\text { type. }\end{array}$ \\
\hline
\end{tabular}

Numbers and types of strakes in patients with mitral annular calcification (MAC) and controls. Numbers between brackets are percentages. 


\begin{tabular}{|c|c|c|c|}
\hline Risk factor & OR & $95 \% \mathrm{Cl}$ & $\mathrm{P}$ \\
\hline MAC & 1.8 & $0.77-4.21$ & 0.08 \\
\hline Age $>=6.5$ & 0.97 & $0.33-2.84$ & ns \\
\hline Men /women & 0.96 & $0.51-1.79$ & ns \\
\hline Ischemic heort disease & 0.82 & $0.48-1.4$ & ns \\
\hline Diaboles mellitus & 2.34 & $1.18-4.62$ & ns \\
\hline Hyportension & 3.09 & $1.82-5.26$ & 0.00 \\
\hline $\begin{array}{l}\text { Peripheral atherosdarotic } \\
\text { disease }\end{array}$ & 1.2 & $0.54-2.64$ & ns \\
\hline Hypercholesterolemial & 2.93 & $0.99-8.65$ & 0.05 \\
\hline Atrial fibrillation & 0.87 & $0.24-3.07$ & ns \\
\hline Anticoagulants & 0.82 & $0.36-1.84$ & ns. \\
\hline Rheumatic mitral stenosis & 1.55 & $0.32-7.4$ & $n s$ \\
\hline Mitral regurgitation > grade 3 & 0.58 & $0.32-11.06$ & ns: \\
\hline Enlarged left atrium & 0.92 & $0.48-1.77$ & ns \\
\hline Prosthetic cardiac valwes. & 2.17 & $0.62 \cdot 7.5$ & ns \\
\hline Eiection fraction< $30 \%$ & 1.32 & $0.49-3.53$ & ns \\
\hline $\begin{array}{l}\text { Increased left ventricular wall } \\
\text { mass, category! }\end{array}$ & 1.75 & $0.84-3.64$ & ns \\
\hline category II & 1.08 & $0.57-2.01$ & $\mathrm{~ns}$ \\
\hline caltegory III & 1.19 & $0.63=2.21$ & ns \\
\hline
\end{tabular}

Multiple logistic regression analysis of the risk of strake in patients with mitral annular calcification (MAC). OR, adjusted adds ratio; $95 \% \mathrm{Cl}, 95$ percent confidence interval; P, P-value. Categories of left ventricular wall mass are defined in the methads section. 


\section{Table 4. Stroke in follow up, Cox model}

\begin{tabular}{|c|c|c|c|}
\hline Risk factor & $H R$ & $95 \% \mathrm{Cl}$ & $P$ \\
\hline $\mathrm{MAC}$ & 0.76 & $0.42-1.36$ & 0.3 \\
\hline$A g e>-65$ & 1.44 & $0.55-3,77$ & 0.4 \\
\hline Men/women & 0.82 & $0.46-1.44$ & 0.5 \\
\hline Hypertension & 2.4 & $1.36-4.26$ & 0.002 \\
\hline Diabeles mellitus & 1.35 & $0.70-2.62$ & 0.4 \\
\hline Ischemic heart disease & 0.80 & $0.45 \cdot 1.43$ & 0.4 \\
\hline Coronary bypass surgery & 0.89 & $0.33-2.36$ & 0.4 \\
\hline Anterior wall infard & 1.59 & 0.55 .4 .57 & 0.4 \\
\hline Apical aneurysm & 5.13 & $0.94-27.9$ & 0.05 \\
\hline Dilated cardiomyopathy & 0.98 & $0.22 \cdot 4.38$ & 0.9 \\
\hline Generalised wasular disease & 0.49 & $0.17-11.39$ & 0.18 \\
\hline Atrial fibrillation & 0.52 & $0.12-2.23$ & 0.3 \\
\hline Enlarged left atrium & 1.16 & $0.62-2.15$ & 0.63 \\
\hline Hypercholesterclemia & 1.93 & $0.72-5.19$ & 0.19 \\
\hline Prosthetic valves & 1.50 & $0.47-4.81$ & 0.5 \\
\hline Mitral regurgitation > grade 3 & 0.77 & $0.32 \cdot 1.85$ & 0.5 \\
\hline Anticoagullants & 0.66 & $0.33-1.34$ & 0.2 \\
\hline Aspirin & 0.58 & $0.26-1.28$ & 0.18 \\
\hline Ejection fraction $<30 \%$ & 0.87 & $0.25-3.03$ & 0.8 \\
\hline Increased left veniricular wall mass & 0.99 & $0.56-1.73$ & 0.9 \\
\hline (A) symptomatic carolid stenosis & 0.98 & 4.35 .22 .1 & 0.00 \\
\hline TIA & 1.01 & $0.23-4.45$ & 0.9 \\
\hline
\end{tabular}

Proportional hazard madel for the risk of stroke in patients with mitral annular calcification (MAC). $H R$, hazard ratio; $95 \% \mathrm{Cl}, 95$ percent confidence interwal; $P$, P-value. In this table, the lowest calegory of left wentricular wall mass is shown, but resulis were similar for the higher ones which are defined in the text. 
Fig 1. The risk of stroke of mitral annular calcification (MAC) with multiple logistic regression analysis. Classes of left ventricular wall mass are defined in the text.

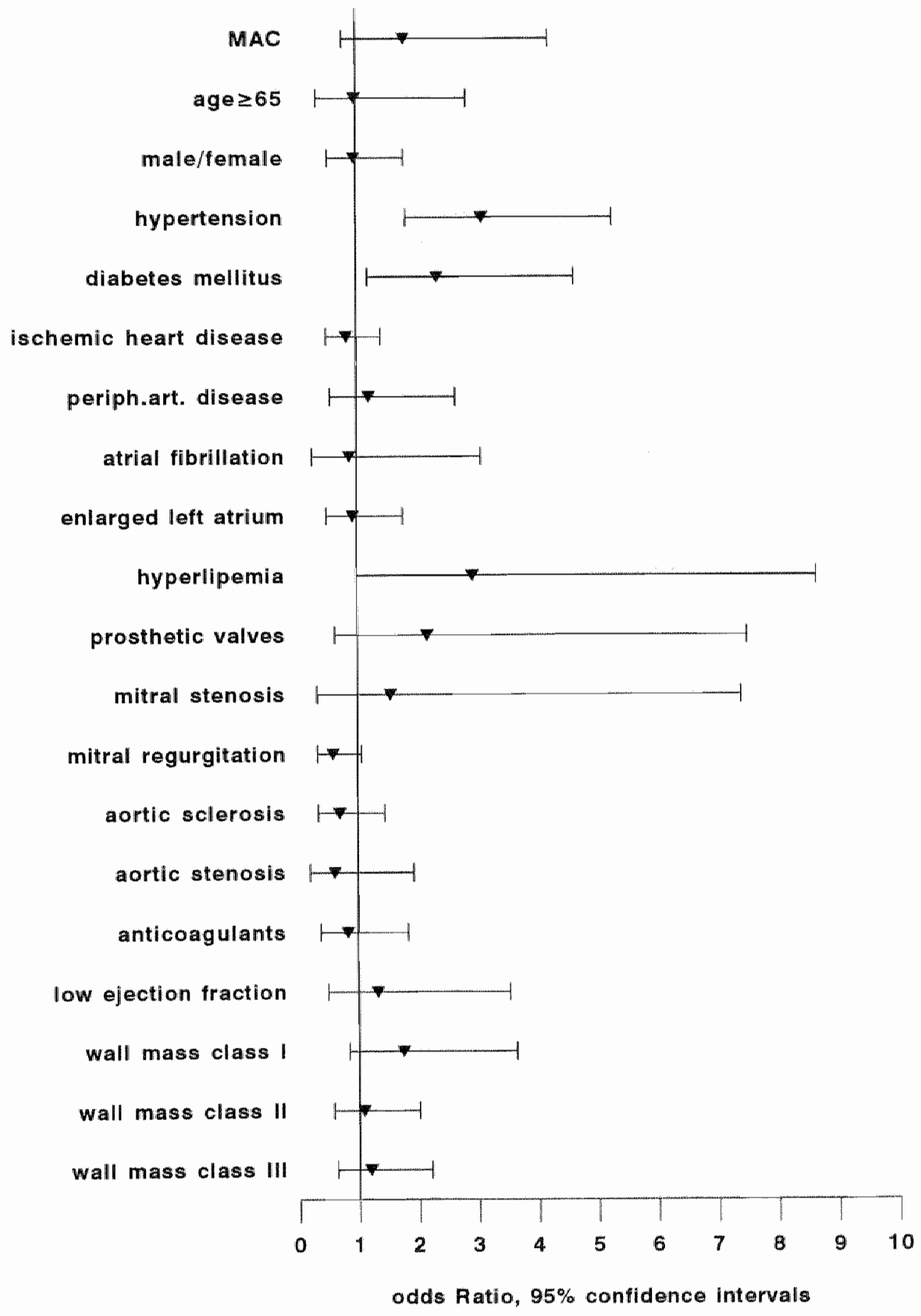


Fig 2. Stroke risk of mitral annular calcification (MAC). Wall mass and ejection fraction classes are defined in the text.

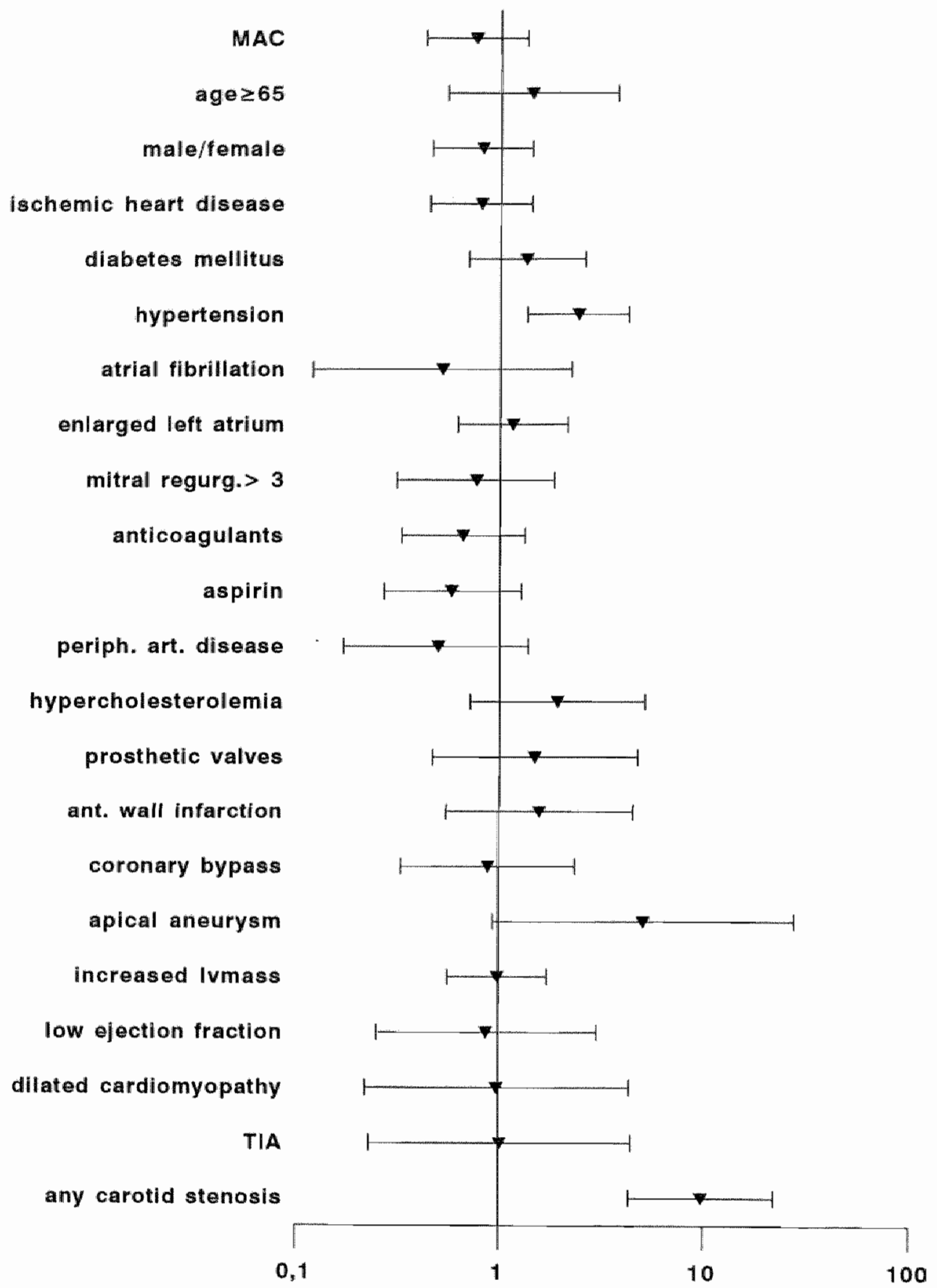

hazard Ratio, $95 \%$ confidence interval. Log scale 


\section{Mitral annular calcification and silent brain infarcts}

Mitral annular calcification was not significantly associated with the presence of one or more asymptomatic brain infarcts on CT in patients that suffered a stroke during follow up(OR,4.28;95\% $\mathrm{Cl}, 0.77$ to $23.8, \mathrm{P}=0.13$ ), and probably not with one or more asymptomatic small deep $(\mathrm{OR}, 7.48 ; 95 \% \mathrm{Cl}, 0.77$ to $71.2 ; \mathrm{P}=0.07)$ or territorial infarcts $(\mathrm{OR}, 3.42 ; 95 \% \mathrm{Cl}, 0.18$ to $62.2, \mathrm{P}=0.5)$ on $\mathrm{CT}$.

In a separate multivariate described in previous chapters analysis older age, female gender, hypertension, diabetes mellitus, hypercholesterolemia, and enlarged left atrium were strongly associated with mitral annular calcification $(\mathrm{P}=0.000)$.

\section{Discussion}

This study does not support the suggestion from previous reports that mitral annular calcification is a risk factor for stroke.

One explanation of this difference may be that this study adjusted for carotid stenosis in stroke patients, which has been found to be associated both with mitral annular calcification and stroke. ${ }^{27}$ Moreover, results were adjusted for extensive models of cardiovascular riskfactors for stroke, associated with mitral annular calcification in previous studies, and confirmed in this analysis. ${ }^{6} 18.38-42$ The follow up of a large number of patients with mitral annular calcification made this possible.

Three studies found an increased prevalence of mitral annular calcification in selected patients with cerebral ischemia. De Bono and Warlow ${ }^{23}$ found mitral annular calcification in eight of 151 patients with cerebral ischemia or amaurosis fugax, and none in the control group, a difference probably caused by mitral annular calcification related cardiac and carotid disease. Nishide et al ${ }^{43}$ found 2.5 times more mitral annular calcification in 350 patients with brain infarcts than in controls, not adjusted for the higher prevalence of cardiac disease in the group with brain ischemia, and for carotid atheromatosis. Jespersen ${ }^{21}$ analysed 388 patients with arterial emboli, and found a prevalence of mitral annular calcification of $27 \%$ in 49 patients suspected of cardiac emboli, 11 of whom had cerebral infarcts, as compared to $8 \%$ in the remaining patients. However, enlarged left atrium and atrial fibrillation were more frequent among the 49 patients, and no data about carotid studies were included in their analysis. 
Five studies described the risk of stroke in a follow up of mitral annular calcification patients. Of 80 patients with mitral annular calcification 12 had ischemia in the carotid territory, but patients were not compared with controls. ${ }^{4}$ Three strokes occurred during a 3.4 years follow up of 63 patients, but most had cardiovascular disease. ${ }^{24}$ In a univariate analysis ${ }^{28}$ of 107 patients younger than 61 years with mitral annular calcification, followed for an average of 4.4 years, brain ischemia occurred 5 times as much as in age and sex matched controls. No adjustments were made for cardiac disease, which were more frequent in patients with mitral annular calcification. Aronow found a 1.7 relative risk of stroke in 526 patients older than 62 years with mitral annular calcification, followed for 39 months, unadjusted for the higher incidence of atrial fibrillation and left atrial enlargement in patients with mitral annular calcification, or for carotid atheromatosis.

Three epidemiological studies analysed the risk of stroke in patients with mitral annular calcification. BAATAF reported a 4.0 times increased incidence of stroke in 121 patients with mitral annular calcification of 420 patients with nonrheumatic atrial fibrillation with or without low-dose warfarin. As with multivariate analysis of 568 patients with non rheumatic atrial fibrillation assigned to placebo in the SPAF study, mitral annular calcification was no risk factor for stroke ${ }^{44}$ the increased risk found by the BAATAF investigators may have been overestimated: firstly, adjustments did not include carotid disease. Secondly, the number of strokes in the control group might have been underestimated. Thirdly, results apply to atrial fibrillation trial patients only, and an interaction between mitral annular calcification and atrial fibrillation increasing stroke risk, can not be excluded. ${ }^{29}$ Mitral annular calcification was associated with a relative risk of stroke of 2.1 in The Framingham study ${ }^{29}$ adjusted for age, sex, hypertension, diabetes mellitus, smoking, atrial fibrillation, coronary heart disease and congestive heart failure, also after exclusion of patients with atrial fibrillation. However, limiting outcomes to cerebral infarcts only, reduced the relative risk to 1.78 with a lower limit of the confidence interval of 1.00. Furthermore, carotid disease was not analysed, and classification into stroke subtypes might have yielded different results.

As cardioembolic infarcts may be more often territorial than lacunar, ${ }^{45} 46$ this study also analysed whether mitral annular calcification was associated with territorial rather than lacunar infarcts, but this was not the case. 
Brain CT scans in healthy volunteers or patients presenting with a stroke often show unexpected ischemic lesions that cause no apparent symptoms, but are a sign of previous brain infarction. Some suggested that such silent infarcts, especially when multiple or territorially located, increased the risk that the stroke resulted from cardiogenic embolism, but others strongly doubt this. ${ }^{47.51}$ No statistically significant association between mitral annular calcification and one or more silent brain infarcts on CT was established in this study, although there was a tendency for small deep silent infarcts to be related with mitral annular calcification, probably because of common underlying vascular risk factors. Obviously, even when stroke patterns, presumed by some to indicate a cardioembolic stroke mechanism, were separately analysed, mitral annular calcification did not appear as a cardioembolic source for stroke.

Patients in this study were referred to a cardiologist, undoubtedly increasing the a priori risk of stroke, but equally in the study and control groups. The analysis adjusted for all generally accepted clinical and echocardiographic risk factors for stroke. Without adjustments, older age and the specific cardiovasular risk factor profile of patients with mitral annular calcification might have biased towards an overestimation of stroke risk in patients with mitral annular calcification. However, any such bias would rather reject and not confirm the hypothesis, that mitral anmular calcification is no risk factor for stroke, and therefore would not influence the conclusion. Patients with mitral annular calcification did not use more aspirin or anticoagulants for any reasons associated with mitral annular calcification, excluding a therapeutic bias.

Some previously established risk factors seem to lower stroke risk in the follow up, but this is no more than an apparent effect, as the design aims at a high power of the study for mitral annular calcification only, and not especially for its covariates.

In conclusion, the data of this study do not argue in favour of the view that mitral anmular calcification is a risk factor for stroke. Stroke in patients with this valve lesion should be attributed to concomitant cardiovascular and carotid disease, which are strongly associated with mitral annular calcification. That knowledge should determine the choice for treatment aimed at lowering the risk of stroke in such patients. 


\section{References}

1. Usher BW. Cardiac valvular disease and stroke. Neurol Clin 1993;11:391-398.

2. Aronow WS. Mitral anular callification: significant and worth acting upon. Geriatrics 1991;46:73-75

3. Oka $\mathrm{M}_{\text {. Onur }} \mathrm{N}$, Gross $\mathrm{S}$. Mitral anulus and valvular calcification. $\mathrm{N}$ Y State J Med 1983;83:837-842.

4. Fulkerson PK, Beaver BM, Auseon JC, Graber HL. Calcification of the Mitral Annulus. Etiology, Clinical Associations, Complications and Therapy. Am J Med 1979;66:967-977.

5. Bigi A, Compostella L, Fichera AM, Foresti E, Gazzano M, Ripamonti A, Roveri N. Structural and chemical characterization of inorganic deposits in calcified human mitral valve. J Inorg Biochem $1988 ; 34: 75-82$.

6. Cacciapuoti F, Perrone N, Diaspro R, Galzerano D, Gentille S, Lapiello B. Slowing of Mitral Valve Annular Calcium in Systemic Hypertension by Nifedipine and Comparisons with Enalapril and Atenolol. Am J Card 1993;72:1038-1042.

7. Dessault $\mathrm{O}$, Toussaint M, Cabrol C, Fouchard J. [Tight mitral stenosis caused by calcifications of the ring extending to the valves]. Ann Cardiol Angeiol Paris 1988;37:309-311.

8. Sommer $\mathrm{K}$, Lajos TZ, Visco JP. Intramyocardial calcification in the elderly. A diagnostic and therapeutic puzzle. Chest 1.992;102:317-319.

9. Motamed HE, Roberts WC. Frequency and significance of mitral anular calcium in hypertrophic cardiomyopathy: analysis of 200 necropsy patients. Am J Cardiol 1987;60;877-884.

10. Forman MB, Virmani R, Robertson RM, Stone WJ Mitral anular calcification in chronic renal failure. Chest 1984;85;367-371.

11. Maher ER, Young $G$, Smyth-Walsh B, Pugh $S$, Curtis JR. Aortic and mitral valve calcification in patients with end-stage renal disease. Lancet $1987: 2: 875-877$.

12. Giampalmo A, Buffa D, Caponnetto $S$, Chiarella F, Pesce C, Sacchetti $\mathbb{R}$. Myxoid degeneration with prolapse and dystrophic calcification of the annulus fibrosus of the mitral valve. Pathological and clinical survey. Appl Pathol 1983;1:194-208

13. Iga $K$, Hori $K$. Left ventricular outflow obstruction caused by mitral ring calcification. Am Heart J 1990;119:418-419.

14. Kelly RP, Kuchar DL, Thorburn CW. Subvalvular mitral calcium as a cause of surgically correctable ventricular tachycardia. Am J Cardiol $1986 ; 57: 884-886$.

15. Savage D, Garrison RJ, Castelli WP, MoNamara PM, Anderson SJ, 
Kannel WB, Feinleib M. Prevalence of Submitral (Anular) Calcium and Its Correlates in a General Population-Based Sample (The Framingham Study). Am J Cardiol 1983;51:1375-1378.

16. Rodan BA, Chen JT, Kirks DR, Benson D Jr. Mitral valve calcification in congenital mitral stenosis. Am Heart J 1983; 105:514-515.

17. Lin CS, Schwartz IS, Chapman I. Calcification of the mitral annulus fibrosus with systemic embolization. A clinicopathologic study of 16 cases. Arch Pathol Lab Med 1987;111:411-414.

18. Nestico PF, Depace NL, Morganroth J, Kotler MN, Ross J. Mitral annular calcification: clinical, pathophysiology, and echocardiographic review. Am Heart J 1984;107:989-996.

19. Davis PH, Hachinski VC. The cardiac factor in stroke. Curr Opin Neurol Neurosurg 1992;5:39-43.

20. Hart RG. Cardiogenic embolism to the brain. Lancet 1992;339:589594.

21. Jespersen CM, Egeblad H. Mitral annulus calcification and embolism. Acta Med Scand 1987;222:37-41.

22. Stein JH, Soble JS. Thrombus Associated With Mitral Valve Calcification. A Possible Mechanism for Embolic Stroke. Stroke 1995;26:1697-1699.

23. De Bono DP, Warlow CP. Mitral-annulus calcification and cerebral or retinal ischemia. The Lancet $1979 ; 383-385$.

24. Furlan AJ, Craciun AR, Salcedo EE, Mellino M. Risk of stroke in patients with mitral annulus calcification. Stroke 1984;15:801-803

25. Jespersen $\mathrm{CM}$, Egeblad $\mathrm{H}$. [Calcified mitral ring. Incidence and complications]. Ugeskr Laeger 1987;149:3394-3397.

26. The Boston Area Anticoagulants for Atrial Fibrilation Trial Investigators. The effect of low-dose warfarin on the risk of stroke in patients with nonrheumatic atrial fibrillation. N Engl J Med 1990;323:1505 1511 .

27. Aronow WS, Schoenfeld MR, Gutstein H. Frequency of thromboembolic stroke in persons greater than or equal to 60 years of age with extracranial carotid arterial disease and/or mitral annular calcium. Am J Cardiol 1992; 70:123-124.

28. Nair CK, Thomson W, Ryschon K, Cook C, Hee TT, Sketch MH Long-term follow-up of patients with echocardiographically detected mitral anular calcium and comparison with age- and sex-matched control subjects. Am J Cardiol 1989;63:465-470.

29. Benjamin EJ, Plehn JF, D'Agostino RB, Belanger AJ, Comai K, Fuller DL, Wolf PA, Levy D. Mitral annular calcification and the risk of stroke in an elderly cohort. N Engl J Med 1992;327:374-379

30. Counseil CE, Clarke MJ, Slattery J, Sandercock PAG. The miracle of DICE therapy for acute stroke: fact or fictional product of subgroup 
analysis? BMI 1994;309:1677-1681

31. Mullenters $\mathrm{R}$, Cheritx $\mathrm{E}$, Dassen $W$, Bleilevens $B$, Wellens $H$. CAESARS; The cardiac storage and retrieval network system. In: Computers in Cardiology. IEEE Computer Society Press 1990, 1990 . $211-214$.

32. Devereux $\mathrm{R}$, Reichek $\mathrm{N}$. Echocardiographic determination of left ventricular mass in man. Circulation 1977;55:613-618.

33. Lauer MS, Anderson KM, Levy D. Infuence of contemporary versus 30-year blood pressure levels on left ventricular mass and geometry: the Framingham Heart Study [see comments]. I Am Coll Cardiol $1991 ; 181287-1294$

34. Sahn DJ, DeMaria AN, Kisslo J, Weyman A. Recommendations regarding quantitation in $\mathrm{M}$-mode electrocardiography: The results of a survey of echocardiographic measurements. The committee on $\mathrm{M}$ mode standardization on the American Socielty of Echocardiography. Circulation 1978;58:1072-1083.

35. Schiller NB, Shah PM, Crawford M, DeMaria A, Devereux R, Feigenbaum $\mathrm{H}_{w}$ Gutgesell $\mathrm{H}$, Reicher $\mathrm{N}$, Sahn D, Schnittger I, Silverman NH, Tajik AJ. Recommendations for quantitation of the left ventricle by two-dimensional echocardiographs. J Am Soc Echo 1989;5;358-367.

36. Teicholz LE, Kreulen T, Herman MV, Gorlin R. Problems in echocardiographic volume determinations: Echocardiographic - angiographic correlations in the presence or absence of asynergy. Am J Cardiol $1976 ; 37: 7-11$.

37. Allen CMC. Clinical diagnosis of the acute stroke syndrome. Q J Med 1983;208:515-523.

38. Nair CK, Aronow WS, Stokke K, Mohiuddin SM, Thomson W, Sketch MH. Cardiac conduction defects in patients older than 60 years with aortic stenosis with and without mitral anular calcium. Am J Cardiol $1984,53: 169-172$.

39. Aronow WS, Kronzon I. Prevalence of hypertrophic cardiomyopathy and its association with mitral anular calcium in elderly patients. Chest 1988;94:1295 1296.

40. Aronow WS, Schwartz KS, Koenigsberg M Correlation of atrial fibrillation with presence or absence of mitral anular calcium in 604 persons older than 60 years. Am J Cardiol 1987;59:1213-1214.

41. Nair CK, Sudhakaran C, Aronow WS, Thomson W, Woodruff MP, Sketch $\mathrm{MH}$. Clinical characteristics of patients younger than 60 years with mitral anular calcium: comparison with age- and sex-matched control subjects. Am J Cardiol 1984;54:1286-1287.

42. Nair CK, Aronow WS, Sketch MH, Mohiuddin SM, Pagano T, Esterbrooks DJ, Hee TT. Clinical and echocardiographic characteristics of patients with mitral anular calcification. Comparison with age- 
and sex-matched control subjects. Am J Cardiol 1983,51:992-995.

43. Nishide M, Irino T, Gotoh M, Naka M, Tsuji K. Cardiac Abnormalities in ischemic Cerebrovascular Disease Studied by Twa-Dimensional Echocardiography. Stroke 1983:14:541-545.

44. The Stroke Prevention in Atrial Fibrillation Investigators. Predictors of thromboembolism in atrial fibrillation: II. Echocardiographic features of patients at risk. Ann Intern Med 1992;116:6-12.

45. Ringelstein EB, Koschorke $\mathrm{S}$, Holling $\mathrm{A}$, Thron $\mathrm{A}$, Lambertz $\mathrm{H}$, Minale $C$. Computed tomographic patterns of proven embolic brain infarctions. Ann Neurol 1989;26:759-765.

46. Kittner SJ, Sharkness CM, Price TR, Plotnick GD, Dambrosia JM, Wolf PA, Mohr JP, Hier DB, Kase CS, Tuhrim S. Infarets with a cardiac source of embolism in the NINCDS Stroke Data Bank: historical features. Neurology 1990;40:281-284.

47. Bogousslavsky I, Cachin C, Regli F, Despland PA, Van-Melle G, Kappenberger $\mathrm{L}$. Cardiac sources of embolism and cerebral infarction-clinical consequences and vascular concomitants: the Lausanne Stroke Registry. Neurology 1991;41:855-859.

48. Kittner SJ, Sharkness CM, Sloan MA, Price TR, Dambrosia JM, Tuhrim S, Wolf PA, Mohr JP, Hier DB. Features on initial computed tomography scan of infarcts with a cardiac source of embolism in the NINCDS Stroke Data Bank. Stroke 1992;23:1748-1751.

49. Petersen $P$. Thromboembolic complications of atrial fibrillation and their prevention: a review. Am J Cardiol 1990;65:24C-28C.

50. Feinberg WM, Seeger JF, Carmody RF, Anderson DC, Hart RG, Pearce LA. Epidemiologic features of asymptomatic cerebral infarction in patients with nonvalvular atrial fibrillation. Arch Intern Med 1990; 150:2340-2344.

51. Boon A, Lodder J, Heuts L, Kessels F. Silent brain infarcts in 755 consecutive patients with a first ever supratentorial ischemic stroke; the relationship with index stroke subtype, vascular risk factors and mortality. Stroke 1994;25:2384-2390. 


\section{General Discussion}

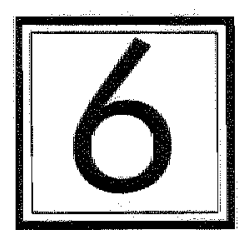





\title{
Silent Infarcts
}

\begin{abstract}
A bout one quarter of all strokes is attributed to a possible cardiA oembolic stroke mechanism. However, a causal relationship between stroke and a potential cardiac source of emboli is often obscured by concomitant risk factors for stroke, and often relies on indirect clinical criteria regarded as specific for a cardioembolic stroke, such as abrupt symptom onset, loss of consciousness, severe handicap, or CT criteria such as infarct size or the presence of silent brain infarcts.
\end{abstract}

This thesis investigated whether silent brain infarcts are indicative of the presence of a cardioembolic source for stroke. Had the study been performed using MRI more silent lesions might have been discovered. However, MRI is less specific for vascular lesions, especially when small. Previous studies trying to relate silent brain infarcts with a specific stroke cause used selected patients such as those with atrial fibrillation or carotid stenosis, not allowing conclusions on the significance of silent infarcts in stroke patients in general. Moreover, results of these studies were not adjusted in multivariate analysis for other risk factors for stroke, or studies were retrospective or small

Silent (asymptomatic) cerebral infarcts, defined as CT evidence of previous infarction but without a clinical history of stroke, do not predict a cardioembolic source in patients with a first supratentorial brain infarct. However, when only silent territorial infarcts are considered, the association is stronger with symptomatic cardioembolic than lacunar stroke, whereas silent lacunar strokes are more common in symptomatic lacunar strokes. Obviously, silent and symptomatic infarcts in the same patient are generally of the same type, suggesting homogeneity in the underlying stroke mechanism: small vessel disease in symptomatic and silent small deep infarcts, and large vessel atheromatosis or cardiac emboli in patients with symptomatic and silent territorial infarcts. Most silent infarcts are lacunar. As there is no independent association of silent infarcts with any carotid stenosis, their presence should not influence the decision of carotid desobstruction. In patients with an established cardioembolic stroke cause, anticoagulant therapy will generally be the therapy of choice to prevent stroke recurrence. This study shows that silent infarcts do not predict such a cardioembolic stroke cause, and thus should not influence the choice of anticoagulant therapy 


\title{
Cardiac valve calcification and stroke
}

\begin{abstract}
some comments on the statistics ased.
Confidemes infervats: in this study the hypothesis that aortic valve or mitral anumar calcifications are independent risk factors for siroke (defned HI hypothesis, a variable "does something") was negated. For mitral annulus cal cif cation the adjusted hazard ratio was 0.76 with a $95 \%$ confidence interval of 0.42 10 1.36. This means that repeating this investigation 100 times would give results compatible with the true (real) values 95 times with $95 \%$ certinty. We estimated that even the ouper limit of the confidence intervalls of 1.36 was clinically insignificant, and therefore consider the conclusions of this investigation as valid. Odds ratio: odds is a different way to express chance or risk: odds = risk/1-risk (e.g. an odds of "three to one" equals a chance of 75\%). In
\end{abstract}

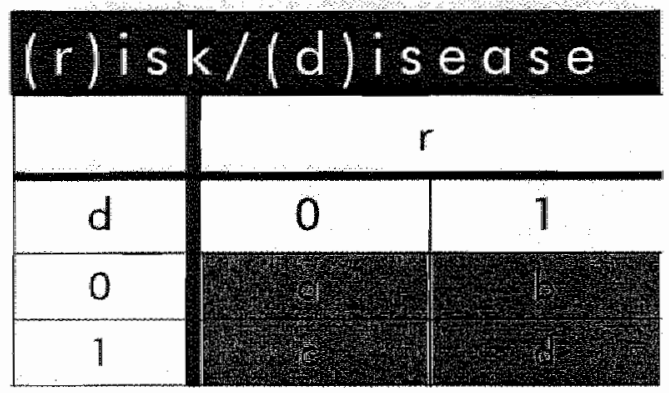

table 1 , the odd for disease $=1$ giwen risk $=0$, would be b/a; for disease $=1$ given risk $=1, d / c$. The odds ratio is: $a d / b c$, a number which is independent of row or column totals, and of exchanging the roles of risk and disease. Thus, calculating with odds ratio instead of probabilities has the advantage that it is independent of the composition of the study groulps.

Confounding: in the table, $d$ may be disease, $r$ a riskfactor and the odds ratio is a measure of association between the two. If a third variable $z$ is associated with both $r$ and $d$, the risk of $r$ for $d$ depends on the level of $z$, which is derined confounding and $z$ is a confounder. Stroke risk is determined by many confounders. To determine the enubolicpotential of cardiac valve calcifications which may also be strong markers of atherosclerosis " requires adjustments for the effect of cardiovascular risk factors for stroke. Analoguous to the $2 \times 2$ table, larger tables are used to calculate the attributive risk of each confounder, adjusted for the others in the model. In multiple logistic regression analysis used in this study the effect was calculated on the dependent variable (stroke) of changing each successive independent dichotomous variable (risk factor), when the others were held constant. Thus, the result was adjusted for confounding (adjusted as opposed to crude odds ratios).

The strong association in this study of cardiac and vascular risk factors (confounders) for stroke with the cardiac valve calcifications explains why the unadjusted results in previous studies suggest an apparent high risk of stroke, especially when vascular disease is underrepresented in control groups such as in population-based studies. 
The reason why established cardioembolic stroke causes such as atrial fibrillation have wide confidence intervals in this study is discussed in the corresponding chapters. However, those findings do not bear significance as to the conclusion on stroke risk, as atrial fibrillation was not aimed to be analysed as an independent risk factor. Instead, it was used as predictor to be adjusted for in estimates of stroke risk of mitral or aortic valve calcification. By design, power (the probability that any significant risk will also be measured ( $\mathrm{HO}$ rejected when $\mathrm{Hl}$ is true) ) is high for the study variables.

In patients with aortic valve calcification, calcified aortic stenosis, and mitral annulus calcification, the belief of some seems true that the cardiac valve calcifications are markers or even a form of atherosclerotic disease, as they all have a strong association with vascular risk factors, such as age, hypertension, and diabetes mellitus. Tricuspid aortic calcification and mitral annulus calcification reflect atherosclerotic disease and are therefore more frequent among the elderly than in the young. In contrast, calcified aortic stenosis occurs more often in younger patients with congenitally bicuspid aortic valves, or with aortic valves damaged by rheumatic fever. These views are further supported by the results presented here on a stroke follow up in three large cohorts of patients with the calcifications. This follow up showed that neither mitral annulus calcification, nor aortic valve calcification with or without stenosis, were associated with an increased risk for stroke. Even when strokes were divided into etiologically different subtypes, no association with one of the valve calcifications was found.

Referral bias was unlikely, since patients and controls were all referred to a cardiologist. Most previous studies did not include all relevant clinical and echocardiographic variables influencing stroke risk in multivariate models, whereas none of them included carotid atheromatosis or therapeutic measures, like aspirin or warfarin use, or cardiac surgery. The observed stroke risks in those studies, especially those reporting a high risk of stroke in patients with mitral annulus calcification, must therefore in part be due to the effect of confounders. 


\section{Hypothethical cases to illustrate therapeutic recommendations.}

\section{Case history 1.}

A 52 years old right-handed male presented with an acute aphasia, and right hemiparesis. He had a history of hypertension but was otherwise normal. Repeated CT-scan after two weeks showed a left medial cerebral artery territorial infarct, a small right frontal territorial infarct and two small deep infarcts in the right internal capsule. Carotid studies showed a high-grade right internal carotid stenosis, and $40 \%$ left carotid narrowing. Echocardiograms revealed a nonprotruding mitral annular calcification without thrombi.

Discussion: as there is no association between silent territorial or small deep infarcts and ipsilateral carotid stenosis, carotid surgery on the asymptomatic side is not indicated, whereas the $40 \%$ narrowing on the symptomatic side also does not urge for such an operation. Mitral annular calcification is not associated with any single or multiple silent infarction. The finding of mitral annular calcification in this patient with silent infarcts was therefore no indication for anticoagulant therapy. The most likely cause of the symptomatic and silent strokes in this patient is hypertension- mediated large and small vessel disease. The therapy of choice is therefore aspirin and treatment of hypertension.

\section{Case history 2.}

A 30 year old female with primary oxalosis but no other risk factors developed a sudden right pure sensory deficit. CT scan in a later stage showed a lacunar infarct in the posterior leg of the left internal capsule. Echocardiogram showed a large calcified mass protruding from the posterior mitral valve leaflet with mass thrombus formation. Carotid studies were normal as was extensive laboratory testing.

Discussion: although lacunar stroke is unlikely caused by cardiac embolism, this does not exclude such a mechanism in individual patients. Although the mitral annulus calcification is not a cardioembolic stroke source, the thrombus may be, necessitating anticoagulant therapy. 


\section{Case history 3.}

A 60 year old patient with severe atherosclerosis was to be operated upon for severe calcified mitral stenosis. Cardiac catheterization was complicated by a fatal stroke. Postmortem investigation revealed a calcified thrombus in the left medial cerebral artery and a complementary defect in the cardiac calcified mass.

Discussion: although statistically uncommon, in this patient embolisation of calcified material from the mitral valve can explain the stroke.

Thus, suspected pathophysiological mechanisms in individual patients add to - and do not refute - the guidelines provided by epidemiological studies. ${ }^{1}$

\section{Suggestions for future research}

The significance of silent brain infarcts might be further clarified with increasingly sensitive detection methods such as MRI, but a major question remains how small lesions on MRI should be interpreted because specificity of MRI is relatively low regarding the question whether asymptomatic small lesions should be regarded as infarcts. This lack of specificity precludes correlation of lesions with clinical symptoms which may evolve in a later stage. Therefore, future studies on sillent infarcts should ideally have a long follow up by MRI and CT and include large general populations such as The Framingham population. In such studies, stroke, stroke subtypes, and cognitive decline, should be adjusted for clinical and echocardiographical vascular risk factors.

The significance of mitral annulus and aortic valve calcification as markers of generalized atherosclerosis was established in this thesis.

Studying stroke risk requires a long follow up and a large study population. In this thesis any increased risk of stroke because of cardiac valve calcification would have been detected. Numbers of patients and the duration of follow up were large enough to discriminate the contribution to stroke of each risk factor. Therefore, until eventual future studies proof otherwise, mitral annular calcification and aortic valve calcification can not be regarded as independent risk factors for stroke or as a cardioembolic stroke source, and deserve no prophylactic stroke risk lowering treatment. An alternative design could be a population-based study. However, if cardiac valve 
calcification is a marker or a form of atherosclerosis, then how should a control group look like? It should be comparable with the study group except for the study variable. Therefore, either the control group should consist of enough atherosclerotic patients, or the study group should consist of patients with cardiac vallve calcification but without other vascular riskfactors. The former is not compatible with a population-based design, the latter not with the findings presented here.

\section{References}

1. Cheng TO. Mitral Annular Calcification Versus Mitral Valve Calcification[Letter to the editor]. Stroke 1995;26:23744. 
Summary

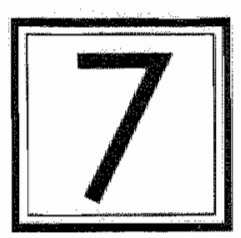



$\mathrm{T}$ The aim of this thesis is to highlight silent brain infarcts and to study a possible role of cardiac valve calcifications as a cardioembolic stroke mechanism.

A review of these topics is given in Chapter 1. The concept of silent infarcts and their relation with symptomatic stroke mechanisms especially cardioembolic stroke is discussed. Silent infarcts are clinically silent hypodense lesions on CT or MRI. Dependent on whether CT or MRI was used, and on patient groups, their prevalence varies between approximately 10 and $90 \%$. Silent infarcts have been found in selected healthy elderly volunteers, in patients with atrial fibrillation, and in patients presenting with a TIA or cerebral infarct. Previous reports suggested that the presence of, especially multiple, silent infarcts was typical of an underlying cardiac source of emboli, "spraying" large numbers of very small emboli into the different cerebral vasular territories. Apart from the accumulating cerebral damage, which might ultimately lead to vascular dementia, silent infarcts have been reported as prognostic unfavorable in patients with a symptomatic brain infarct. They also have been associated with atherosclerotic disease, especially carotid stenosis. Some investigators advocate to consider asymptomatic carotid endarteriectomy in patients with silent infarcts.

However, first, previous studies were done on selected patient subgroups or results were not adjusted for cardiac and vascular risk factors, thus not allowing conclusions about their cause. Second, because it is plausible that symptomatic and silent infarcts in the same patient have a similar underlying cause, the significance of silent infarcts may differ with the index stroke subtype.

Infiltration of aortic valve tissue with deposits containing calcium (aortic valve calcification) is found in young patients with rheumatic valvular damage, middle aged patients with congenital bicuspid valves, and in elderly patients with atherosclerotic disease. Although the exact mechanism is unclear, high valvular stress e.g. in hypertension, may play a role. Release of calcified material with subsequent embolism is rare except when the valve is manipulated during cardiac surgery or catheterisation. Reports of spontaneous embolisation in systemic or carotid artery territories are sparse, but consistent. However, there is much evidence to believe that aortic valve calcification is a form of atherosclerosis, which in itself is a risk factor for stroke. 
These considerations also apply to calcification of the mitral annulus, with the exception that there is evidence from large epidemiological studies for a two to fourfold increase of the risk in stroke in such patients, but the independent contribution of general vascular riskfactors especially carotid atheromatosis remains to be determined.

Chapter 2 presents a prospective series of 755 patients presenting with a first supratentorial ischemic stroke, in which silent infarcts were investigated, and found in $27 \%$ of the patients. We analysed the cardiac and vascular risk factors independently associated with silent infarcts, and we investigated whether subtypes of silent infarcts were associated with certain index stroke subtypes. $82 \%$ of silent infarcts were small deep (lacunar) infarcts, and were significantly stronger associated with a lacunar than atherothrombotic (odds ratio: 1.97; Pvalue: 0.00 ) or cardioembolic (odds ratio: $2.71 ; \mathrm{P}=0.00$ ) index stroke. The minority of silent infarcts were territorial types, equally but stronger associated with cardioembolic or atherothrombotic index stroke, than with lacunar index stroke $(P=0.04)$. Age and hypertension, but not carotid stenosis were only independently associated with silent lacunar infarcts $(P=0.01)$. Multiple silent infarcts were not associated with a possible cardioembolic source.

In conclusion, the silent and first symptomatic small deep infarcts in the same patient may have a common underlying mechanism, presumably small-vessel vasculopathy, whereas cardiogenic embolism or large vessel thromboembolism are the most likely cause in both silent and first symptomatic territorial infarcts. Single or multiple silent infarcts do not predict a cardioembolic stroke mechanism in first symptomatic supratentorial brain infarcts. As silent infarcts do not predict carotid embolic stroke cause in first symptomatic brain infarcts, the decision on carotid endarteriectomy should not depend on their presence. Silent infarcts do not affect the degree of initial handicap, 30-days case fatality or one-year mortality.

Chapter 3 reports the results of an investigation of risk factors associated with mitral annulus calcification in 657 patients, and aortic valve calcification in 815 patients, compared with 568 control patients, as there is discussion about whether the valve calcification is a marker of generalized atherosclerosis. Increasing age, hypertension and enlarged left atrium were strongly associated with each of the valvular calcifications ( $P=0.0$ ). Hypercholesterolemia was associated with each of the valvular calcifications, although just 
significantly only with mitral annulus calcification ( $(P=0.02)$.

Female gender and diabetes mellitus were significantly associated with mitral annulus calcification $(p=0.0)$, but not with calcified aortic stenosis.

The results confirm our hypothesis that the valve calcifications are expressions of atherosclerotic disease on different predilection sites and not a primary degenerative process.

Chapter 4 describes an analysis of the risk of stroke in the follow up of a cohort of 815 patients with aortic valve calcification or calcified aortic stenosis. Twenty-four $(8 \%)$ patients with aortic valve calcification, $24(5 \%)$ patients with calcified aortic stenosis, and $27(4 \%)$ controls had a stroke in the followup period. Neither of the valve calcifications were associated with stroke of any type, or with the presence of silent brain infarcts. The only risk factors strongly associated with stroke in these series were hypertension and symptomatic or asymptomatic carotid stenosis $(\mathrm{P}=0.0)$.

In conclusion, aortic valve calcification and calcified aortic stenosis are no independent risk factors for stroke, but markers of atherosclerosis, which agrees with the conclusions of Chapter 3 .

Chapter 5 discusses the analysis of the risk of stroke in a cohort of 657 patients with mitral annulus calcification, compared with 562 control patients.

Fifty-one patients with mitral annulus calcification $(7 \%)$ and 27 controls $(5 \%)$ had a stroke in the followup period. Only hypertension and any carotid stenosis $(\mathrm{P}=0.0)$, but not mitral annulus calcification were strongly associated with stroke. The valve calcification was not associated with any stroke subtype or with the presence of silent infarcts. Mitral annulus calcification, like aortic valve calcification, is a marker of generalised atherosclerotic disease and not a cardiac source of emboli. The strongly increased risk of stroke in those patients reported in previous studies, is the result of confounding by concomitant risk factors for stroke, especially carotid atheromatosis. 



\section{Samenvatting}

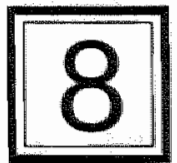



$\mathrm{H}$ et doel van dit proefschrift is enerzijds de bestudering van twee hartafwijkingen die als een bron van embolieen worden beschouwd: kalkvorming in de annulus mitralis en in de aortaklep; anderzijds de analyse van een verschijnsel dat wordt beschouwd als een indicator voor de aanwezigheid van een cardiale emboliebron: asymptomatsiche herseninfarcten. De resultaten van drie prospectieve onderzoeken worden in dit proefschrift beschreven.

In hoofdstuk 1 volgt een overzicht van de daarna besproken onderwerpen. Het concept van een mogelijke samenhang tussen asymptomatische herseninfarcten en symptomatische, in het bijzonder cardioembolische herseninfarcten, wordt besproken. Asymptomatische herseninfarcten zijn klinisch niet waargenomen tekenen van eerdere infarcering op CT of MRI. De prevalentie variëert tussen 10 en ongeveer $90 \%$, afhankelijk van de detectiemethoden en de patièntengroep. Ze worden gevonden bij gezonde proefpersonen, bij patiënten met boezemfibrilleren, en bij patiënten met een TIA of herseninfarct. De aanwezigheid van asymptomatische herseninfarcten, in het bijzonder wanneer er meerdere tegelijk worden gevonden, zou volgens sommigen specifiek zijn voor een onderliggende cardiale emboliebron, die als het ware microscopisch kleine embolieèn sproeit. Naast cumulatie van cerebrale schade door succesieve embolieën, die uiteindelijk kan leiden tot multi-infarct dementie, zouden asymptomatische infarcten een slechte prognose inhouden bij een patiënt die tegelijk ook een symptomatisch infarct heeft. Asymptomatische infarcten werden ook geassocièerd met atherosclerose, vooral met carotis stenose. Sommige onderzoekers propageren daarom carotis desobstructie bij patiënten met asymptomatische herseninfarcten.

Eerdere onderzoeken werden echter in geselecteerde patiëntengroepen verricht, of resultaten werden niet gecorrigeerd voor cardiovasculaire risicofactoren, en lieten daarom geen definitieve conclusies toe over de betekenis van asymptomatische herseninfarcten. Omdat het aannemelijk is dat symptomatische en asymptomatische herseninfarcten bij dezelfde patiènt ook dezelfde oorzaak hebben, kan hun betekenis variëren met het type symptomatische herseninfarct.

Calciuminfiltraties in aortakleppen worden gevonden bij jonge patiènten met rheumatisch hartkleplijden, bij patiënten van middelbare leeftijd met congenitaal bicuspide aortakleppen, en bij ouderen met atherosclerose (tricuspide aortasclerose). Het precieze mechanis- 
me is ondwidelijk, maar een verhoogde belasting van het klep apparaat, zoals voorkomt bij hypertensie, kan een rol spelen. Embolisatie van verkalkt materiaal afkomstig van een aortaklep is zeldzaam, maar komt voor bij manipulaties van de klep, zoals bij hartcatheterisaties en hartoperaties. Er zijn consistente, maar schaarse meldingen van embolieèn met calcium bevattend materiaal, in carotis stroomgebieden bij patienten met aortaklep calcificaties. Deze kunnen echter ook het gevolg zijn van atherosclerose, wat sterk met hartklepverkalkingen is geassocieerd. Deze associatie is zo sterk, dat wel wordt beweerd dat hartklepverkalking een vorm van atherosclerose is.

Deze overwegingen zijn ook grotendeels van toepassing op mitraal annulus calcificatie, zij het dat er goede epidemiologische onderzoeken zijn gedaan, die een verdubbeld tot viervoudig verhoogd risico voor het krijgen van een herseninfarct vinden bij patiënten met mitraal annulus calcificatie.

Een gemeenschappelijk kenmerk van alle onderzoeken naar het effect van hartklepverkalkingen op het risico voor een herseninfarct is de beperkte correctie voor de aanwezigheid van andere factoren die zowel samengaan met hartklepverkalkingen als ook zelf het risico van een herseninfarct verhogen (confounders).

In hoofdstuk 2 presenteren we een prospectief onderzoek bij 755 patiënten met een eerste supratentoriëel gelegen herseninfarct, bij wie we asymptomatische herseninfarcten bestudeerden, die voorkwamen bij $27 \%$ van de patienten. We analyseerden cardiovasculaire risicofactoren die waren geassocieerd met asymptomatische herseninfarcten, en we onderzocluten of sommige typen daarvan samengingen met sommige typen symptomatische infarcten. De meeste asymptomatische herseninfarcten waren lacunair $(82 \%)$, en waren significant sterker geassocièerd met symptomatische lacunaire dan atherothrombotische (odds ratio: 1.97 ; p-value: 0.00 ) of cardioembolische (odds ratio: $2.71 ; p=0.00$ ) herseninfarcten. De minderheid van asymptomatische herseninfarcten was corticaal, en even sterk geassocièerd met cardioembolische als atherothrombotische symptomatische herseninfarcten, maar minder met lacunare symptomatische herseninfarcten $(p=0.04)$. Leeftijd en hypertensie, maar niet carotis stenose, waren uitsluitend geassocièerd met asymptomatische lacunaire herseninfarcten ( $p=0.01)$ Multipele asymptomatische herseninfarcten waren niet met een cardiale emboliebron geassocieerd. 
We concluderen, dat asymptomatische en symptomatische herseninfarcten bij dezelfde patiènt waarschijnlijk eenzelfde oorzaak hebben: bij symptomatische en asymptomatische lacunaire infarcten is de waarschijnlijke oorzaak micro-angiopathie, terwijl een cardioembolisch mechanisme of carotisatheromatose bij zowel symptomatische als asymptomatische corticale infarcten de oorzaak kan zijn. Asymptomatische herseninfarcten, al dan niet multipel, zijn niet voorspellend voor een eventuele onderliggende cardiale emboliebron bij een eerste supratentoriëel gelegen symptomatisch herseninfarct. Ze vergroten ook niet de kans, dat een onderliggende carotisstenose de oorzaak van het symptomatische infarct is. De beslissing om over te gaan tot carotischirurgie dient daarom niet te worden geleid door de aanwezigheid van een of meer asymptomatische herseninfarcten. De invaliditeit in het acute stadium na het herseninfarct, of de mortaliteit in de eerste maand of het eerste jaar, worden door de aanwezigheid van asymptomatische herseninfarcten niet be-invloed.

In hoofdstuk 3 presenteren we de resultaten van een risicofactorenonderzoek bij 657 patiènten met mitraal annulus calcificatie, en 815 patiënten met aortaklep verkalking, vergeleken met 562 gerandomiseerde referentiepatiènten. Leeftijd, hypertensie, hypercholesterolemie, en een vergroot linker atrium waren meer of minder sterk geassocieerd met elk van de hartklepverkalingen $(P=0.0)$. Vrouwelijk geslacht en diabetes mellitus waren significant geassocièerd met mitraal annulus calcificatie en aortaklepverkalking zonder stenose ( $P$ $=0.0$ ).

De resultaten bevestigen onze hypothese, dat de hartklepverkalkingen een vorm van vaatlijden representeren die toeslaat op predilectieplaatsen, en niet een primaire degeneratieve aandoening.

In hoofdstuk 4 beschrijven we een analyse van het risico van een herseninfarct tijdens de follow up van een cohort van 815 patienten met aortaklepverkalking. Vierentwintig $(8 \%)$ patiënten met aortaklepverkalking, vierentwintig $(5 \%)$ patienten met verkalkte aortastenose, en 27 (4\%) patiënten uit de controlegroep kregen een herseninfarct in de follow up. Geen van de klepcalcificaties was geassocieerd met een herseninfarct in de follow up van welk type dan ook, of met de aanwezigheid van asymptomatische herseninfarcten. De enige risicofactoren die in deze studie sterk het risico op een herseninfarct bepaalden waren hypertensie en carotisstenose (om het even aan welke kant, dus of symptomatisch of asymptomatisch $(\mathrm{P}=0.0)$ ). 
In overeenstemming met de bevindingen beschreven in hoofdstuk 3 , concluderen we dat aortaklepcallcificatie met of zonder stenose geen onafhankelijke risicofactor is voor een herseninfarct, maar een uiting of een vorm van atherosclerose.

In hoofdstuk 5 beschrijven we een soortgelijke analyse als in hoofdstuk 4, maar dan bij een cohort van 657 patiénten met mitraal annulus calcificatie, in vergelijking met 562 controle patiënten.

Eenenvijftig patiënten met mitraal annulus calcificatie (7\%) en 27 controlepatienten $(5 \%) \mathrm{kregen}$ een infarct in de follow up. Alleen hypertensie en carotisstenose $(\mathrm{P}=0.0)$, maar niet mitraal annulus calcificatie, waren sterk met het optreden van een herseninfarct in de follow up geassocièerd. De hartklepcalcificatie was niet met enig subtype symptomatisch of asymptomatisch herseninfarct (corticaal of lacunair) geassocieerd. We concluderen, dat noch een mitraal annulus calcificatie, noch een aortaklepcalcificatie, een risicofactor is voor een herseninfarct, maar een symptoom is van gegeneraliseerd vaatlijden. Wij menen dat het grote risico voor het krijgen van een herseninfarct, beschreven in eerdere studies, moet worden toegeschreven aan confounding factoren. 


\section{Papers}

The results of the investigations presented in this thesis have been published or submitted as follows:

Silent brain infarcts in 755 consecutive patients with a first-ever supratentorial ischemic stroke; the relationship with index stroke subtype, vascular risk factors, and mortality. Stroke. 1994;25: $2384-2390$.

Arthur Boon, MD, Jan Lodder, MD, Lisette Heuts-van Raak, MD,

Fons Kessels, MD.

Cardiac Calcification: Risk Factor Profiles in Patients with Calcification of the Mitral Annulus or Aortic Valve.

Submitted.

Arthur Boon, MD, Emile Cheriex, MD Ian Lodder, MD, Fons Kessels, MD.

The Risk of Stroke in a Cohort of 815 Patients With Calcification of the Aortic Valve with or without Stenosis.

Presented at the International Stroke Conference, Prague, October 1995.

Stroke, 1996; 27:......... In press.

Arthur Boon, MD, Jan Lodder, MD, Emile Cheriex, MD, Fons Kessels, MD.

The Risk of Stroke in a Cohort of 657 Patients With Mitral Annulus Calcification. Submitted.

Arthur Boon, MD, Jan Lodder, MD, Emile Cheriex, MD, Fons Kessels, MD.

Departments of Neurology of the St-Anna Hospital, Geldrop (A.B.), and of the University Hos pital Maastricht (J.L.; L.H.); Department of Cardiology, University Hospital Maastricht (E.C.); Department of Epidemiology, University of Limburg, Maastricht (F.K.), The Netherlands. 



\section{Acknowledgements}

I am much indebted to the following persons:

Dr. J. Lodder for the way he raised my interest in vascular research, and for the rapid feed-back on papers and chapters even when he was responsible for many successive thesis within a short period of time. Jan, your supervision was very inspiring and pleasant, and I hope that our co-operation in cerebrovascular investigation will continue after this thesis.

Prof. Dr. J. Troost for creating the ideal conditions and atmosphere for me to work on this thesis during the last year of neurological training.

The reviewing committee, and in particular the chairman Prof. Dr. H.J. Wellens, for reading and criticizing this thesis in minute detail The general practitioners in several regions of the Netherlands who responded to my questionnaires and put files at my disposal to trace patients not returning for hospital visits. This was of great help for the investigation on cardiac valve calcification.

Dr. Lisette Heuts-van Raak for her vast amount of work for the Maastricht Stroke Registry, on which the chapter on silent brain infarcts was based. Lisette, many investigators profited from your critical and accurate datamanagement, necessary to maintain such a registry.

F. Kessels, Fons, we had many instructive discussions about statistics and epidemiology. You convinced me that both are powerful and sometimes the only available tools to solve - and to raise questions. Your tireless phantasy in finding psychedelic file- and fieldnames was amazing.

Emile Cheriex, for his contribution to the investigation on cardiac valve calcification, and for his co-operation in using his work CAESARS as a basis for the follow up.

Rob Mulleneers for his technical support. The secretaries of the AZM archives for supplying thousands of files and CTscans during the investigations on cardiac valve calcification.

Thera van Lieshout, for her administrative support.

Angelique and Carla, without your superb management of the outpatient clinic finishing this thesis would have lasted much longer. Ulrike, thank you for your help and understanding in these - for us both - busy times. 


\section{Curriculum Vitae}

The author was born in The Hague on. August 28th, 1957. After secondary school (VWO-B) he studied medicine at the Leiden University from 1977-1984. During studies, he worked at the Department of Submicroscopical Pathology (Dr. D.J. Ruiter). From 1985 untill 1988 he worked as a neurology resident in the Reinier de Graaff Gasthuis in Delft. Neurological training including clinical neurophysiology (Prof. Dr. F. Spaans) was completed at the University Hospital Maastricht in 1994 (Prof. Dr. P.J.M. van der Lugt, and later Prof. Dr. J. Troost).

From 1994 he works as a neurologist in the St-Anna Hospital in Geldrop, associated with Jos Breuer and Hans van Lieshout. 
Index

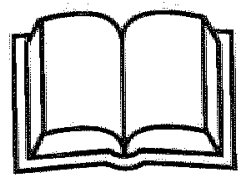




\section{A}

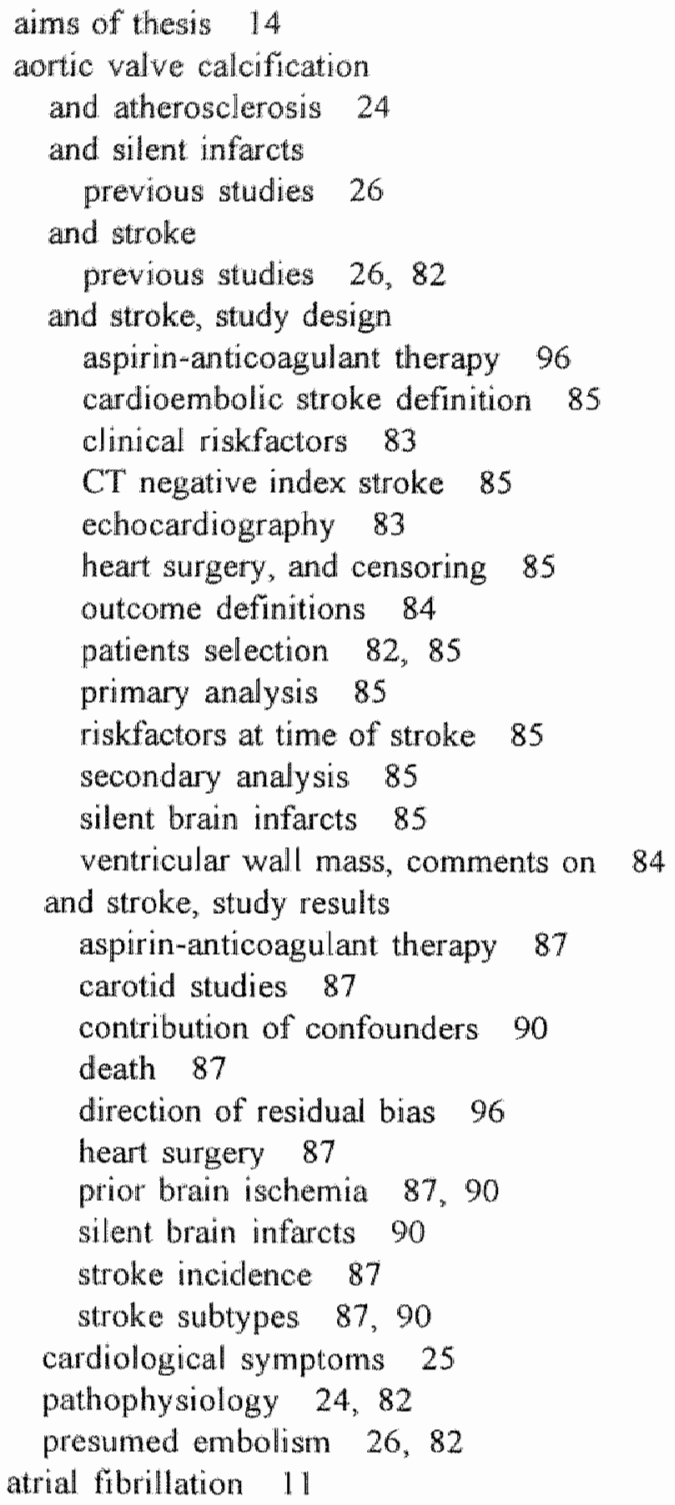




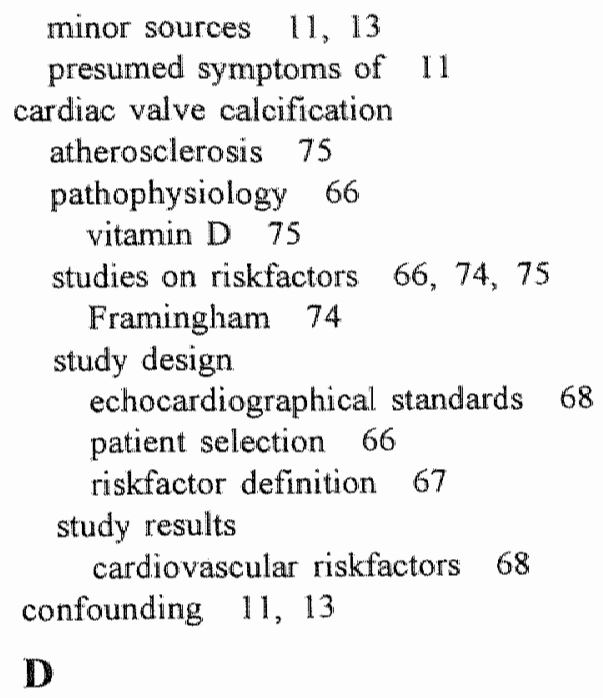

\section{M}

mitral annular calcification associated diseases 104

atherosclerosis 27

cardiological symptoms 27

carotid territory embolism 27

epidemiological studies 27, 104, 118

BAATAF 30,105

carotid stenosis 105

Framingham 118

pathophysiology 27,104

prevalence 27,104

mitral annulus calcification

and stroke

effect of residual bias 119

and stroke, study design

cardiac surgery 109

cardioembolic stroke 108

censoring 108

clinical riskfactors 106

CT negative index stroke 107

echocardography 106

patient selection 105

primary nd secondary analysis 109

prior stroke or TIA 110

riskfactors at time of stroke 108 
stroke definitions 107

ventricular wall mass, comments on 107

and stroke, study results

aspirin/anticoagulants 110

asymptomatic brain infarcts 117

perioperative stroke $\$ 10$

stroke incidence 110

stroke risk 110

stroke subtypes 110

R

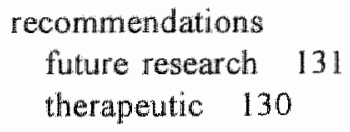

